\title{
Detecção de ovos de $S$. mansoni a partir da detecção de seus contornos
}

\author{
Edwin Delgado Huaynalaya \\ DisSERTAÇÃO APRESENTADA \\ $\mathrm{AO}$ \\ Instituto de MATEmÁtica e EstatísticA \\ DA \\ Universidade De SÃo PaUlo \\ PARA \\ OBTENÇÃO DO TÍTULO \\ $\mathrm{DE}$ \\ Mestre EM Cî̂nCIAS \\ Programa: Ciência da Computação \\ Orientadora: Prof ${ }^{a}$. Dra ${ }^{a}$ Nina S. T. Hirata
}

Durante o desenvolvimento deste trabalho o autor recebeu auxílio financeiro do CNPq

Processo individual 190002/2009-3

São Paulo, 4 de junho de 2012 


\title{
Detecção de ovos de $S$. mansoni a partir da detecção de seus contornos
}

\author{
Esta dissertação contém as correções e alterações \\ sugeridas pela Comissão Julgadora durante a defesa \\ realizada por Edwin Delgado Huaynalaya em 25/04/2012. \\ O original encontra-se disponível no Instituto de \\ Matemática e Estatística da Universidade de São Paulo.
}

Comissão Julgadora:

- Prof ${ }^{\mathrm{a}}$. Dr ${ }^{\mathrm{a}}$. Nina S. T. Hirata (orientadora) - IME-USP

- Prof. Dr. Ronaldo Fumio Hashimoto - IME-USP

- Prof. Dr. Eduardo Finger - Salomão Zoppi Diagnósticos 


\section{Agradecimentos}

Agradeço a meus pais (Marcelino e Celia) e à minha irmã Raquel pelo aprendizado e incentivo nos estudos que me proporcionaram e continuam proporcionando na minha vida, pela confiança que sempre depositaram em mim e pelo incondicional apoio em todos os momentos. À minha esposa Marisol, pelas sugestões, pelo apoio, amor, carinho, compreensão, paciência, especialmente neste período em que passei a viver em São Paulo.

Agradeço à minha orientadora Nina S. T. Hirata por tudo que dela aprendi e pela atenção, diretrizes e incentivo ao longo destes anos. Agradeço aos Professores Paulo Feofiloff, Cristina Gomes Fernandes, Junior Barrera, Yoshiharu Kohayakawa, Alan Mitchell, Roberto Hirata e Ronaldo Fumio Hashimoto, pelos diferentes conhecimentos que deles aprendi, por seus comentários, sugestões e esclarecimentos que ajudaram a avançar meu trabalho.

Agradeço ao Dr. Eduardo Finger, por gentilmente permitir o acceso as lâminas utilizadas na geração das imagens deste trabalho.

Agradeço ao $\mathrm{CNPq}$ pelo apoio financeiro recebido durante a elaboração deste trabalho.

Agradeço ao Robert A. McLaughlin (University of Western Australia), por fornecer o código fonte do método da transformada Hough para detecção de elipses, que é uma parte importante no método proposto neste trabalho ${ }^{1}$.

Com especial carinho agradeço aos amigos peruanos do Lab. de Processamento de imagens Jorge Luis, Leissi, Christopher, Frank, Herbert, Rosario, Leandro, Edu, Jesús e Miguel, pela amizade, momentos de alegrias, e também pelos auxílios com Linux e Latex. Estou grato de ter compartilhado parte da minha vida com vocês, desejo-lhes sucesso em seus objetivos.

Agradeço aos amigos brasileiros Fábio de Oliveira, William, Alexandre, Charles Iury, Giseli, Henrique, David da Silva, Esdras, Wonder, Marta, Bruno, Daniel Oliveira, Fabio Roberto, Jihan, André, Andrea, Silvia, Talita, Maysa, Fabrício, Sergio, David Martins e Rafael, pelas correções com o português e as sugestões que contribuíram positivamente no meu trabalho. Aprendi muito

\footnotetext{
${ }^{1}$ I would like to thank Robert A. McLaughlin (University of Western Australia), for providing me the source code for detecting ellipses based on the Hough transform, used in this work.
} 
de vocês.

Agradeço aos amigos do IME-USP Alvaro, Daniel Javier, Edwin Miguel, Edith, Erika, Luisa, Karina, Juan, Carlos Eduardo, Alfonso, Mijail, Carlos Leonardo, Reynaldo, Boris, Geiser e amigos da USP Flávia, Milton, Anu Lähde, José Armando, Marvin, Maritza, Reynaldo, Mario, Victor Manuel, Moacir, Celso, Gladson, Haroldo, Emilio, Sasaki, pelas brincadeiras, momentos de lazer, horas de café, bandejão e esporte, que compartilhamos e fizeram do mestrado uma lembrança muito bonita e inesquecível.

Peço desculpas se esqueci algum nome, desde já agradeço a todos vocês, pois direta ou indiretamente, contribuíram para a finalização deste trabalho. Um grande abraço e muito obrigado. 


\section{Resumo}

Schistosoma mansoni é o parasita causador da esquistossomose mansônica que, de acordo com o Ministério da Saúde do Brasil, afeta atualmente vários milhões de pessoas no país. Uma das formas de diagnóstico da esquistossomose é a detecção de ovos do parasita através da análise de lâminas microscópicas com material fecal. Esta tarefa é extremamente cansativa, principalmente nos casos de baixa endemicidade, pois a quantidade de ovos é muito pequena. Nesses casos, uma abordagem computacional para auxílio na detecção de ovos facilitaria o trabalho de diagnóstico.

Os ovos têm formato ovalado, possuem uma membrana translúcida, apresentam uma espícula e sua cor é ligeiramente amarelada. Porém nem todas essas características são observadas em todos os ovos e algumas delas são visíveis apenas com uma ampliação adequada. Além disso, o aspecto visual do material fecal varia muito de indivíduo para indivíduo em termos de cor e presença de diversos artefatos (tais como partículas que não são desintegradas pelo sistema digestivo), tornando difícil a tarefa de deteç̧ão dos ovos.

Neste trabalho investigamos, em particular, o problema de detecção das linhas que contornam a borda de vários dos ovos. Propomos um método composto por duas fases. A primeira fase consiste na detecção de estruturas do tipo linha usando operadores morfológicos. A detecção de linhas é dividida em três etapas principais: (i) realce de linhas, (ii) detecção de linhas, e (iii) refinamento do resultado para eliminar segmentos de linhas que não são de interesse. O resultado dessa fase é um conjunto de segmentos de linhas. A segunda fase consiste na detecção de subconjuntos de segmentos de linha dispostos em formato elíptico, usando um algoritmo baseado na transformada Hough. As elipses detectadas são fortes candidatas a contorno de ovos de S. mansoni. Resultados experimentais mostram que a abordagem proposta pode ser útil para compor um sistema de auxílio à detecção dos ovos.

Palavras-chave: S. mansoni, imagens microscópicas, detecção de linhas, morfologia matemática, transformada Hough 



\section{Abstract}

Schistosoma mansoni is one of the parasites that causes schistosomiasis. According to the Brazilian Ministry of Health, several million people in the country are currently affected by schistosomiasis. One way of diagnosing it is by egg identification in stool. This task is extremely time-consuming and tiring, especially in cases of low endemicity, when only few eggs are present. In such cases, a computational approach to help the detection of eggs would greatly facilitate the diagnostic task.

Schistosome eggs present oval shape, have a translucent membrane and a spike, and its color is slightly yellowish. However, not all these features are observed in every egg and some of them are visible only with an adequate microscopic magnification. Furthermore, the visual aspect of the fecal material varies widely from person to person in terms of color and presence of different artifacts (such as particles that are not disintegrated by the digestive system), making it difficult to detect the eggs.

In this work we investigate the problem of detecting lines that delimit the contour of the eggs. We propose a method comprising two steps. The first phase consists in detecting line-like structures using morphological operators. This line detection phase is divided into three steps: (i) line enhancement, (ii) line detection, and (iii) result refinement in order to eliminate line segments that are not of interest. The output of this phase is a set of line segments. The second phase consists in detecting subsets of line segments arranged in an elliptical shape, using an algorithm based on the Hough transform. Detected ellipses are strong candidates to contour of $S$. mansoni eggs. Experimental results show that the proposed approach has potential to be effectively used as a component in a computer system to help egg detection.

Keywords: S. mansoni, microscopic images, line detection, mathematical morphology, Hough transform 



\section{Sumário}

Resumo

$\begin{array}{lc}\text { Lista de Figuras } & \text { ix }\end{array}$

Lista de Algoritmos $\quad$ xiii

1 Introdução 1

1.1 Motivação . . . . . . . . . . . . . . . . . . . . . . . 4

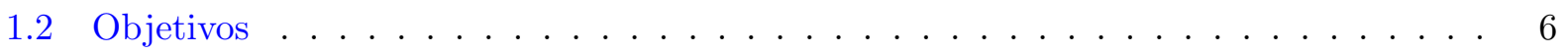

1.3 Organização do trabalho . . . . . . . . . . . . . . . . . . . . 6

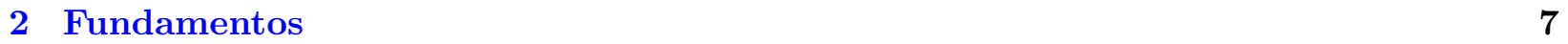

2.1 Definições preliminares . . . . . . . . . . . . . . . . . . . 7

2.2 Conversão para imagens em tons de cinza . . . . . . . . . . . . . . . . . 9

2.3 Limiarização . . . . . . . . . . . . . . . . . . . . . . . . 10

2.4 Máscaras para detecção de linhas . . . . . . . . . . . . . . . . . . . . . 10

2.5 Morfologia matemática binária . . . . . . . . . . . . . . . . . 10

2.6 Morfologia matemática para imagens em tons de cinza . . . . . . . . . . . . . . . . . . . . . . . . . .

2.7 Transformada Hough . . . . . . . . . . . . . . . . . . . . . . . . . . . 18

2.7.1 Transformada Hough para retas . . . . . . . . . . . . . . . . . . 18

2.7.2 Transformada Hough para elipses . . . . . . . . . . . . . . . . . . . . 19

3 Detecção de contornos de ovos de S. Mansoni $\quad 25$

3.1 Visão geral da abordagem proposta . . . . . . . . . . . . . . . . . . 26

3.2 Detecção de estruturas do tipo linha . . . . . . . . . . . . . . . . . . . 27

3.2 .1 Realce das linhas . . . . . . . . . . . . . . . . 27

Suavização da imagem . . . . . . . . . . . . . . . . . . . . . . 27

Filtro de ordem . . . . . . . . . . . . . . . . . . . . 29

Fechamento Top-Hat . . . . . . . . . . . . . . . . 30

3.2 .2 Detecção de linhas . . . . . . . . . . . . . . . . . . . . . . . . 31

Erosão por linhas . . . . . . . . . . . . . . . . . . . . . . 32

Composição dos resultados . . . . . . . . . . . . . . . . . 33

3.2 .3 Refinamento do resultado . . . . . . . . . . . . . . . . . 33 
3.3 Detecção de elipses a partir do mapa de linhas . . . . . . . . . . . . . . . 34

4 Resultados $\quad 37$

4.1 Conjunto de dados . . . . . . . . . . . . . . . . . . . . 37

4.2 Parâmetros . . . . . . . . . . . . . . . . . . . 39

4.3 Avaliação de Resultados . . . . . . . . . . . . . . . . . . . . . . . . 39

4.4 Exemplos de deteç̧ão . . . . . . . . . . . . . . . . . . . . . . . . . . . . . . . . . . . . . . . . .

4.5 Resultados com outros métodos . . . . . . . . . . . . . . . . . 50

$\mathbf{5}$ Conclusões $\quad \mathbf{5 7}$

5.1 Contribuições do trabalho . . . . . . . . . . . . . . . . . . 58

5.2 Trabalhos futuros . . . . . . . . . . . . . . . . . . . 58

A Implementações associadas $\quad \mathbf{6 1}$

A.1 Requisitos . . . . . . . . . . . . . . . . . . . . . 6 . 61

A.2 Configurações . . . . . . . . . . . . . . . . . . . . 62

A.3 Funções auxiliares . . . . . . . . . . . . . . . . . . . . . 62

$\begin{array}{ll}\text { Referências Bibliográficas } & 63\end{array}$

$\begin{array}{lc}\text { Índice Remissivo } & 66\end{array}$ 


\section{Lista de Figuras}

1.1 Ciclo da esquistossomose (figura extraída de [33]). . . . . . . . . . . . . . 2

1.2 Região com ovo de S. mansoni da imagem de uma lâmina de microscópio com ampliação 10 vezes. O ovo é o objeto claro ovalado na região central. Os demais objetos são artefatos (partículas) . . . . . . . . . . . . . . . . 3

1.3 Ovo de S. mansoni, em ampliação 40x. . . . . . . . . . . . . . . 4

1.4 Processo do diagnóstico de esquistossomose motivador deste trabalho. . . . . . . . . 5

2.1 (a) Resultado da conversão da imagem colorida original a tons de cinza. (b) Imagem da superfície. . . . . . . . . . . . . . . . . . . . . . 9

2.2 (a) Máscara $9 \times 9$ para detectar linhas horizontais. (b) Máscara para detectar linhas verticais. (c) Máscara para detectar linhas com orientação de 45 graus. (d) Máscara para detectar linhas com orientação de -45 graus. . . . . . . . . . . . . . . . . . . 11

2.3 (a) Máscara $G_{x}$ do operador Sobel. (b) Máscara $G_{y}$ do operador Sobel. (c) Máscara do operador Laplaciano da Gaussiana. . . . . . . . . . . . . . . . . . . . . . 11

2.4 Efeitos da erosão e dilatação em uma imagem binária. . . . . . . . . . . . . . . . 12

2.5 Efeito da aplicação de abertura (b) e de fechamento (c) na imagem em (a). . . . . . 13

2.6 Efeito da aplicação do gradiente morfológico em imagem binária. . . . . . . . . . . 14

2.7 Erosão e dilatação em uma imagem em níveis de cinza. . . . . . . . . . . . . . . 16

2.8 Gradiente morfológico de uma imagem em níveis de cinza. . . . . . . . . . . . . . 16

2.9 Efeito da aplicação do Fechamento Top-Hat. . . . . . . . . . . . . . . . . . . 17

2.10 Exemplo de aplicação do filtro de ordem sobre um sinal, com janela de tamanho 7 e

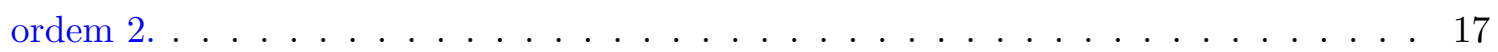

2.11 Parâmetros de uma reta $[11] \ldots \ldots \ldots \ldots$

2.12 Geometria básica para encontrar o centro da elipse $[35] . \ldots \ldots$. . . . . . . 20

3.1 (a) Imagem de uma região com ovo de S. mansoni, com ampliação 40x. (b) Suavizada usando o filtro da mediana. (c) Detecção de linhas com máscaras (imagem negada).

(d) Detecção de contornos pelo método Sobel (imagem negada). . . . . . . . . . . . . 25

3.2 Janela retangular com três regiões (esquerda, central e direita) . . . . . . . . . . 27

3.3 Exemplo de análise de uma região específica usando a janela da figura 3.2 . . . . . . 28

3.4 (a) Imagem original. (b) Resultado da aplicação do método de suavização. . . . . . . 29

3.5 (a) Imagem suavizada. (b) Resultado da aplicação do filtro de ordem. . . . . . . . . 30 
3.6 As três imagens na parte superior correspondem respectivamente à imagem original, o resultado do método de suavizado e o resultado do rank filter. As três imagens na parte inferior correspondem às respectivas superfícies. . . . . . . . . . . . . . 31

3.7 (a) Resultado do fechamento Top-Hat com disco de raio 7. (b) Imagem da superfície. 32

3.8 (a) Imagem negada da erosão por linhas de tamanho 72 pixels em diferentes orientações. (b) Imagem da superficie. (c) Resultado da limiarização. . . . . . . . . . . . . 33

3.9 (a) Imagem binária. (b) Resultado da abertura com área de 600 pixels. . . . . . . . 34

3.10 Resultado após remoção de componentes que tocam as bordas. . . . . . . . . . . . 35

3.11 Imagem de saída da detecção de elipses usando a Transformada Hough. . . . . . . 36

4.1 Resultados TP, FP ou FN . . . . . . . . . . . . . . . . . . . . . . . 41

4.2 Sequência de operações. (a) Imagem de entrada. (b) Suavizado. (c) Filtro de Ordem. (d) Fechamento Top-Hat. (e) Máximo de erosões por linhas de diferentes orientações, seguida de limiarização. (f) Abertura por área. (g) Remoção de componentes que tocam a borda. (h) Detecção de elipses usando a Transformada Hough. . . . . . . . . 43

4.3 Sequência de operações. (a) Imagem de entrada. (b) Suavizado. (c) Filtro de Ordem. (d) Fechamento Top-Hat. (e) Máximo de erosões por linhas de diferentes orientações, seguida de limiarização. (f) Abertura por área. (g) Remoção de componentes que tocam a borda. (h) Detecção de elipses usando a Transformada Hough. . . . . . . . . 44

4.4 Sequência de operações. (a) Imagem de entrada. (b) Suavizado. (c) Filtro de Ordem. (d) Fechamento Top-Hat. (e) Máximo de erosões por linhas de diferentes orientações, seguida de limiarização. (f) Abertura por área. (g) Remoção de componentes que tocam a borda. (h) Detecção de elipses usando a Transformada Hough. . . . . . . . . 45

4.5 Sequência de operações. (a) Imagem de entrada. (b) Suavizado. (c) Filtro de Ordem. (d) Fechamento Top-Hat. (e) Máximo de erosões por linhas de diferentes orientações, seguida de limiarização. (f) Abertura por área. (g) Remoção de componentes que tocam a borda. (h) Detecção de elipses usando a Transformada Hough. . . . . . . . 46

4.6 Sequência de operações. (a) Imagem de entrada. (b) Suavizado. (c) Filtro de Ordem. (d) Fechamento Top-Hat. (e) Máximo de erosões por linhas de diferentes orientações, seguida de limiarização. (f) Abertura por área. (g) Remoção de componentes que tocam a borda. (h) Detecção de elipses usando a Transformada Hough. . . . . . . . 47

4.7 Sequência de operações. (a) Imagem de entrada. (b) Suavizado. (c) Filtro de Ordem. (d) Fechamento Top-Hat. (e) Máximo de erosões por linhas de diferentes orientações, seguida de limiarização. (f) Abertura por área. (g) Remoção de componentes que tocam a borda. (h) Detecção de elipses usando a Transformada Hough. . . . . . . . . 48

4.8 Resultados em imagem sem ovo. (a) Imagem de entrada. (b) Detecção de linhas. (c) Detecção de elipses usando a Transformada Hough. . . . . . . . . . . . . . . . 49

4.9 Resultados em imagem sem ovo. (a) Imagem de entrada. (b) Detecção de linhas. (c) Detecção de elipses usando a Transformada Hough. . . . . . . . . . . . . . . . . 49 
4.10 Resultados em uma região maior que tem presença de ovo. (a) Imagem de entrada.

(b) Método proposto. . . . . . . . . . . . . . . . . . . . 50

4.11 Resultados em uma região maior que tem presença de ovo. (a) Imagem de entrada.

(b) Método proposto. . . . . . . . . . . . . . . . . . . 50 50

4.12 Resultados em uma região maior que tem presença de ovo. (a) Imagem de entrada.

(b) Método proposto. . . . . . . . . . . . . . . . . . . . 5 51

4.13 Resultados em uma região maior que tem presença de ovo. (a) Imagem de entrada.

(b) Método proposto. . . . . . . . . . . . . . . . . . 51

4.14 Resultados em uma região maior que tem presença de ovo. (a) Imagem de entrada.

(b) Método proposto. . . . . . . . . . . . . . . . . . . 5 52

4.15 Resultados em uma região maior que não tem presença de ovo. (a) Imagem de entrada. (b) Método proposto. . . . . . . . . . . . . . . . . 5 52

4.16 Resultados em uma região maior que não tem presença de ovo. (a) Imagem de entrada. (b) Método proposto. . . . . . . . . . . . . . . . . . . . 52

4.17 Resultados em uma região maior que não tem presença de ovo. (a) Imagem de entrada. (b) Método proposto. . . . . . . . . . . . . . . . . . 53

4.18 Resultados em uma região maior que não tem presença de ovo. (a) Imagem de entrada. (b) Método proposto. . . . . . . . . . . . . . 53

4.19 Comparação de métodos de detecção de bordas. (a) Imagem de entrada. (b) Resultado do método de suavizado e filtro de ordem. (c) Imagem negada do Método de Sobel. (d) Imagem negada do Método Laplaciano. (e) Imagem negada do Gradiente Morfológico. (f) Método proposto. . . . . . . . . . . . . . . . . . . 54

4.20 Comparação de métodos de detecção de bordas. (a) Imagem de entrada. (b) Resultado do método de suavizado e filtro de ordem. (c) Imagem negada do Método de Sobel. (d) Imagem negada do Método Laplaciano. (e) Imagem negada do Gradiente Morfológico. (f) Método proposto. . . . . . . . . . . . . . . . . . 55 


\section{Lista de algoritmos}

1 hist $2 D \leftarrow$ houghRetas $(f)($ Hough para retas [7]) . . . . . . . . . . . . . 19

2 listaPontosCentrais $\leftarrow$ encontrarCentroElipse $(f, B)$ (Candidatos a centro de elip-

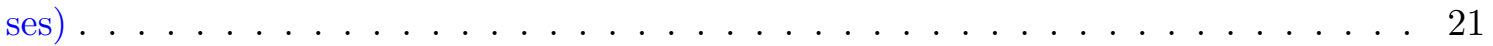

3 hist $3 D \leftarrow$ outrosParametrosElipse $\left(\mathbf{x}, a_{i n i}, a_{f i m}, b_{i n i}, b_{f i m}, \theta_{i n i}, \theta_{f i m}, f\right)$ (estimas eixos e orientação da elipse centrada em $\mathbf{x}) \ldots \ldots \ldots$. . . . . . . . . . 22

$4 h \leftarrow$ houghElipses (f, B, tMax, tMin, proporcaoMinima) (Hough para elipses [35]) . 23

5 Parte que substitui linhas 16 a 18 do algoritmo $4 \ldots \ldots \ldots \ldots$ 


\section{Capítulo 1}

\section{Introdução}

A esquistossomose é a segunda doença parasitária mais prevalente no mundo, estando atrás apenas da malária, e pode ocorrer em homens e animais. É adquirida pela exposição da pele em água, por exemplo de rios, lagos ou represas, contaminada com a forma larval infecciosa do agente etiológico: helmintos do gênero Schistosoma [12].

Existem cinco espécies de Schistosoma que parasitam o homem, sendo um deles o Schistosoma mansoni. Cerca de $85 \%$ de casos devidos ao S. Mansoni concentram-se na África subsaariana. O S. Mansoni pode também ser encontrado na América do Sul e nas Antilhas [32]. No Brasil, as ocorrências de esquistossomose são devidas ao S. Mansoni.

Estima-se que atualmente cerca de 200.000.000 de pessoas no mundo encontram-se com esquistossomose, e que cerca de 200.000 indivíduos por ano chegam a falecer em decorrência da doença [3]. Apesar de vir declinando ao longo dos anos, de acordo com o Ministério da Saúde, no Brasil a doença acomete atualmente entre 2,5 a 6 milhões de pessoas [5].

A figura 1.1 mostra o ciclo da esquistossomose. Os ovos do Schistosoma são expelidos juntamente com as fezes de indivíduos contaminados. Em contato com a água, os ovos liberam os miracídios (primeiro estágio de vida livre do parasita) e estes penetram os tecidos de alguns tipos de caramujos que são os hospedeiros intermediários. Nos caramujos, os miracídios desenvolvem-se em esporocistos, que por sua vez geram as cercárias (segunda fase de vida livre do parasita). As cercárias nadam livremente nas águas e podem penetrar a pele humana, completando o ciclo de transmissão [6].

Durante a fase crônica, as infecções por S. mansoni são oligossintomáticas (com um único ou dois sintomas fortes, enquanto os demais são aparentemente inexistentes). Na fase aguda, elas geralmente dão sintomas como coceira na pele (prurido), febre, linfadenopatia (crescimento de um ou mais linfonodos), diarréia, eosinofilia (quantidade alta de eosinófilos no sangue), hepatosplenomegalia (crescimento de fígado e baço), entre outros [12].

No hospedeiro definitivo, o S. mansoni aloja-se nas veias do sistema porta-hepático (vasos 


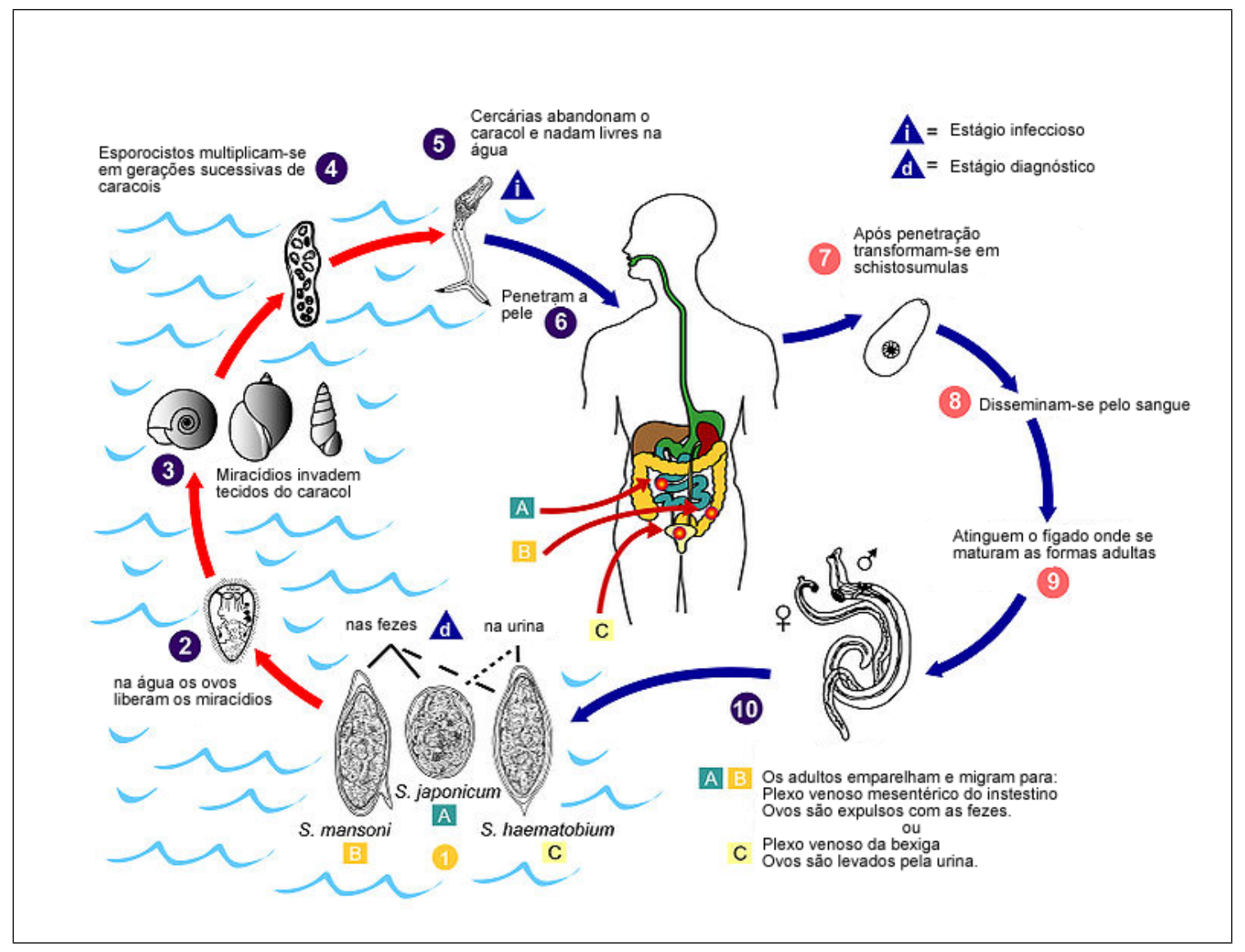

Figura 1.1: Ciclo da esquistossomose (figura extraída de [33]).

sanguíneos que ligam o intestino ao fígado) e, vivendo em estado de cópulo, libera entre 300 e 3000 ovos/dia durante anos. A maior parte destes ovos migra para os intestinos e são expelidos juntamente com as fezes. Porém, uma fração é levada pelo fluxo sanguíneo para o sistema porta-hepático onde embolizam na microvasculatura dos espaços porta e elicitam um processo inflamatório granulomatoso. Sem tratamento, este processo comumente evolui de duas formas: $95 \%$ dos infectados evolui com sintomatologia tolerável e baixa mortalidade numa apresentação clínica denominada de forma intestinal. Os 5\% restantes apresentam processo inflamatório hepático intenso que no longo prazo gera fibrose difusa, hipertensão portal, varizes esofageanas, hemorragia e morte [12].

O controle da esquistossomose pode ser realizado atuando-se na prevenção (eliminação dos caramujos, educação em saúde ambiental para as populações de risco, e investimento em saneamento), diagnóstico e tratamento. Uma das formas para o diagnóstico da esquistossomose é mediante a técnica Kato-Katz [32], que consiste na detecção de presença de ovos de S. mansoni em lâminas de microscópio com material fecal da pessoa infectada.

O material fecal contém várias partículas que não são desintegradas pelo sistema digestivo. 
Desta forma, o preparo da lâmina para detecção de ovos de parasitas em geral pode envolver algum processo de sedimentação para separar tais partículas. No entanto, dependendo do tipo de parasita em questão, tal sedimentação pode não ser trivial, como é o caso do S. mansoni. Em consequência, as imagens microscópicas das lâminas analisadas para diagnóstico da esquistossomose são bastante ruidosas. Um exemplo é mostrado na figura 1.2.

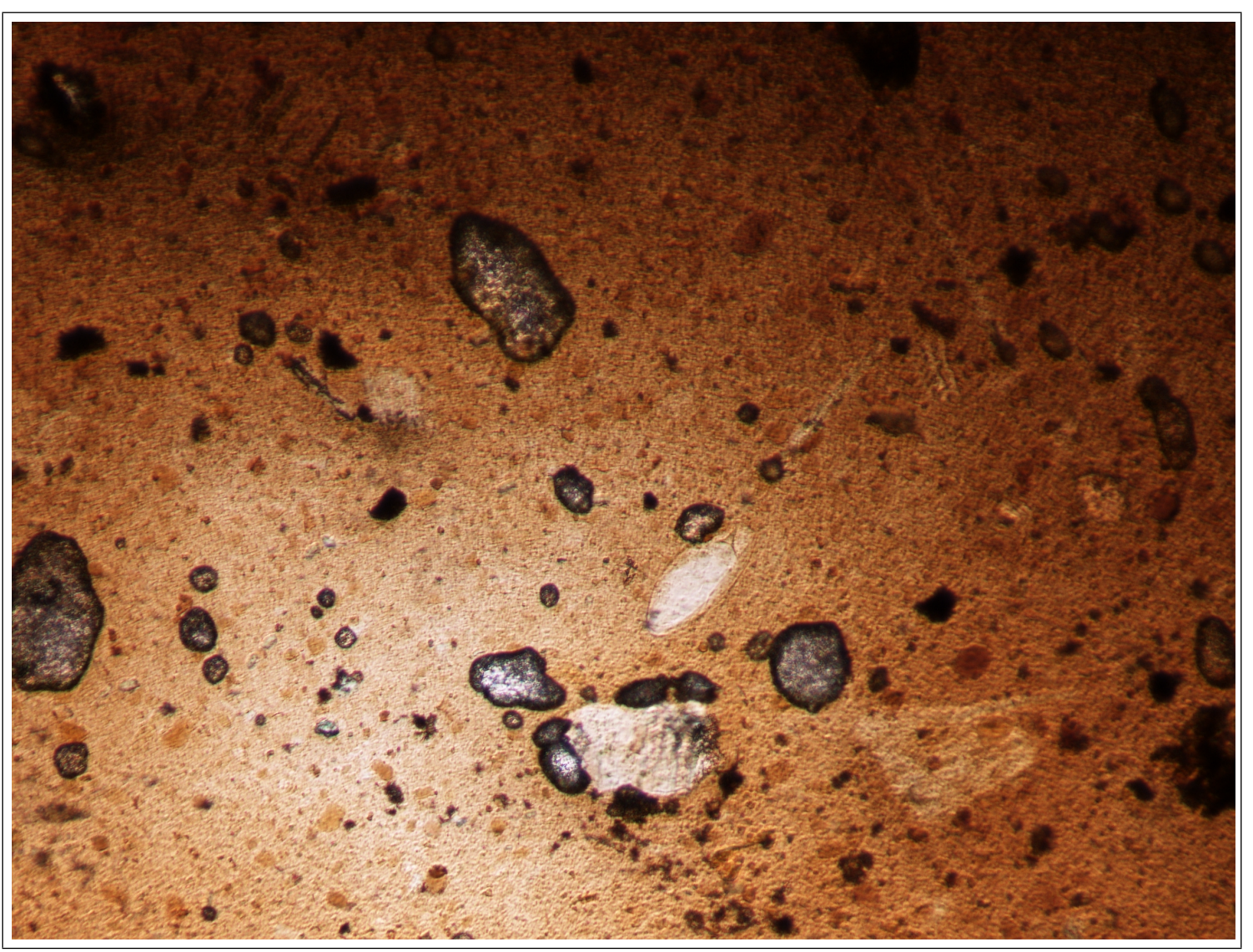

Figura 1.2: Região com ovo de S. mansoni da imagem de uma lâmina de microscópio com ampliação 10 vezes. O ovo é o objeto claro ovalado na região central. Os demais objetos são artefatos (partículas).

Os ovos de S. mansoni possuem algumas características que permitem sua detecção [31]:

- cor marrom-amarelada,

- forma elipsoidal,

- borda fina de cor escura,

- tamanho de $114 \sim 182 \times 45 \sim 73 \mu \mathrm{m}$,

- uma membrana translúcida, e

- uma espícula na parte lateral. 
A figura 1.3 mostra um ovo de S. mansoni na lâmina, obtida em ampliação $40 \mathrm{x}^{1}$.

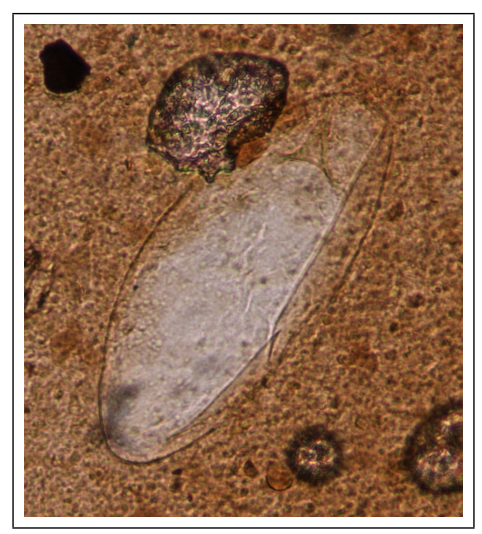

Figura 1.3: Ovo de S. mansoni, em ampliação 40x.

O contorno dos ovos muitas vezes aparece nas imagens como linhas escuras, fragmentadas ou não, dispostas em formato aproximadamente elíptico. Por outro lado, em vários dos ovos a maioria das bordas não aparece ou são confundidas com o fundo. A cor dos ovos em algumas das imagens é relativamente mais clara que a do fundo. No entanto, esta não é uma característica comum a todos os ovos. A espícula lateral que nem sempre é visível nas imagens serve, em geral, para confirmar a identidade de um ovo.

\subsection{Motivação}

O diagnóstico de Esquistossomose através de um microscópio óptico é um processo que requer uma análise cuidadosa e demorada da lâmina. Para cada lâmina examinada, deve-se percorrer toda a extensão do material fecal nela depositada, analisando-se a cada vez uma região no campo visual do microscópio. Para cada região, são necessários ajustes manuais no foco e também mudanças de ampliação. Por exemplo, considerando-se ampliação 20x, é necessário examinar cerca de 400 campos visuais por lâmina. Portanto, a tarefa de análise é bastante cansativa, principalmente quando o número de ovos é pequeno ou nulo.

Dependendo da localização geográfica do paciente, podem existir diferenças na densidade de ovos presentes nas lâminas. Por exemplo, em certas localizações tais como em algumas regiões no nordeste do Brasil a densidade de ovos é geralmente alta (dezenas de ovos), sendo o diagnóstico relativamente simples. Já em outras localizações, como em algumas regiões de São Paulo, a densidade de ovos é muito baixa, dificultando o diagnóstico. As lâminas de microscópio usadas neste trabalho apresentam densidade de ovos muito baixa (entre 1 e 7).

Para auxiliar o diagnóstico de esquistossomose, uma possível abordagem é a utilização de

\footnotetext{
${ }^{1} \mathrm{O}$ símbolo x neste texto indica a ampliação usada no microscópio; por exemplo, 40x lê-se 40 vezes.
} 
técnicas computacionais de processamento e análise de imagens para detecção de ovos. Tais técnicas podem ser desenvolvidas para detectar regiões das imagens nas quais há forte indício de presença de ovos. O especialista teria seu trabalho simplificado pois bastaria que ele analisasse essas regiões e confirmasse ou não a presença de ovos (ver figura 1.4).

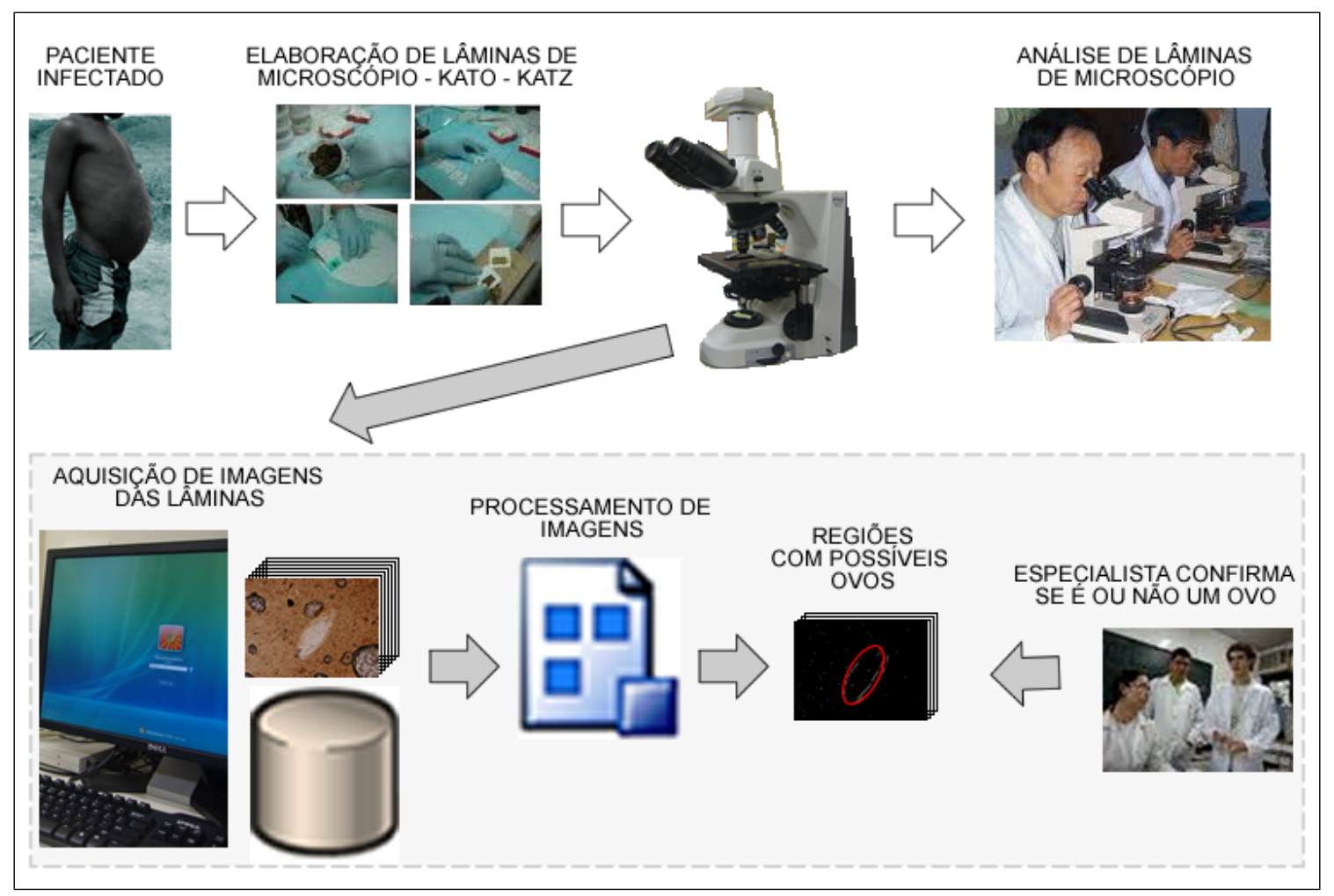

Figura 1.4: Processo do diagnóstico de esquistossomose motivador deste trabalho.

Uma vez que os ovos são caracterizados pelos aspectos morfológicos citados acima, é natural que as técnicas de processamento e análise de imagens procurem explorar tais características na detecção. Porém, devido a natureza complexa das imagens e o fato de nem todos os ovos apresentarem todas as características simultaneamente, uma técnica robusta para a detecção de ovos deverá analisar várias das características de forma conjunta. Consequentemente, torna-se importante o desenvolvimento de técnicas robustas para a extração dessas características das imagens a serem analisadas.

Outro desafio importante na análise de imagens de lâminas é a automatização do percorrimento de toda a sua superfície. Para isso torna-se necessário o controle computacional do microscópio com respeito ao ajuste de posição espacial, foco e ampliação. Essa questão não é abordada neste trabalho. 


\subsection{Objetivos}

O principal objetivo deste trabalho é tratar o problema de detecção de uma das características que podem identificar a presença de ovos: o conjunto de linhas que definem o contorno dos ovos.

Essas linhas, embora não sejam completamente visíveis em todos os ovos, aparecem de forma nítida e em grande proporção em vários casos. O problema de detecção de estruturas do tipo linha pode ser visto como um dos subproblemas cuja solução será útil na composição de uma solução para a detecção dos ovos em imagens do tipo consideradas neste trabalho.

Especificamente, objetivamos propor uma abordagem baseada em morfologia matemática para a deteç̧ão dessas linhas. A Morfologia Matemática (MM) é uma abordagem não-linear para processamento de imagens que explora informações relativas à forma dos objetos presentes nas imagens $[27,29]$.

Após a detecção das linhas, as imagens resultantes poderão conter segmentos de linhas que não fazem parte do contorno de ovos. Desta forma é também objetivo deste trabalho refinar o resultado detectando subconjuntos de linhas que se organizam em forma elíptica, e tenham um tamanho condizente com o dos ovos.

\subsection{Organização do trabalho}

Este texto está organizado da seguinte forma: no capítulo 2 apresentamos conceitos e definições básicas relacionadas às imagens, operadores morfológicos e transformada Hough, que são utilizados neste trabalho. Em seguida, no capítulo 3 descrevemos o algoritmo proposto para detecção de linhas. Os operadores morfológicos são utilizados para realçar e detectar as linhas e também para filtrar as linhas que não são de interesse. Também descrevemos a aplicação do algoritmo para detecção de elipses, que é baseado na transformada Hough, para selecionar segmentos de linhas que se apresentam em disposição elíptica. No capítulo 4 são apresentados os resultados obtidos após a aplicação do algoritmo proposto e do algoritmo de detecção de elipses. No capítulo 5 são apresentadas as conclusões deste trabalho. No apêndice A descrevemos as implementações associadas a esta dissertação.

u 


\section{Capítulo 2}

\section{Fundamentos}

Neste capítulo são apresentadas algumas definições/conceitos básicos, as definições de operadores da Morfologia Matemática utilizados ao longo do texto, e a transformada Hough para detecção de elipses.

\subsection{Definições preliminares}

Imagem digital: neste texto, uma imagem digital monocromática é definida como sendo uma função de $\mathbb{E}=\mathbb{Z}^{2}$ em $K=[0, k-1] \subseteq \mathbb{Z}$. O conjunto de todas as imagens digitais possíveis é denotado por $K^{\mathbb{E}}$ [2]. O valor de $k$, usualmente 256, é o número de tons de cinza das imagens. Um elemento de $\mathbb{E}$ é denominado pixel.

Imagem binária: uma imagem digital é dita binária se sua amplitude (ou níveis de cinza) apresenta apenas dois valores possíveis, geralmente 0 e 1 . Nas imagens binárias deste texto, o valor 1 corresponde aos objetos e o valor 0 ao fundo da imagem. Nas figuras de imagens binárias, o fundo é apresentado em cor branca enquanto os objetos são apresentados em cor preta.

Modelo de cor: um sistema de coordenadas tridimensional onde cada cor é representada por um único ponto [14].

RGB: o modelo de cor mais popular, baseado num sistema de coordenadas de três eixos definindo um subespaço em forma de cubo. Os eixos representam, respectivamente, a intensidade de vermelho, verde e azul [14].

Vizinhança de um pixel: a definição de vizinhança de um pixel é importante para diversos processamentos e conceitos como contornos e conectividade. Geralmente são definidos 2 tipos de vizinhança: a vizinhança-4 e a vizinhança-8. Para o pixel localizado na posição $(x, y) \in \mathbb{E}$, a vizinhança 4 é o conjunto de pixels localizados nas posições: $(x+1, y),(x, y+$ 
$1),(x-1, y),(x, y-1)$; a vizinhança 8 é o conjunto de pixels localizados nas posições: $(x+1, y),(x+1, y+1),(x, y+1),(x-1, y+1),(x-1, y),(x-1, y-1),(x, y-1) e(x+1, y-1)[4]$.

Conectividade: dois pixels são conectados (vizinhos) se um pertence à vizinhança do outro. Dependendo da vizinhança (4 ou 8) adotada, tem-se a respectiva conectividade (4 ou 8).

Caminho conexo: um caminho conexo entre dois pixels $P$ e $Q$ é uma sequência de pixels $p_{1}, p_{2}, p_{3}, \ldots, p_{N}$ na qual $p_{i}$ é vizinho a $p_{i+1}, i=1,2, \ldots, N-1, p_{1}=P$ e $p_{N}=Q$, segundo a conectividade adotada.

Componente conexo: é um conjunto maximal de pixels, tal que para quaisquer $P$ e $Q$ pertencentes ao conjunto, existe um caminho conexo entre eles contido no conjunto.

Objeto: no contexto deste trabalho, objeto é um componente conexo.

Contorno ou borda: curva que delimita um componente conexo [14].

Pico: tomando-se uma imagem digital como uma superfície topológica, um pico é uma região conexa de pixels, que possuem amplitude maior que seus pixels vizinhos externos.

Vale: tomando-se uma imagem digital como uma superfície topológica, um vale é uma região conexa de pixels, que possuem amplitude menor que seus pixels vizinhos externos.

Alvo: objeto de interesse em uma imagem digital. No contexto deste trabalho, alvos são as curvas que definem o contorno dos ovos de Schistosoma Mansoni.

Objeto alvo: idem alvo.

Fundo: todo o resto da imagem que não é objeto.

Morfologia Matemática: Morfologia Matemática (MM) é um ramo de análise e processamento não-linear de imagens, que explora informações sobre estruturas geométricas presentes na imagem [10]. Sua ideia básica consiste em extrair informação acerca de formas usando elementos estruturantes, utilizados para sondar localmente uma imagem [26]. Os fundamentos teóricos da MM são baseados na teoria dos reticulados completos [15]. No caso de imagens binárias, o reticulado [14] em questão é o reticulado dos conjuntos. 


\subsection{Conversão para imagens em tons de cinza}

Uma imagem digital colorida pode ser representada em distintos modelos de cores, sendo que pelo menos três matrizes 2D são necessárias para representar uma imagem colorida. Alguns dos mais populares sistemas de cores são: RGB (Red, Green, Blue), CMY (Cyan, Magenta, Yellow), e HSI (Hue, Saturation, Intensity). Por exemplo, num sistema como o RGB, a imagem pode ser definida como:

$$
f_{R G B}(\mathbf{x})=\left(R_{\mathbf{x}}, G_{\mathbf{x}}, B_{\mathbf{x}}\right)
$$

na qual $\mathbf{x} \in \mathbb{E}$ é um ponto (pixel) na imagem e $f_{R G B}(\mathbf{x})$ é o valor das componentes $R, G$ e $B$ nesse ponto.

O padrão NTSC, criado pela International Telecommunication Union, estabeleceu uma fórmula para calcular o valor da intensidade do nível de cinza, $f(\mathbf{x})$ a partir dos componentes $R G B$ de uma imagem colorida $f_{R G B}$ :

$$
f(\mathbf{x})=0.299 R_{\mathbf{x}}+0.587 G_{\mathbf{x}}+0.114 B_{\mathbf{x}}
$$

Neste trabalho usamos a equação 2.2 para converter as imagens de cores de 24 bits para tons de cinza de 8 bits. Uma imagem em tons de cinza pode ser vista na figura 2.1. Ao seu lado é apresentada uma visão da superfície correspondente. Nessa visão de superfície, as regiões claras da imagem correspondem às elevações enquanto as regiões escuras correspondem aos vales.

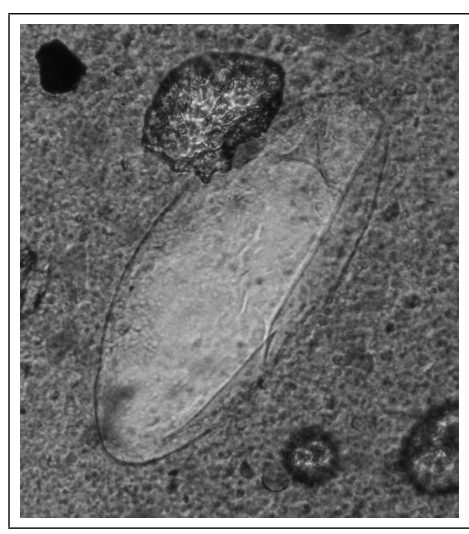

(a)

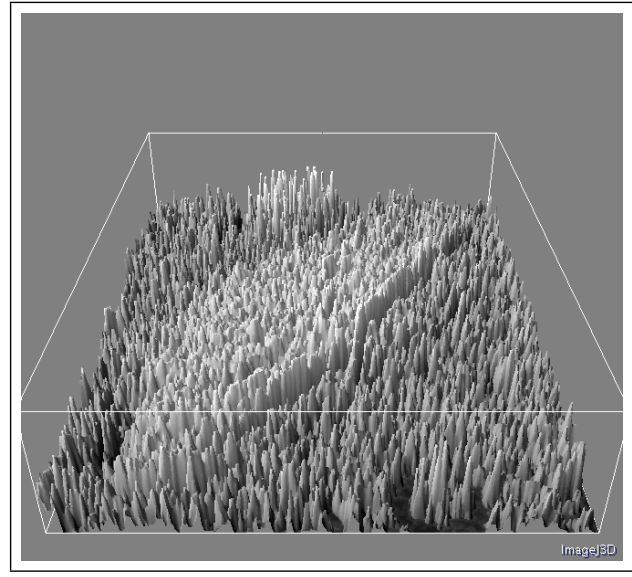

(b)

Figura 2.1: (a) Resultado da conversão da imagem colorida original a tons de cinza. (b) Imagem da superfície. 


\subsection{Limiarização}

A limiarização é a operação de conversão de uma imagen em tons de cinza em uma imagem binária, processo também conhecido como binarização. É uma operação que atribui o valor 0 ou 1 a cada pixel da imagem $f$ baseado em uma comparação com um valor global de limiarização $L$. Formalmente,

$$
[\operatorname{Lim}(f, L)](\mathbf{x})= \begin{cases}1, & \text { se } f(\mathbf{x}) \geq L \\ 0, & \text { se } f(\mathbf{x})<L\end{cases}
$$

\subsection{Máscaras para detecção de linhas}

Uma maneira comum para identificar descontinuidades de cor (intensidade) tais como pontos isolados, linhas e bordas em imagens digitais é através da operação de convolução. A convolução consiste da varredura da imagem por uma máscara de coeficientes, calculando a soma dos produtos dos coeficientes pelos níveis de cinza dentro da região delimitada pela máscara [14].

Diferentes máscaras são usadas para detecção de linhas com diferentes orientações. Como as imagens consideradas neste trabalho tem resolução alta e as linhas alvo tem uma espessura mínima aproximada de 3 pixels, as máscaras foram adaptadas como mostrado na figura 2.2, permitindo detectar algumas linhas horizontais, verticais e diagonais com espessura de 3 pixels.

Existem operadores que usam máscaras para detecção de contornos, como o método de Sobel, e Laplaciana da Gaussiana que produzem, respectivamente, uma aproximação do gradiente das intensidades e uma aproximação da segunda derivada das intensidades da imagem (ver máscaras em 2.3). O efeito em ambos os casos é o de destacar as diferenças de intensidade entre pixels vizinhos na imagem. Porém, esses operadores são altamente sensíveis ao ruído [14].

\subsection{Morfologia matemática binária}

Devido a equivalência entre funções binárias e subconjuntos definidos em $\mathbb{E}$, na Morfologia Matemática as imagens binárias são geralmente tratadas como conjuntos. Nas definições que seguem, o domínio das imagens considerado é $\mathbb{E}=\mathbb{Z}^{2}$, e $A$ e $B$ (subconjuntos de $\mathbb{E}$ ) denotam, respectivamente, uma imagem binária e um elemento estruturante. O elemento $\mathbf{x} \in \mathbb{E}$ denota a posição de um ponto da imagem.

Definição 1 A translação de A por x é definida por [10]:

$$
A_{\mathbf{x}}=\{\mathbf{a}+\mathbf{x}: \mathbf{a} \in A\}
$$




\begin{tabular}{|c|c|c|c|c|c|c|c|c|}
\hline-1 & -1 & -1 & -1 & -1 & -1 & -1 & -1 & -1 \\
\hline-1 & -1 & -1 & -1 & -1 & -1 & -1 & -1 & -1 \\
\hline-1 & -1 & -1 & -1 & -1 & -1 & -1 & -1 & -1 \\
\hline 2 & 2 & 2 & 2 & 2 & 2 & 2 & 2 & 2 \\
\hline 2 & 2 & 2 & 2 & 2 & 2 & 2 & 2 & 2 \\
\hline 2 & 2 & 2 & 2 & 2 & 2 & 2 & 2 & 2 \\
\hline-1 & -1 & -1 & -1 & -1 & -1 & -1 & -1 & -1 \\
\hline-1 & -1 & -1 & -1 & -1 & -1 & -1 & -1 & -1 \\
\hline-1 & -1 & -1 & -1 & -1 & -1 & -1 & -1 & -1 \\
\hline
\end{tabular}

(a)

\begin{tabular}{|c|c|c|c|c|c|c|c|c|}
\hline 0 & -1 & -1 & -1 & -1 & -1 & -1 & 2 & 2 \\
\hline 0 & -1 & -1 & -1 & -1 & -1 & 2 & 2 & 2 \\
\hline 0 & -1 & -1 & -1 & -1 & 2 & 2 & 2 & -1 \\
\hline-1 & -1 & -1 & -1 & 2 & 2 & 2 & -1 & -1 \\
\hline-1 & -1 & -1 & 2 & 2 & 2 & -1 & -1 & -1 \\
\hline-1 & -1 & 2 & 2 & 2 & -1 & -1 & -1 & -1 \\
\hline-1 & 2 & 2 & 2 & -1 & -1 & -1 & -1 & 0 \\
\hline 2 & 2 & 2 & -1 & -1 & -1 & -1 & -1 & 0 \\
\hline 2 & 2 & -1 & -1 & -1 & -1 & -1 & -1 & 0 \\
\hline
\end{tabular}

(c)

\begin{tabular}{|l|l|l|l|l|l|l|l|l|}
\hline-1 & -1 & -1 & 2 & 2 & 2 & -1 & -1 & -1 \\
\hline-1 & -1 & -1 & 2 & 2 & 2 & -1 & -1 & -1 \\
\hline-1 & -1 & -1 & 2 & 2 & 2 & -1 & -1 & -1 \\
\hline-1 & -1 & -1 & 2 & 2 & 2 & -1 & -1 & -1 \\
\hline-1 & -1 & -1 & 2 & 2 & 2 & -1 & -1 & -1 \\
\hline-1 & -1 & -1 & 2 & 2 & 2 & -1 & -1 & -1 \\
\hline-1 & -1 & -1 & 2 & 2 & 2 & -1 & -1 & -1 \\
\hline-1 & -1 & -1 & 2 & 2 & 2 & -1 & -1 & -1 \\
\hline-1 & -1 & -1 & 2 & 2 & 2 & -1 & -1 & -1 \\
\hline
\end{tabular}

(b)

\begin{tabular}{|c|c|c|c|c|c|c|c|c|}
\hline 2 & 2 & -1 & -1 & -1 & -1 & -1 & -1 & 0 \\
\hline 2 & 2 & 2 & -1 & -1 & -1 & -1 & -1 & 0 \\
\hline-1 & 2 & 2 & 2 & -1 & -1 & -1 & -1 & 0 \\
\hline-1 & -1 & 2 & 2 & 2 & -1 & -1 & -1 & -1 \\
\hline-1 & -1 & -1 & 2 & 2 & 2 & -1 & -1 & -1 \\
\hline-1 & -1 & -1 & -1 & 2 & 2 & 2 & -1 & -1 \\
\hline 0 & -1 & -1 & -1 & -1 & 2 & 2 & 2 & -1 \\
\hline 0 & -1 & -1 & -1 & -1 & -1 & 2 & 2 & 2 \\
\hline 0 & -1 & -1 & -1 & -1 & -1 & -1 & 2 & 2 \\
\hline
\end{tabular}

(d)

Figura 2.2: (a) Máscara $9 \times 9$ para detectar linhas horizontais. (b) Máscara para detectar linhas verticais. (c) Máscara para detectar linhas com orientação de 45 graus. (d) Máscara para detectar linhas com orientação de -45 graus.

\begin{tabular}{|c|c|c|}
\hline-1 & -2 & -1 \\
\hline 0 & 0 & 0 \\
\hline 1 & 2 & 1 \\
\hline
\end{tabular}

(a)

\begin{tabular}{|l|l|l|}
\hline-1 & 0 & 1 \\
\hline-2 & 0 & 2 \\
\hline-1 & 0 & 1 \\
\hline
\end{tabular}

(b)

\begin{tabular}{|c|c|c|c|c|}
\hline 0 & 0 & -1 & 0 & 0 \\
\hline 0 & -1 & -2 & -1 & 0 \\
\hline-1 & -2 & 16 & -2 & -1 \\
\hline 0 & -1 & -2 & -1 & 0 \\
\hline 0 & 0 & -1 & 0 & 0 \\
\hline
\end{tabular}

(c)

Figura 2.3: (a) Máscara $G_{x}$ do operador Sobel. (b) Máscara $G_{y}$ do operador Sobel. (c) Máscara do operador Laplaciano da Gaussiana.

$n a$ qual + é a adição usual de vetores.

Definição 2 A reflexão de $B$ é definida por [10]:

$$
\check{B}=\{-b: b \in B\}
$$

Definição 3 A erosão de $A$ por $B$, denotada por $A \ominus B$, é definida por [10]:

$$
A \ominus B=\left\{\mathbf{x}: B_{\mathbf{x}} \subseteq A\right\}
$$

$A$ erosão de $A$ por $B$ é o conjunto de todos os pontos $\mathbf{x}$ tais que B, quando deslocado por $\mathbf{x}$, está 
contido em A [14].

Definição 4 A dilatação de $A$ por $B$, denotada por $A \oplus B$, é definida por [10]:

$$
A \oplus B=\left\{\mathbf{x}: A \cap \check{B}_{\mathbf{x}} \neq \emptyset\right\}
$$

A dilatação de $A$ por $B$ é o conjunto de todos os pontos $\mathbf{x}$ tais que a translação do elemento estruturante refletido por $\mathbf{x}$ intersecta $A$.

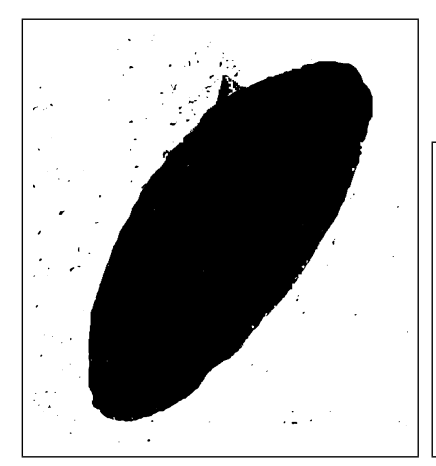

(a) Imagem original.

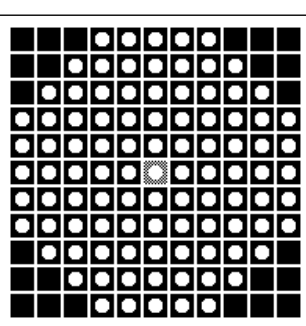

(b) EE disco 5 .

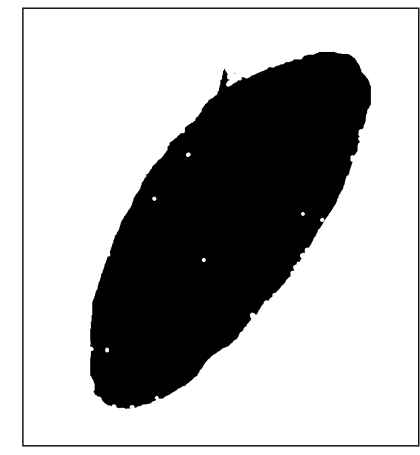

(c) Erosão da imagem original.

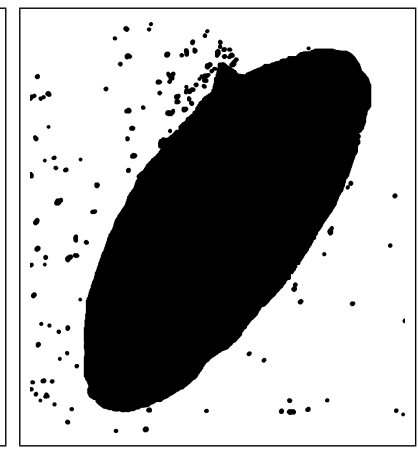

(d) Dilatação da imagem original.

Figura 2.4: Efeitos da erosão e dilatação em uma imagem binária.

Na figura 2.4 podem ser vistos, respectivamente, os resultados dos operadores erosão e dilatação quando aplicados em uma imagem binária. As figuras 2.4(c) e 2.4(d) mostram o resultado após a erosão e dilatação, utilizando um elemento estruturante em forma de disco (fig. 2.4(b)) com raio 5 e centrado na origem.

Como efeitos da erosão na imagem binária da figura 2.4(c), pode-se verificar o desaparecimento de objetos menores que o elemento estruturante, a diminuição do tamanho dos objetos (e consequente aumento da área do fundo) e uma possível divisão de alguns componentes conexos. Pode-se observar do resultado da dilatação na imagem binária (figura 2.4(d)) o desaparecimento de buracos menores que o elemento estruturante utilizado, a ampliação dos objetos da imagem (obviamente a redução da área do fundo) e a fusão de componentes conexos próximos [19]. Na erosão, não se pode afirmar se o número de componentes conexos na imagem irá aumentar ou diminuir, pois depende do número de pequenos componentes conexos que serão eliminados e dos objetos que serão divididos.

Definição 5 A abertura de $A$ por $B$, denotada por $A \circ B$, é definida por [10]:

$$
A \circ B=(A \ominus B) \oplus B
$$


A abertura geralmente suaviza o contorno dos objetos, separa istmos estreitos e elimina protusões finas [14].

Definição 6 O fechamento de $A$ por $B$, denotado por $A \bullet B$, é definido por [10]:

$$
A \bullet B=(A \oplus B) \ominus B
$$

O fechamento tende a suavizar os contornos, mas em oposição à abertura, geralmente funde as fraturas em golfos finos, elimina pequenos buracos e preenche fragmentações em um contorno [14].

O resultado da abertura usando o elemento estruturante da figura 2.4(b) é mostrado em 2.5(b). Nota-se que vários componentes menores que o elemento estruturante foram removidos devido à erosão, e poucos deles foram restaurados na dilatação. O resultado do fechamento usando o elemento estruturante da figura 2.4(b) é mostrado em 2.5(c). Observa-se que pequenos detalhes da região do fundo que são menores que o elemento estruturante foram eliminados, além disso nota-se a união de vários componentes.

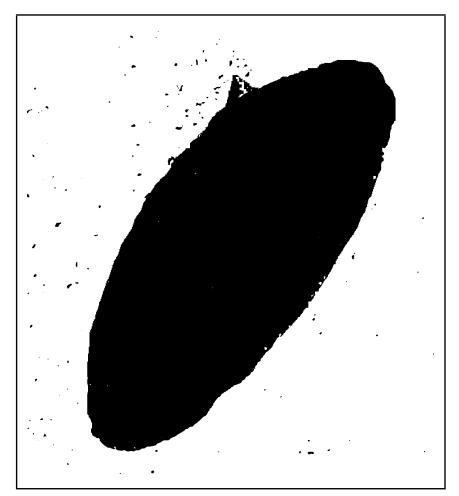

(a) Imagem original.

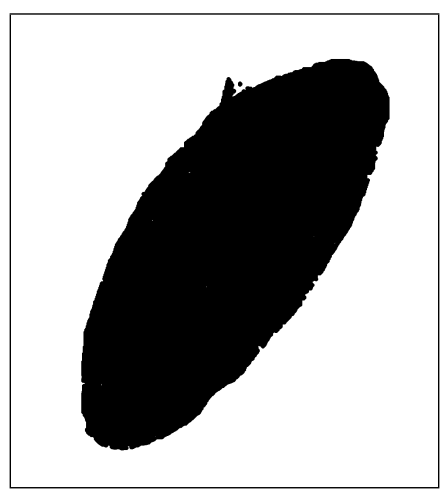

(b) Abertura.

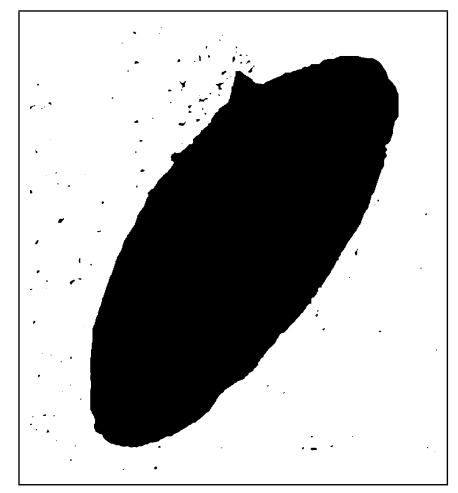

(c) Fechamento.

Figura 2.5: Efeito da aplicação de abertura (b) e de fechamento (c) na imagem em (a).

Definição 7 O gradiente morfológico é usado para detectar bordas em imagens, erodindo e dilatando a imagem original e, depois, subtraindo a imagem erodida da imagem dilatada. O gradiente morfológico de $A$ por $B$, denotado por $\operatorname{grad}(A, B)$, é definido por [10]:

$$
\operatorname{grad}(A, B)=(A \oplus B)-(A \ominus B)
$$

A figura 2.6(b) mostra o gradiente morfológico usando o elemento estruturante da figura 2.4(b). O gradiente morfológico é geralmente calculado usando-se o elemento caixa $3 \times 3$ ou cruz. 


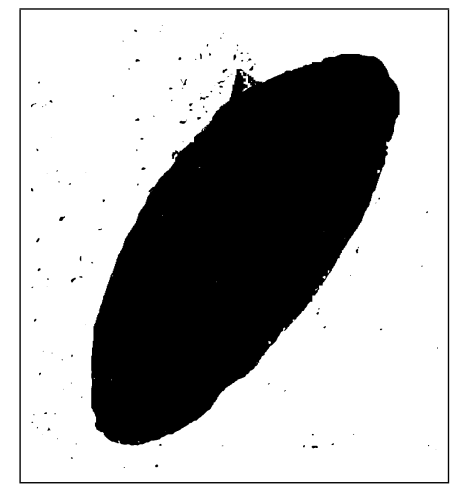

(a) Imagem original.

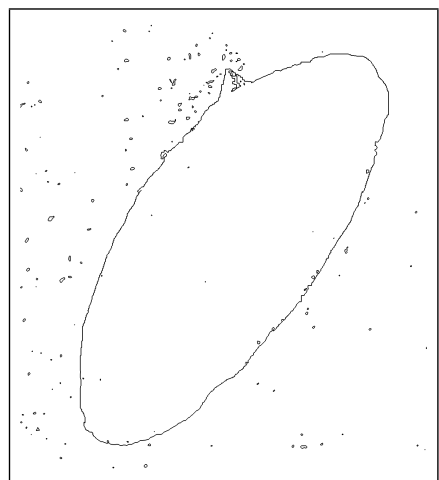

(b) Gradiente morfológico.

Figura 2.6: Efeito da aplicação do gradiente morfológico em imagem binária.

Definição 8 A abertura por área $\alpha$ de A segundo a conectividade $B$ é definida por

$$
A \circ(\alpha)_{B}=\bigcup\left\{C_{i}, \text { area }\left(C_{i}\right) \geq \alpha\right\}
$$

e consiste do conjunto de componentes conexos $C_{i}$ em $A$ cuja área (número de pixels) é maior ou igual a $\alpha$, isto é, os componentes conexos com área menor que $\alpha$ são removidos [10]. O elemento estruturante $B$ define a conectividade em questão (um elemento estruturante caixa $3 \times 3$ corresponde à conectividade 8 e um elemento estruturante cruz corresponde à conectividade 4).

Definição 9 Sejam $S$ e $T$ duas imagens binárias tais que $S \subseteq T$, denominadas imagem marcadora e imagem máscara, respectivamente. A reconstrução morfológica por dilatação de $T$, a partir dos marcadores $S$, é definida por [10]:

$$
T \Delta_{B} S=\left(S \oplus_{T} B\right)^{\infty}
$$

A operação $\oplus_{T}$ denota a dilatação condicional; $S$ é dilatado sucessivamente por $B$, porém o resultado fica condicionado a $T$, sem poder expandir-se além de T. O expoente $\infty$ indica que a dilatação condicional é aplicada até a estabilização do resultado.

Dada uma imagem $A$ definida em um domínio finito $T$, em algumas situações é conveniente remover os componentes de $A$ que tocam a borda de $T$ (uma vez que tais componentes podem estar incompletos ou podem consistir de resíduos resultantes do efeito de borda). Para isto, realiza-se a reconstrução por dilatação de $A$ usando a moldura de $T$ (as linhas que correspondem aos pixels na borda de $T$ ), denotada por $\partial T$, como imagem marcadora, e subtraí-la da imagem original [10]. 
Mais especificamente,

$$
\Gamma_{B}(A)=A-\left(A \Delta_{B} \partial T\right),
$$

na qual $B$ é o elemento estruturante que indica a conectividade considerada.

\subsection{Morfologia matemática para imagens em tons de cinza}

As imagens em tons de cinza são definidas por funções do tipo $f: \mathbb{E} \rightarrow\{0,1, \ldots, k-1\}$. Mesmo em aplicações nas quais o resultado desejado é binário, como no nosso caso, as imagens são inicialmente processadas em tons de cinza para preservar melhor as informações. Em geral, somente após processamento adequado (seja para realçar detalhes de interesse, seja para atenuar ruídos) é que elas são convertidas para imagens binárias (visando, muitas vezes, eficiência computacional).

Nas definições que seguem, $f$ denota uma imagem em tons de cinza e $B \subseteq \mathbb{E}$ denota um elemento estruturante plano.

Definição 10 A erosão de $f$ por $B$ em qualquer posição $\mathbf{x}$ é definida por [10]:

$$
(f \ominus B)(\mathbf{x})=\min \left\{f(z): z \in B_{\mathbf{x}}\right\} .
$$

$A$ erosão é então um filtro de mínimo sob a janela $B$.

Definição 11 A dilatação de $f$ por $B$ em qualquer posição x é definida por [10]:

$$
(f \oplus B)(\mathbf{x})=\max \left\{f(z): z \in \check{B}_{\mathbf{x}}\right\} .
$$

A dilatação é então um filtro de máximo sob a janela $B$.

A dilatação e a erosão nas imagens em níveis de cinza apresentam efeitos mais sutis. As partes claras usualmente aumentam em uma imagem dilatada, como na Figura 2.7(b), que é o resultado da dilatação da imagem da Figura 2.7(a) pelo elemento estruturante da figura 2.4(b). Na erosão de imagens em níveis de cinza, as partes claras geralmente diminuem em relação à imagem original. A Figura 2.7(c) mostra esse efeito. O elemento estruturante utilizado na erosão foi o mesmo utilizado na dilatação da Figura 2.7(b).

As definições de abertura, fechamento e gradiente morfológico de imagens em tons de cinza são dadas de forma análoga ao caso binário [10]. A figura 2.8(b) mostra o gradiente morfológico da figura 2.8(a). Os pontos de maior valor na imagem gradiente mostram onde há maior diferença entre valores de pixels vizinhos. 


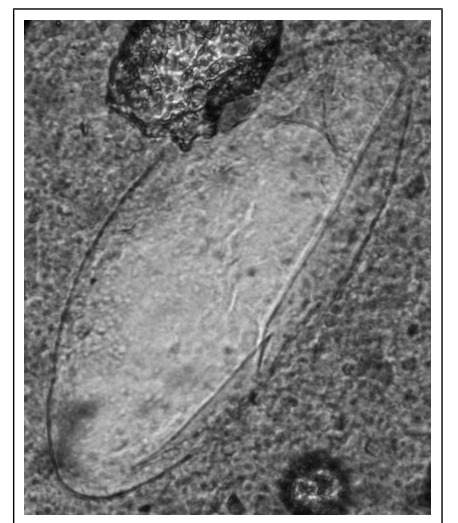

(a) Imagem original em níveis de cinza

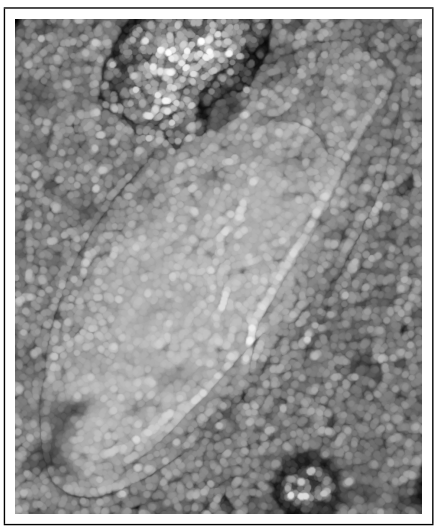

(b) Imagem dilatada

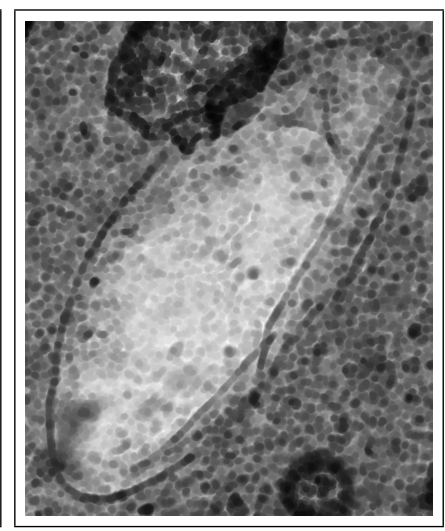

(c) Imagem erodida

Figura 2.7: Erosão e dilatação em uma imagem em níveis de cinza.

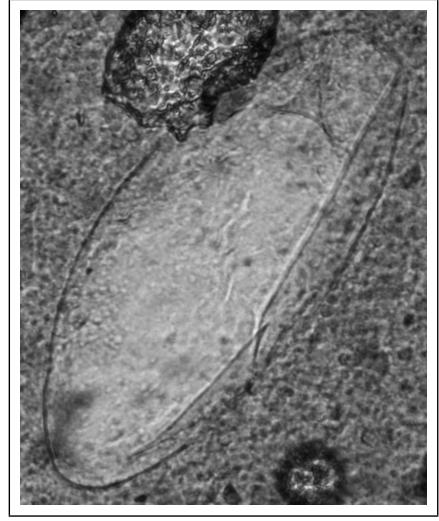

(a) Imagem original.

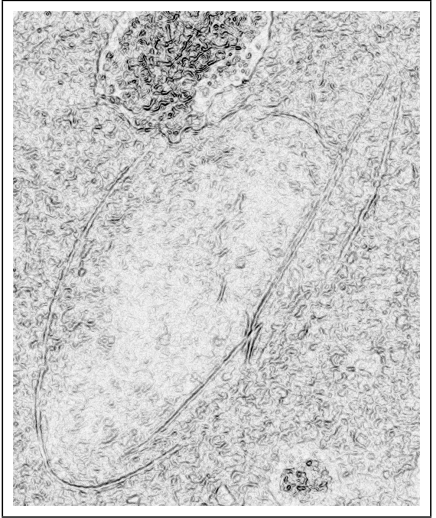

(b) Negação do gradiente morfológico.

Figura 2.8: Gradiente morfológico de uma imagem em níveis de cinza.

Definição 12 O fechamento top-hat é definido como [10]:

$$
f \bullet B=(f \bullet B)-f .
$$

O fechamento top-hat é o resultado da subtração entre o fechamento e a imagem original. Ele detecta regiões que correspondem aos vales da imagem $f$ (regiões mais escuras no nosso caso) e que sejam mais estreitos que o elemento estruturante $B$ [14]. A figura 2.9(b) mostra o fechamento TopHat da figura 2.9(a). Nota-se que as regiões escuras da imagem, isto é os vales foram recuperados.

Definição 13 Sejam $z_{1}, z_{2}, \ldots, z_{m}$ os valores da imagem $f$ em uma vizinhança definida por $B$ em torno de um ponto $\mathbf{x}$. Sejam $z_{(1)}, z_{(2)}, \ldots, z_{(m)}$ os mesmos valores ordenados. O filtro de ordem $k$, 


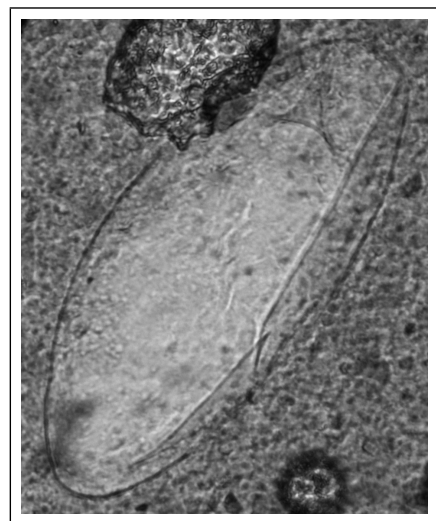

(a) Imagem original.

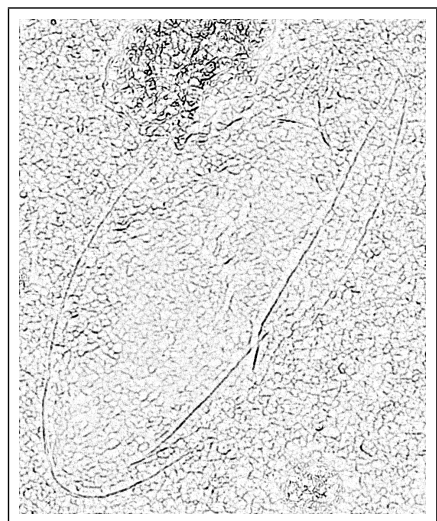

(b) Negação do Fechamento Top-Hat.

Figura 2.9: Efeito da aplicação do Fechamento Top-Hat.

$k \in[1, m]$, é definido como [16]:

$$
\left[R_{B, k}(f)\right](\mathbf{x})=z_{(k)}
$$

De acordo com esta notação, o filtro da mediana é denotado por $R_{B,(m+1) / 2}$. Os filtros de ordem $R_{B, 1}$ e $R_{B, m}$ correspondem à erosão (mínimo) e dilatação (máximo), respectivamente.

Na figura 2.10, observa-se um exemplo da aplicação do filtro de ordem em um sinal, com uma janela de tamanho 7 e ordem 2 .

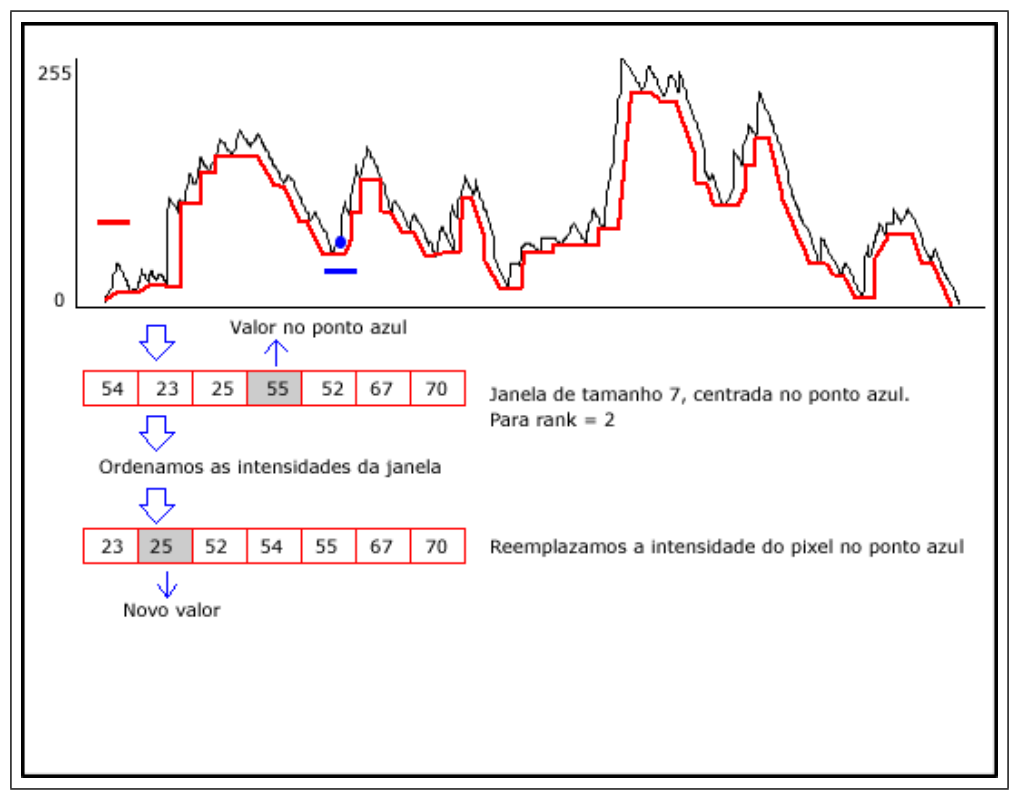

Figura 2.10: Exemplo de aplicação do filtro de ordem sobre um sinal, com janela de tamanho 7 e ordem 2. 


\subsection{Transformada Hough}

A transformada Hough é uma técnica de extração de características usada em análise de imagens, visão computacional e processamento de imagens digitais [28]. O propósito da técnica é encontrar instâncias aproximadas de objetos dentro de classes específicas de formas (linhas, elipses, círculos, etc.), através de um mapeamento do espaço da imagem a um espaço paramétrico [11,22]. Uma característica importante é que vários pontos que pertencem a uma mesma curva serão mapeados para um mesmo ponto no espaço paramétrico.

Descrevemos primeiramente a transformada Hough para detecção de retas, com o intuito de facilitar o entendimento sobre a transformada Hough para a detecção de elipses.

\subsubsection{Transformada Hough para retas}

O conjunto de todas as retas em um plano constitui uma família que pode ser caracterizada por dois parâmetros. Uma reta arbitrária pode ser representada por um único ponto nesse espaço paramétrico. Especificamente, uma reta pode ser definida pelo ângulo $\theta$ de sua normal e pela sua distância algébrica $\rho$ até a origem (veja figura 2.11). A equação de uma reta correspondente ao par $(\theta, \rho)$ é $x \cos \theta+y \sin \theta=\rho$.

Se restringimos $\theta$ ao intervalo $[0, \pi]$, os parâmetros para uma reta são únicos. Com esta restrição, cada reta no plano $x \times y$ corresponde a um único ponto no plano $\theta \times \rho$ [11], conforme ilustrado na figura 2.11 .

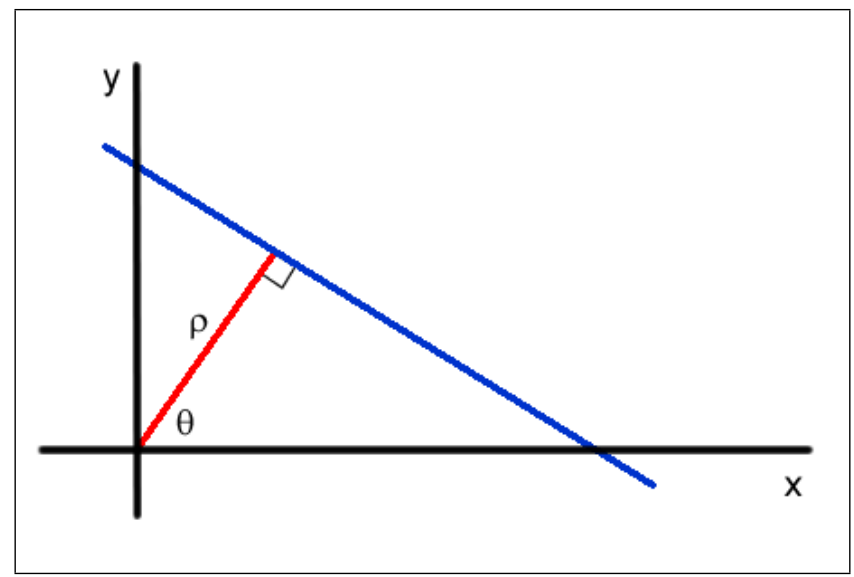

Figura 2.11: Parâmetros de uma reta [11].

O processamento baseado na transformada Hough para detectar retas (em imagens binárias) baseia-se na forma paramétrica de uma reta e está descrito no algoritmo 1.

Dada uma imagem binária $f$, o algoritmo 1 realiza uma varredura de $f$ e para cada pixel com valor um, realiza uma iteração variando o valor de $\theta$ de 0 até $\pi$, com incrementos de $\Delta \theta$. Para 


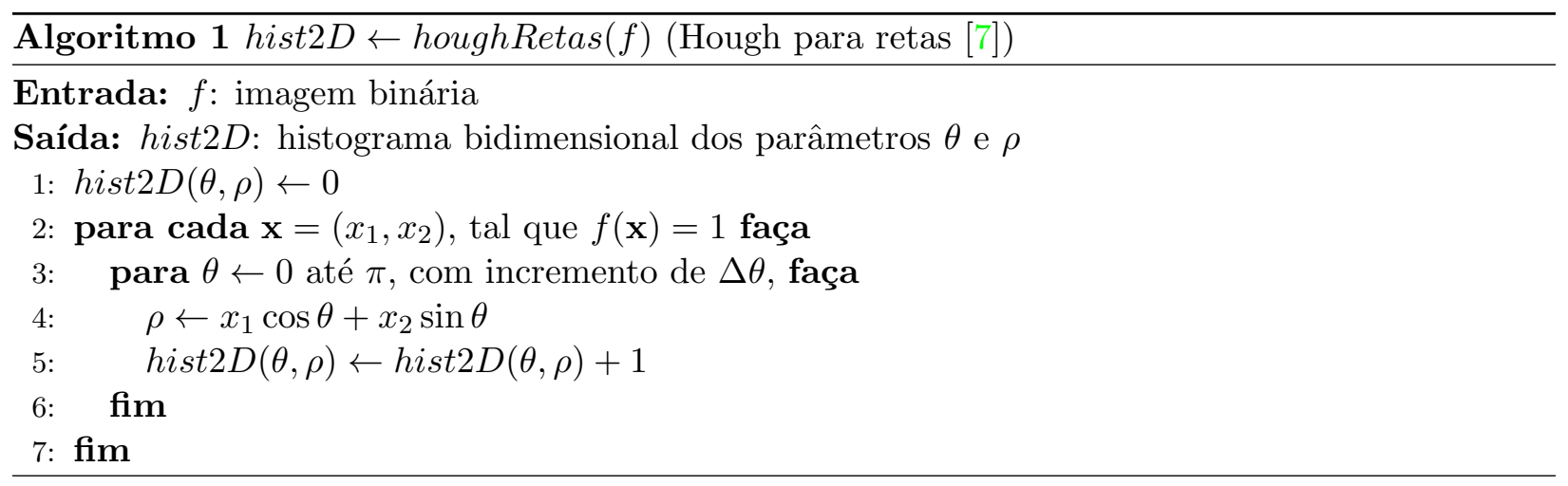

cada valor de $\theta$ na iteração, calcula o correspondente parâmetro $\rho$ (correspondendo à reta que passa por aquele ponto e cuja normal possui ângulo $\theta$ ). Em seguida, incrementa em uma unidade a ocorrência desse par de parâmetros em hist $2 D(\theta, \rho)$. No final da varredura da imagem, teremos uma matriz preenchida com votos (ocrorrências) para cada par de coordenadas $(\theta, \rho)$. Note que um ponto faz com que o histograma seja incrementado em vários pares de parâmetros; e que um certo par de parâmetros é incrementado uma vez para cada ponto localizado num mesmo segmento de reta (fazendo com que a frequência desse parâmetro seja alta). Os parâmetros da célula com maior valor determinam uma possível linha (segmento de reta) presente na imagem [7].

\subsubsection{Transformada Hough para elipses}

Na representação paramétrica de elipses são necessários cinco parâmetros: as coordenadas do centro da elipse (que comprendem dois parâmetros), a orientação, e os comprimentos do eixo maior e do eixo menor [7]. Dentre as diferentes abordagens para detectar elipses, citamos Yuen et al. [35] que propuseram um método eficiente usando a transformada Hough, baseado em algumas ideias propostas previamente por outros autores. O método divide-se em duas partes: a primeira parte corresponde a buscar os parâmetros que definem o centro da elipse, e a segunda parte consiste em buscar os outros três parâmetros. Esse método é descrito a seguir por meio de algoritmos elaborados a partir de uma implementação realizada por R. A. McLaughlin [23,24] do método descrito em [35], e gentilmente cedida pelo autor.

De acordo com a abordagem proposta em [35], para encontrar o centro da elipse, suponha que $\mathbf{p}=\left(p_{1}, p_{2}\right)$ e $\mathbf{q}=\left(q_{1}, q_{2}\right)$ são dois pontos da elipse com tangentes não paralelas, que se intersectam no ponto $\mathbf{t}=\left(t_{1}, t_{2}\right)$. Seja $\mathbf{m}=\left(m_{1}, m_{2}\right)$ o ponto médio de pq. O centro da elipse deve estar localizado na reta que passa por tm. Veja figura 2.12.

A reta que passa por tm é:

$$
y\left(t_{1}-m_{1}\right)=x\left(t_{2}-m_{2}\right)+m_{2} t_{1}-m_{1} t_{2}
$$




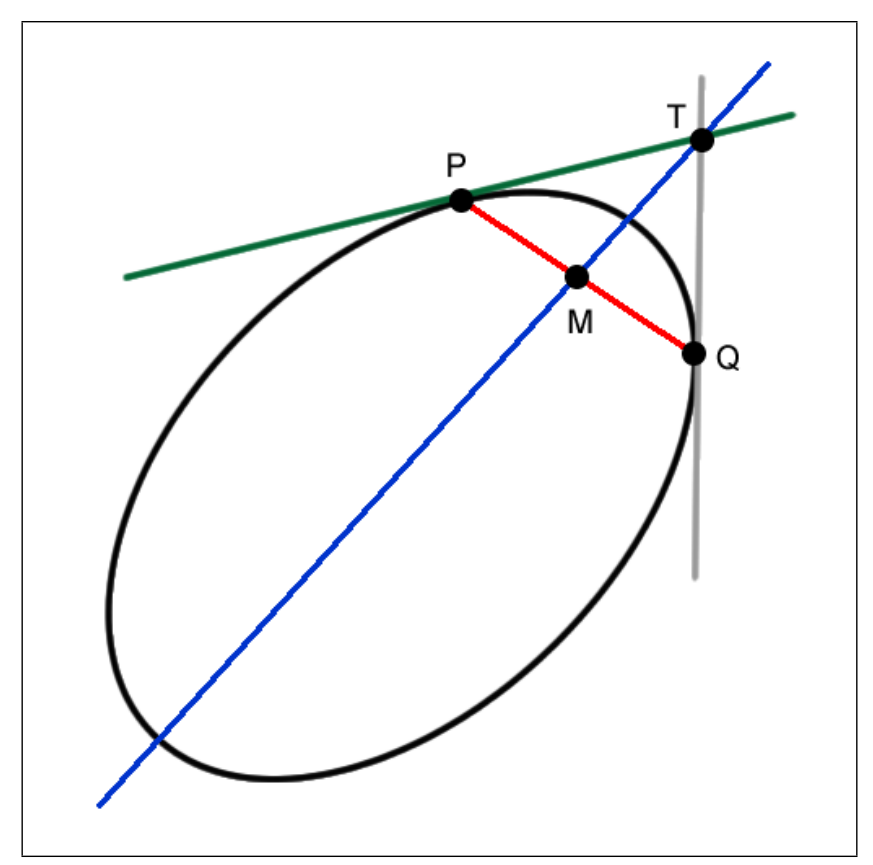

Figura 2.12: Geometria básica para encontrar o centro da elipse [35].

na qual

$$
\begin{gathered}
t_{1}=\frac{p_{2}-q_{2}-p_{1} \zeta_{1}+q_{1} \zeta_{2}}{\zeta_{2}-\zeta_{1}} \\
t_{2}=\frac{\zeta_{1} \zeta_{2}\left(q_{1}-p_{1}\right)-q_{2} \zeta_{1}+p_{2} \zeta_{2}}{\zeta_{2}-\zeta_{1}} \\
m_{1}=\frac{p_{1}+q_{1}}{2}, m_{2}=\frac{p_{2}+q_{2}}{2}
\end{gathered}
$$

e $\zeta_{1}$ e $\zeta_{2}$ são as inclinações das tangentes da elipse no ponto $\mathbf{p}$ e $\mathbf{q}$ respectivamente.

Retas do tipo da equação 2.18 podem ser construídas a partir de diferentes pares de pontos da elipse, e elas se intersectam num mesmo ponto (o centro da elipse) se os pontos pertencem à mesma elipse. Dessa forma, usando-se um arranjo acumulador, para cada reta calculada incrementa-se a frequência de cada um dos pontos pelos quais a reta passa. No final, a célula do arranjo que recebe maior votação (por ser, provavelmente, o ponto de intersecção das diversas retas) é candidato a centro de elipse.

Esse processo está descrito no algoritmo 2. Dada uma imagem binária $f$, calcula-se inicialmente, para todos os pontos $\mathbf{x}$ no foreground da imagem, a tangente no ponto $\mathbf{x}$ (linhas 2 a 5). Para isso, considera-se os pontos de foreground na vizinhança $16 \times 16$, centrada em $\mathbf{x}$, e usando o método de mínimos quadrados (que consiste em encontrar o melhor ajuste a esses pontos, minimizando a soma dos quadrados das diferenças entre o valor estimado e os pontos) encontra-se a reta tangente 
que passa pelo ponto x. O ponto e o ângulo da tangente são armazenados em listaHough. Em seguida, para cada par de pontos $\mathbf{p}$ e $\mathbf{q}$ armazenados, calcula-se o ponto de interseção $\mathbf{t}$ e o ponto médio $\mathbf{m}$ (conforme equações 2.19 a 2.21), e incrementa-se no histograma hist2D a frequência de cada ponto na reta que passa por $\mathbf{t}$ e $\mathbf{m}$ (linhas 6 a 11). Note que hist2D é uma estrutura similar à imagem, com a diferença de que cada ponto armazena o número de votos recebidos. Ao final, selecionam-se os máximos locais no histograma, considerando-se a vizinhaça definida pela janela $B$. Para cada ponto do histograma, avalia-se se o valor do ponto central sob a janela possui frequência duas vezes maior que a média de todos os demais pontos sob a janela no histograma. Os pontos selecionados são considerados os candidatos a centro de elipse.

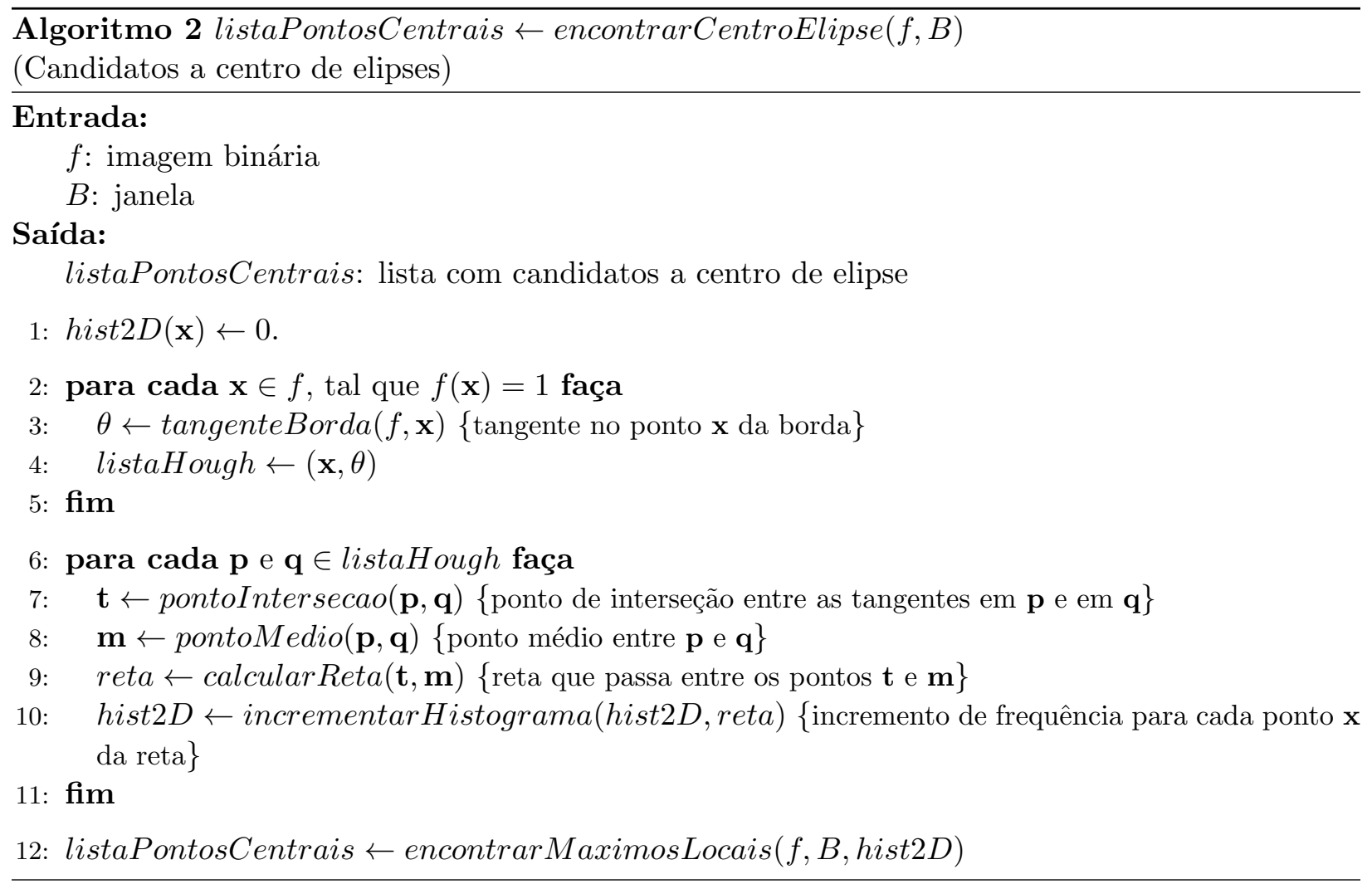

Uma vez tendo sido calculados os candidatos a centro de elipse, o conjunto de pontos da imagem que correspondem à elipse relativa a cada centro pode ser encontrado através de uma segunda varredura da imagem. Na implementação de R. A. McLaughlin, descrita aqui, a abordagem utilizada difere um pouco daquela descrita em [35]. Os três parâmetros são estimados simultaneamente, usando-se uma estratégia de acúmulo e busca inicialmente grosseira e progressivamente refinada. Mais especificamente, o espaço de busca dos parâmetros é dividido em intervalos de tamanho uniforme. Na implementação de R. A. McLaughlin são considerados 20 intervalos. Portanto, o histograma acumulador é uma matriz $20 \times 20 \times 20$, na qual uma célula está associada aos intervalos 
de valores correspondentes aos parâmetros $a, b$ e $\theta$ (eixos e orientação). Uma vez calculado o histograma, os intervalos da célula com maior frequência são particionados novamente em subintervalos, repetindo-se o mesmo processo, porém restrito a intervalos menores de valores para os parâmetros. Esse processo é iterativamente repetido até uma precisão aceitável.

Dada uma imagem binária $f$, um candidato $\mathbf{x}$ a centro de elipse, e os intervalos dos parâmetros $a, b$ e $\theta$, o procedimento para calcular o histograma referente aos três parâmetros é descrito no algoritmo 3 .

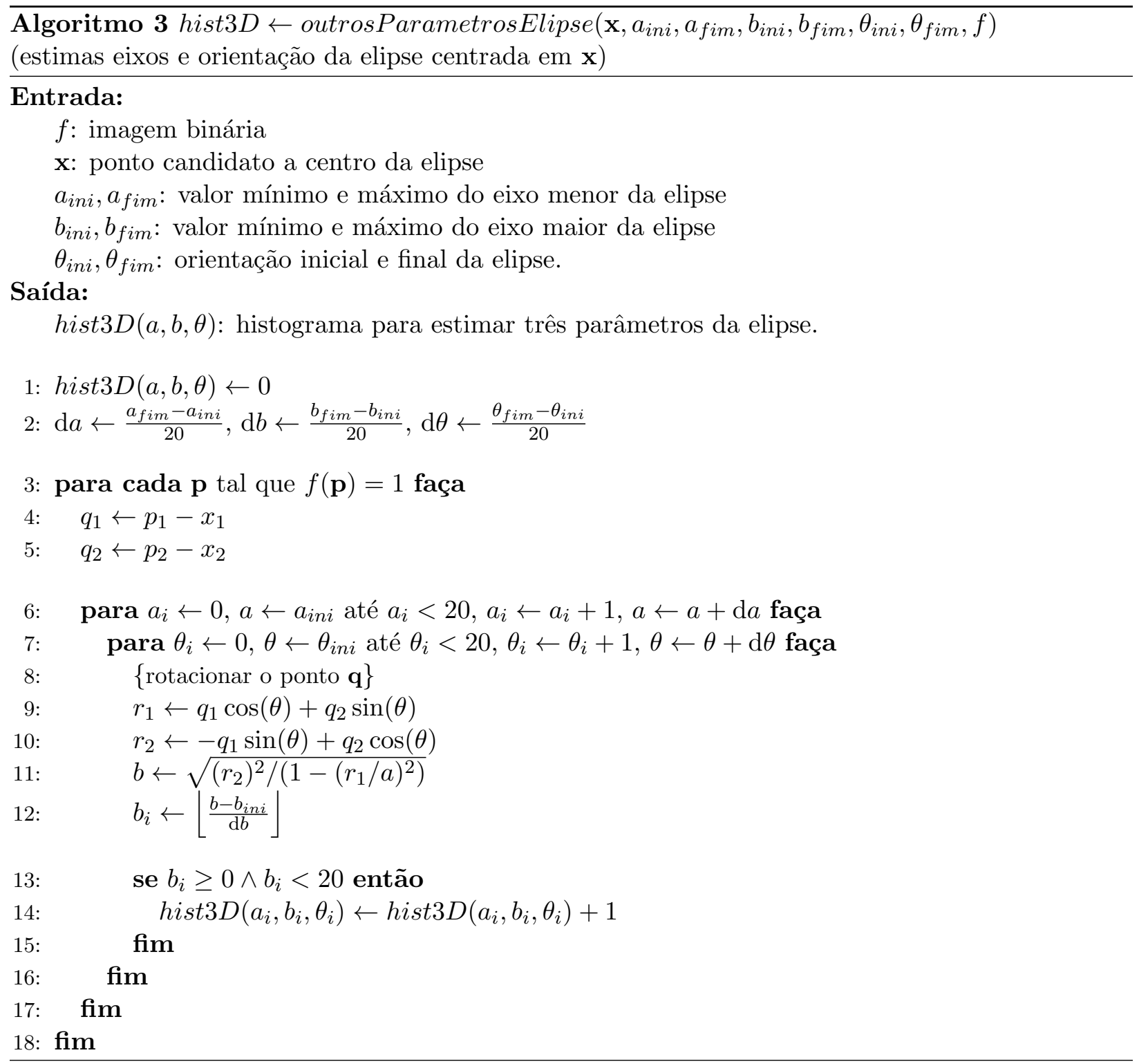

Para calcular o histograma, cada ponto $\mathbf{p}$ no foreground da imagem é transladado de forma que sua origem relativa coincida com o centro $\mathbf{x}$ da elipse. Para cada ponto, os parâmetros $a$ e $\theta$ são variados 20 vezes (um valor para cada intervalo). Para cada par $(a, \theta)$, calcula-se o valor do 
respectivo parâmetro $b$ e caso esse seja um valor válido, incrementa-se a célula correspondente a $(a, b, \theta)$ (linhas 7 a 18). O algoritmo devolve um histograma acumulador hist $3 D(a, b, \theta)$ de tamanho fixo $20 \times 20 \times 20$, com frequências associadas a diferentes valores dos parâmetros $a, b$ e $\theta$.

O procedimento completo para detecção de elipses em imagens binárias é composto pelos dois algoritmos acima (o algoritmo para detectar candidatos a centro de elipses, e o algoritmo para estimar os eixos e orientação referentes a esses centros) conforme descrito no algoritmo 4.

Algoritmo $4 h \leftarrow$ houghElipses $(f, B, t$ Max, tMin, proporcaoMinima $)$

(Hough para elipses [35])

\section{Entrada:}

$f$ : imagem binária

$B$ : janela

tMax: tamanho máximo de uma elipse, correspondente a duas vezes o tamanho do eixo maior tMin: tamanho mínimo de uma elipse, correspondente a duas vezes o tamanho do eixo menor proporcaoMinima: proporção mínima de pontos que configura detecção de uma elipse

\section{Saída:}

listaElipses: lista das elipses encontradas

\section{1: listaPontosCentrais $\leftarrow$ encontrarCentroElipse $(f, B)$}

2: para cada $\mathbf{x}=\left(x_{1}, x_{2}\right) \in$ listaPontosCentrais faça

3: $\quad a_{\text {ini }} \leftarrow 0, b_{\text {ini }} \leftarrow 0$

4: $\quad a_{\text {fim }} \leftarrow \frac{t \text { Max }}{2}, b_{\text {fim }} \leftarrow \frac{t \text { Max }}{2}$

5: $\quad \theta_{\text {ini }} \leftarrow 0, \theta_{\text {fim }} \leftarrow \pi$

6: $\quad$ para $i \leftarrow 0$ até $4, i \leftarrow i+1$ faça

7: $\quad$ hist $3 D \leftarrow$ outrosParametrosElipse $\left(\mathbf{x}, a_{\text {ini }}, a_{f i m}, b_{i n i}, b_{\text {fim }}, \theta_{i n i}, \theta_{\text {fim }}, f\right)$

8: $\quad\left(a_{i}, b_{i}, \theta_{i}\right) \leftarrow$ encontrarMaximo $($ hist $\left.3 D)\right)$

9: $\quad \Delta a \leftarrow \frac{a_{f i m}-a_{i n i}}{20}, \Delta b \leftarrow \frac{b_{f i m}-b_{i n i}}{20}, \Delta \theta \leftarrow \frac{\theta_{f i m}-\theta_{i n i}}{20}$

10: $\quad a_{\max } \leftarrow a_{i n i}+\Delta a a_{i}, b_{\max } \leftarrow b_{i n i}+\Delta b b_{i}, \theta_{\max }^{20} \leftarrow \theta_{i n i}+\Delta \theta \theta_{i}$

11: $\quad a_{\text {ini }} \leftarrow a_{\max }-\Delta a, a_{\text {fim }} \leftarrow a_{\max }+\Delta a$

12: $\quad b_{\text {ini }} \leftarrow b_{\max }-\Delta b, b_{\text {fim }} \leftarrow b_{\max }+\Delta b$

13: $\quad \theta_{\text {ini }} \leftarrow \theta_{\max }-\Delta \theta, \theta_{\text {fim }} \leftarrow \theta_{\max }+\Delta \theta$

14: fim

15: $\quad$ proporcaoElipse $\leftarrow$ proporcao $\left(f, x_{1}, x_{2}, a_{\max }, b_{\max }, \theta_{\max }\right)$

16: se (proporcaoElipse > proporcaoMinima) então

17: $\quad$ listaElipses $\leftarrow\left(x_{1}, x_{2}, a_{\max }, b_{\max }, \theta_{\max }\right)$

\section{8: fim}

19: fim

O algoritmo 4 recebe como parâmetros uma imagem binária $f$, uma janela $B$, tamanhos máximo tMax e mínimo tMin dos eixos da elipse, e a proporção mínima de pontos necessária para que seja 
configurada a detecção de uma elipse.

Inicialmente, calcula-se a lista de candidatos a centro de elipse usando o algoritmo 2 descrito acima (linha 1). Em seguida, para cada ponto $\mathbf{x}$ na lista de candidatos a centro de elipse, inicializase os valores mínimo e máximo dos três parâmetros - eixo maior, eixo menor e orientação (linhas 3 a 5). Em seguida, o procedimento para estimar os parâmetros para o candidato a centro considerado (algoritmo 3) é repetido cinco vezes. A cada iteração é encontrada a célula com maior frequência e os valores mínimo e máximo dos três parâmetros são reinicilizados com os extremos do intervalo correspondente à célula. Uma vez estimados os parâmetros, realiza-se uma nova varredura na imagem para calcular a proporção de pontos da elipse presentes na imagem (linha 15). Se essa proporção for maior que o valor especificado no parâmetro proporcaoMinima, armazena-se os cinco parâmetros numa lista de elipses, a qual é devolvida ao final.

O algoritmo 4 detecta todas as elipses que satisfazem os tamanho especificados nos parâmetros de entrada. No entanto, objetos excessivamente alongados ou com largura muito pequena não correspondem a ovos de S. mansoni. Portanto, para efeitos de aplicação neste trabalho, modificouse o algoritmo 4 das linhas 16 a 18, conforme trecho descrito no algoritmo 5. Essa modificação garante que apenas elipses cujo comprimento do eixo menor seja maior que um dado valor e que a proporção entre os eixos seja também maior a um certo valor são detectadas. Foi observado experimentalmente que quando a proporção entre os eixos é maior que 1.5, os parâmetros não definem elipses que são condizentes com a forma dos ovos.

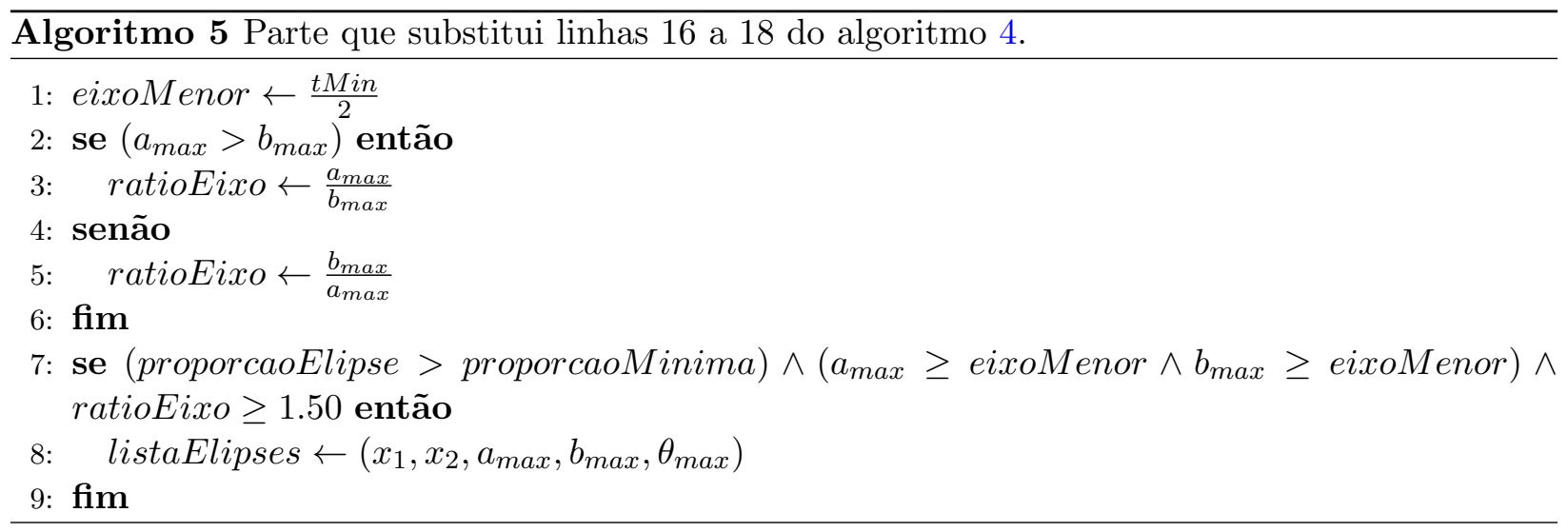




\section{Capítulo 3}

\section{Detecção de contornos de ovos de S. Mansoni}

A aplicação direta de técnicas tradicionais para detecção de bordas ou linhas, que se baseiam em diferenças de intensidades entre pixels adjacentes, não apresentam resultados satisfatórios para as imagens consideradas neste trabalho. As técnicas tradicionais, como o uso de máscaras para detectar linhas em diferentes orientações ou o método de Sobel, tendem a gerar um mapa de contornos altamente ruidoso [30,34] conforme pode ser visto na figura 3.1.

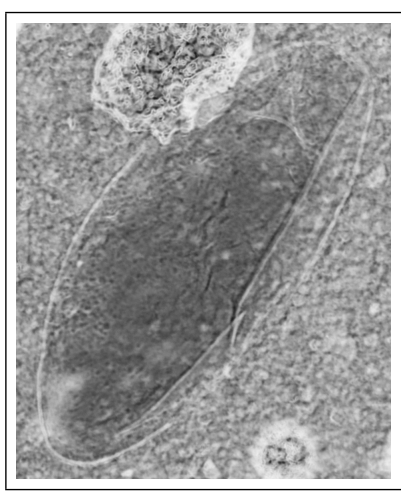

(a)

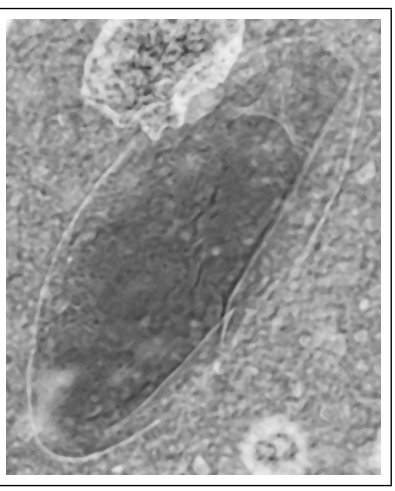

(b)

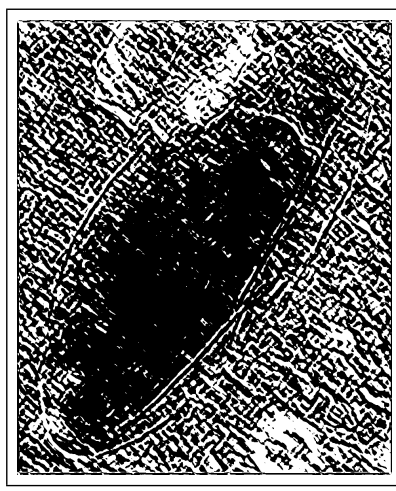

(c)

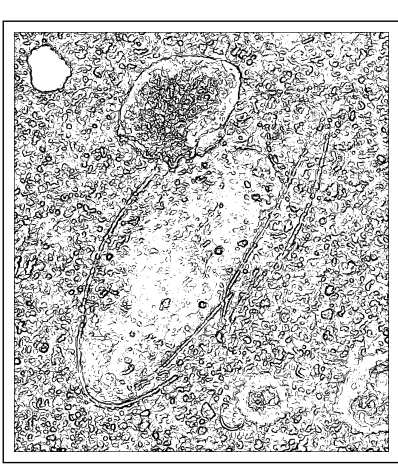

(d)

Figura 3.1: (a) Imagem de uma região com ovo de S. mansoni, com ampliação 40x. (b) Suavizada usando o filtro da mediana. (c) Detecção de linhas com máscaras (imagem negada). (d) Detecção de contornos pelo método Sobel (imagem negada).

A figura 3.1(b) mostra o resultado após a aplicação do filtro da mediana com uma janela de $11 \times 11$ pixels sobre a imagem da figura 3.1(a). As imagens foram invertidas pois as máscaras usadas são próprias para detectar linhas que formam elevações e não vales. O filtro da mediana foi aplicado com o objetivo de suavizar a imagem, diminuindo o ruído mas ao mesmo tempo preservando as linhas alvo. O tamanho da janela escolhido corresponde à espessura máxima de uma linha alvo e na prática suavizou a imagem e manteve as linhas alvo. A figura 3.1(c) mostra a imagem máxima das convoluções usando as quatro máscaras da figura 2.2 sobre a imagem mostrada em 3.1(b). A figura 3.1(d) mostra o resultado do método Sobel usando as máscaras correspondentes da figura 2.3 
sobre a imagem mostrada em 3.1(b).

Devido aos resultados ruins com detectores usuais, neste trabalho optou-se por explorar uma abordagem morfológica para tratar o problema de detecção de linhas, pois os operadores morfológicos podem ser usados tanto para realçar algumas estruturas, como para suprimir outras.

$\mathrm{Na}$ literatura encontramos alguns trabalhos que também utilizam a abordagem morfológica para problemas similares. Ge Xing-wei et al. [13] propõem uma abordagem morfológica para detectar bordas em imagens gerais com fundo complexo, usando múltiplos elementos estruturantes, filtrando assim o ruído de diferentes tipos e magnitudes e ao mesmo tempo mantendo a maioria dos detalhes da imagem. Song, X. et al. [30] propõem um detector de bordas robusto baseado num filtro alternado sequencial e obtém bons resultados mesmo em imagens ruidosas. Lee, J. et al. [21] apresenta um detector de bordas morfológico simples baseado em resíduos da erosão e da dilatação, e uma combinação deles permite obter resultados bons para imagens com ruído.

Cheng-Hsiung et al. [17] propõem um filtro de ordem adaptativo para supressão de ruído em imagens, usando uma janela que pode-se expandir se o pixel central é ruidoso. Zhong, L. et al. [38] propõem uma variação do filtro da mediana para atenuar o ruído impulsivo e manter os detalhes da imagem. Esses trabalhos usam o filtro de ordem, por sua característica principal de preservar contornos e ao mesmo tempo suavizar a imagem, sendo essa uma diferença importante em relação a outros filtros.

Dentre os trabalhos que utilizam a abordagem morfológica para detecção de estruturas do tipo linha, citamos o trabalho de Zana et al. [36], que propõem um tratamento morfológico para reconhecimento de partes de formas lineares em imagens de vasos retinais, e de Zhang et al. [37], que propõem um método para a detecção da rede rodoviária em imagens obtidas por satélite.

Os trabalhos citados acima tratam de problemas e tipo de imagens muito específicas e portanto as abordagens propostas neles não são diretamente aplicáveis às nossas imagens. No entanto, algumas ideias usadas para detectar linhas alvo nos problemas específicos citados acima influenciaram a elaboração de nosso método.

\subsection{Visão geral da abordagem proposta}

O método que propomos é estruturado em duas fases. A primeira fase consiste de três etapas que visam detectar linhas nas imagens, e a segunda fase visa detectar linhas dispostas em forma elíptica, conforme explicado a seguir:

1. Detecção de linhas, usando operadores da morfologia matemática.

(a) Realce de linhas: uma vez que as imagens são bastante ruidosas, nesta etapa pretende-se 
realçar as linhas ao mesmo tempo em que pretende-se atenuar os ruídos.

(b) Detecção de linhas: nesta etapa pretende-se detectar as linhas propriamente ditas nas imagens resultantes da etapa de realce.

(c) Refinamento do resultado: nesta etapa pretende-se filtrar a imagem resultante na etapa anterior, eliminando-se, por exemplo, componentes muito pequenos.

2. Detecção de elipses, de tamanho condizente com o tamanho esperado dos ovos, sobre o mapa de linhas gerado na fase (1).

Observe que as etapas da primeira fase são relativamente independentes. A etapa de realce de linhas, assim como a de refinamento do resultado, podem ser eventualmente omitidos do processo. Optou-se por assim organizar o processamento para facilitar a exposição da abordagem proposta no trabalho.

A seguir são descritas as técnicas utilizadas em cada uma das etapas da primeira fase e, em seguida, a segunda fase da abordagem proposta. Para facilitar o entendimento, cada um dos passos é ilustrado através dos resultados obtidos para uma imagem de referência, a imagem da figura 2.1.

\subsection{Detecção de estruturas do tipo linha}

\subsubsection{Realce das linhas}

Nesta etapa, aplicam-se três métodos que visam realçar as linhas.

\section{Suavização da imagem}

As linhas que aparecem no contorno dos ovos são formados por pixels de intensidade em geral baixa. No entanto, em meio aos pixels de intensidade baixa observam-se alguns pixels de intensidade maior, que resultam em descontinuidades nas linhas. Para atenuar essas regiões de descontinuidade, propõe-se o operador de suavização descrito a seguir.

Seja $B$ uma janela retangular, dividida em três regiões de mesmo tamanho, $B_{1}, B_{2}$ e $B_{3}$ (ver figura 3.2).

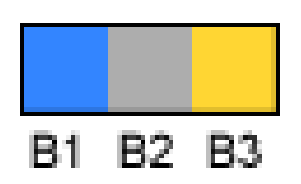

Figura 3.2: Janela retangular com três regiões (esquerda, central e direita). 
Sejam $m_{1}, m_{2}$ e $m_{3}$ as médias das intensidades dos pixels sob as regiões $B_{1}, B_{2}$ e $B_{3}$, respectivamente. A ideia desse operador é reforçar linhas com a mesma orientação da janela $B$. As médias nas três regiões são comparadas e quando a região central possui intensidade relativamente maior que as regiões laterais, a intensidade dos pixels na região central é diminuída.

Dada uma imagen $f$, o operador de suavização é definido, para todos os pixels sob a região $B_{2}$, por:

$$
\left[S_{(B, s)}(f)\right](\mathbf{x})= \begin{cases}\min \left\{m_{1}, m_{2}, m_{3}\right\}, & \text { se }\left|m_{1}-m_{3}\right|<s,\left|m_{1}-m_{2}\right| \geq s \text { e }\left|m_{3}-m_{2}\right| \geq s \\ f(\mathbf{x}), & \text { caso contrário. }\end{cases}
$$

na qual $s$ define a diferença entre as médias das regiões, usada para decidir se o operador será aplicado ou não.

A janela retangular $B$ deve ter uma espessura aproximada ao das linhas alvo e um comprimento maior que às descontinuidades. A figura 3.3 mostra uma região de uma imagem com ampliação 40x na qual está sobreposta uma janela de espessura 8 e comprimento 60 pixels com orientação $\theta=68$.

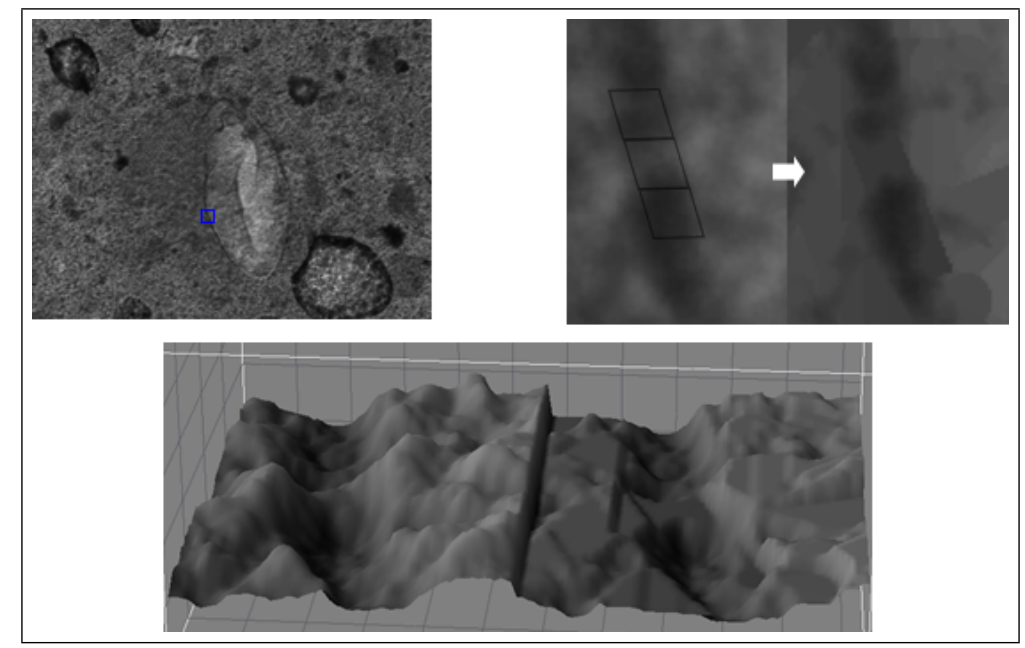

Figura 3.3: Exemplo de análise de uma região específica usando a janela da figura 3.2.

Para atenuar linhas em diferentes orientações, o operador de suavização $S$ é aplicado usandose a janela $B$ com diferentes orientações $\theta$. Após o cálculo considerando diferentes orientações $\theta$, toma-se o mínimo de todos os resultados e da imagem original, preservando assim as regiões escuras na qual encontram-se as linhas alvo.

Formalmente, dada uma imagem de entrada (em tons de cinza) $f$, a suavização é calculada por:

$$
T_{0}=\bigwedge_{\theta}\left\{S_{\left(B_{\theta}, s\right)}(f)\right\} \bigwedge f
$$


na qual $B_{\theta}$ é um elemento estruturante retangular $B$, do tipo mostrado na figura 3.2, com orientação $\theta$.

A figura 3.4 mostra o resultado desta operação na imagem de referência (figura 2.1), usando $B$ igual ao retângulo $8 \times 60$ e $s$ igual a 80 . Observa-se que o fundo é suavizado enquanto as linhas são preservadas.

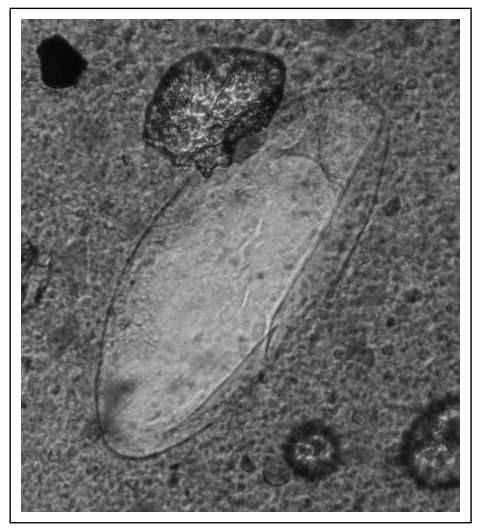

(a)

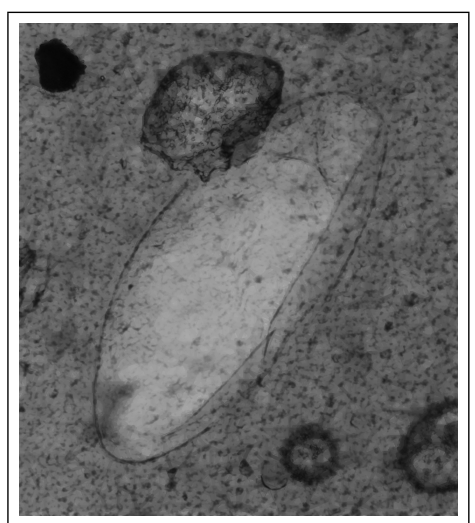

(b)

Figura 3.4: (a) Imagem original. (b) Resultado da aplicação do método de suavização.

\section{Filtro de ordem}

Para reforçar estruturas lineares com intensidade baixa e pouca espessura, aplica-se um filtro de ordem (veja defição em 2.17) com ordem $k$ pequeno. $\mathrm{O}$ valor da ordem $k$ deve ser pequeno, pois as linhas alvo apresentam pixels de intensidade baixa. A largura do elemento estruturante $B$ deve ser menor que a espessura de uma linha alvo. Dessa forma, dada a imagem $T_{0}$, o filtro de ordem é calculado por:

$$
\operatorname{RankFilter}\left(T_{0}, B, k, \theta\right)=\left[R_{B_{\theta}, k}\left(T_{0}\right)\right](\mathbf{x}),
$$

onde $B_{\theta}$ é o elemento estruturante $B$ com orientação $\theta$.

O filtro deve ser aplicado para diferentes orientações $\theta$. Após o cálculo do filtro de ordem para várias orientações $\theta$, toma-se o mínimo entre todos os resultados e a imagem original, obtendo-se uma imagem que preserva as regiões escuras. Formalmente:

$$
T_{1}=\bigwedge_{\theta}\left\{\operatorname{RankFilter}\left(T_{0}, B, k, \theta\right)\right\} \bigwedge T_{0}
$$

Para nossas imagens com ampliação 40x, os parâmetros foram estimados experimentalmente. O valor da ordem foi fixado em $k \leftarrow 1$, pois as linhas alvo apresentam pixels de intensidade baixa. Note-se neste caso, que o filtro de ordem é um processo de erosão. As orientações consideradas 
foram $\theta \leftarrow 0,23,45,68,90,113,135,158$; não se consideraram outras orientações basicamente devido à complexidade computacional. A janela considerada foi do tipo linha e tamanho $B \leftarrow 1 \times 6$; ela permitiu uma ligeira melhora nas partes lineares da imagem com orientação $\theta$. Observou-se que se o tamanho da janela é maior, outras estruturas que não são de interesse são realçadas, gerando ruído.

A figura 3.5 mostra o resultado desta operação na imagem $T_{0}$.

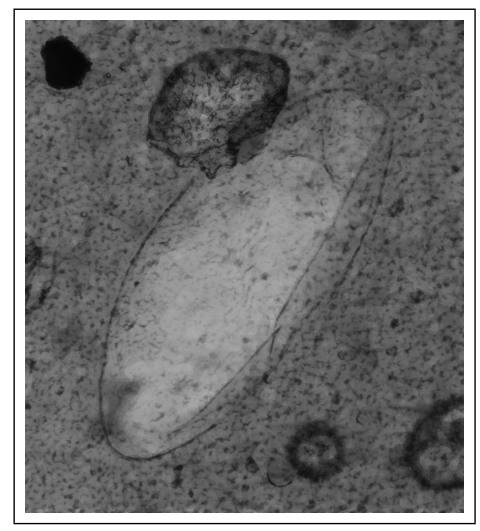

(a)

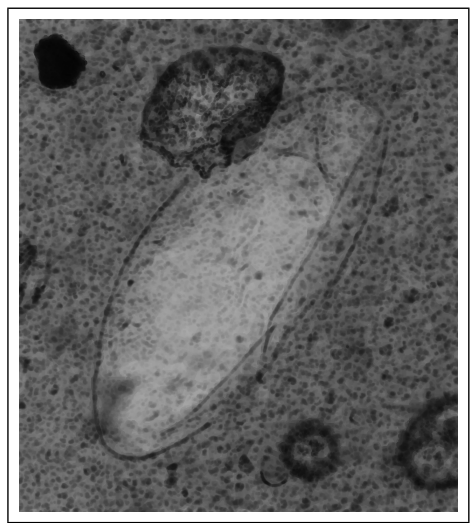

(b)

Figura 3.5: (a) Imagem suavizada. (b) Resultado da aplicação do filtro de ordem.

Para efeitos de comparação visual, na figura 3.6 observa-se um exemplo da aplicação do método de suavizado e do filtro de ordem numa região específica no contorno de um ovo. Observa-se como o método de suavizado atenua o ruído, sem perder as regiões escuras onde encontra-se as linhas alvo. Observa-se também como o filtro de ordem ajuda a reforçar as regiões escuras, as quais são fortemente exploradas no método.

\section{Fechamento Top-Hat}

Em seguida, utilizamos o operador fechamento Top-Hat para realçar pixels com intensidade baixa. Este operador realça vales com espessura menor que um certo tamanho e que são justamente aqueles preenchidos pelo fechamento. Nesta fase é importante escolher um tamanho adequado para o elemento estruturante $B$. Se $B$ for pequeno, os vales maiores que $B$, que podem corresponder a partes das linhas alvo, não serão realçados. Por outro lado, se $B$ for grande, serão realçados todos os vales menores que $B$, incluindo os vales correspondentes a ruídos. O tamanho do elemento estruturante $B$ deve ser proporcional à espessura das linhas alvo. A forma do elemento estruturante depende das características da linha que desejamos detectar.

Para as imagens consideradas e processadas com o filtro de ordem, a espessura das linhas alvo é aproximadamente de 4 a 14 pixels. Desta forma, usando um elemento estruturante de largura 


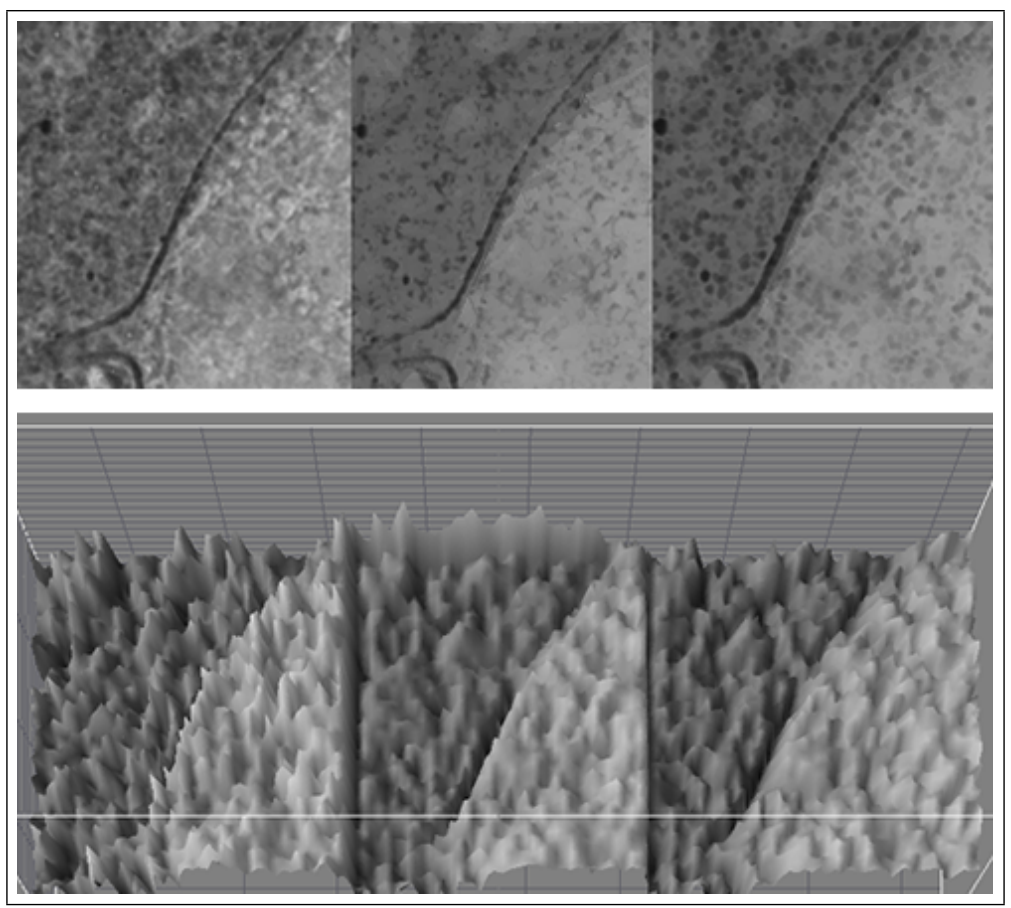

Figura 3.6: As três imagens na parte superior correspondem respectivamente à imagem original, o resultado do método de suavizado e o resultado do rank filter. As três imagens na parte inferior correspondem às respectivas superfícies.

aproximadamente 14 é possível recuperar os vales menores, onde se encontram as linhas alvo. A forma do elemento estruturante usado é um disco de raio 7 pixels (diâmetro 14), pois na prática em comparação a um elemento estruturante linha, cruz e caixa, o disco recuperou menos ruído.

Dada a imagem $T_{1}$, o operador fechamento Top-Hat é calculado por:

$$
T_{2}=T_{1} \hat{\bullet} B
$$

na qual $B$ é o elemento estruturante.

A figura 3.7 mostra o resultado deste operador na imagem de referência.

\subsubsection{Detecção de linhas}

Após o realce da etapa anterior, uma primeira abordagem seria aplicar uma limiarização. Porém, o valor de limiar adequado dependerá da qualidade de realce obtida. Além disso, poderá fragmentar demasiadamente as linhas. Desta forma, para a detecção de linhas explora-se informações direcionais. 


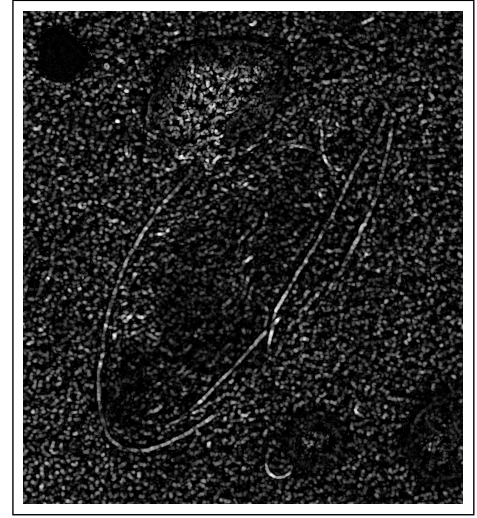

(a)

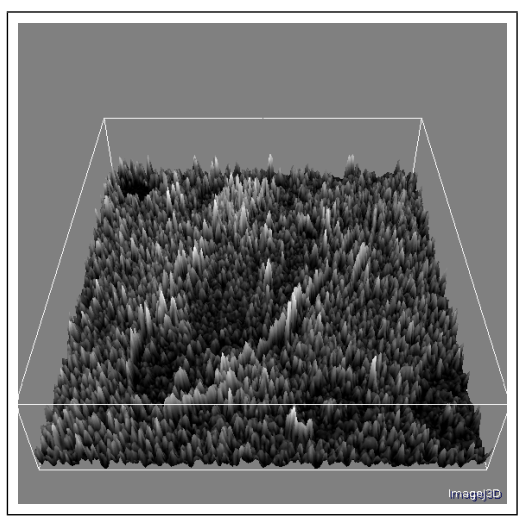

(b)

Figura 3.7: (a) Resultado do fechamento Top-Hat com disco de raio 7. (b) Imagem da superfície.

\section{Erosão por linhas}

A erosão por elementos estruturantes do tipo linha visa refinar a busca por segmentos de linhas. Após o realce de candidatos a linhas feito na etapa anterior, aplicamos erosões com elementos estruturantes tipo linha de diferentes orientações $B_{\theta}$. O resultado de cada erosão criará uma imagem formada com estruturas tipo linha com a mesma orientação de $B$, e apenas com linhas com comprimento maiores que o de $B$. Linhas com comprimento menor que $B$, assim como ruídos, tendem a desaparecer. Assim, o tamanho de $B$ deve ser proporcional ao menor tamanho dos segmentos de linha alvo fragmentadas na imagem.

Baseado em testes, em nossas imagens com ampliação 40x, o tamanho foi fixado em 72 pixels, pois várias imagens apresentam bordas fragmentadas em linhas de um tamanho aproximado a esse. As diferentes orientações utilizadas são importantes, pois com um número pequeno de orientações várias linhas alvo poderão ser perdidas, enquanto que com muitas orientações, o custo computacional aumenta. Baseado em testes, foram estabelecidos os seguintes valores para $\theta: 0,5,11,16,22$, $27,33,38,45,50,56,61,66,71,77,82,90$ 95, 101, 106, 112, 117, 123, 128, 135, 140, 146, 151, 157, 162,168 e 173.

Formalmente, temos portanto que

$$
T_{3, \theta}=T_{2} \ominus B_{\theta},
$$

para os valores de $\theta$ acima.

Ao invés de uma simples erosão, poderia-se utilizar uma abertura, que permitiria a recuperação mais fiel de estruturas do tipo linha. Porém, experimentalmente verificou-se que a abertura tende a prejudicar o passo de composição dos resultados descritos a seguir. 


\section{Composição dos resultados}

Após o cálculo das erosões, calcula-se o máximo entre todos os resultados obtidos no processo de erosão, obtendo-se assim uma imagem em tons de cinza contendo estruturas tipo linha de diferentes orientações. As figuras 3.8(a) e 3.8(b) mostram o resultado do máximo e a respectiva superfície. Formalmente,

$$
T_{4}=\bigvee_{\theta}\left\{T_{3, \theta}\right\}
$$

Finalmente, aplica-se uma limiarização, com limiar $l$ de valor pequeno para recuperar as estruturas obtidas em $T_{4}$. Experimentalmente o limiar com valor $l \leftarrow 1$ gerou os melhores resultados. A imagem resultante é binária, contendo as linhas (ver figura 3.8(c)). Formalmente,

$$
T_{5}=\operatorname{Lim}\left(T_{4}, l\right)
$$

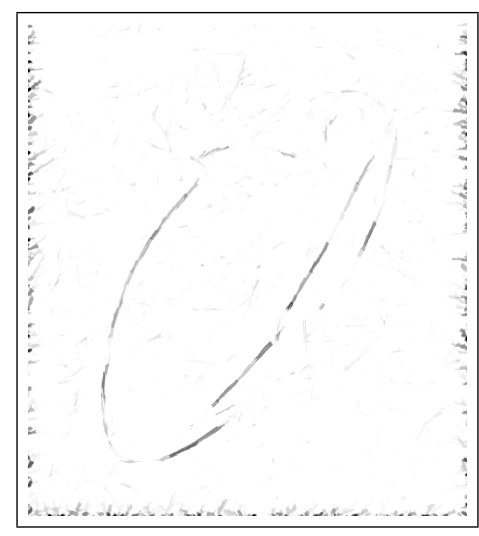

(a)

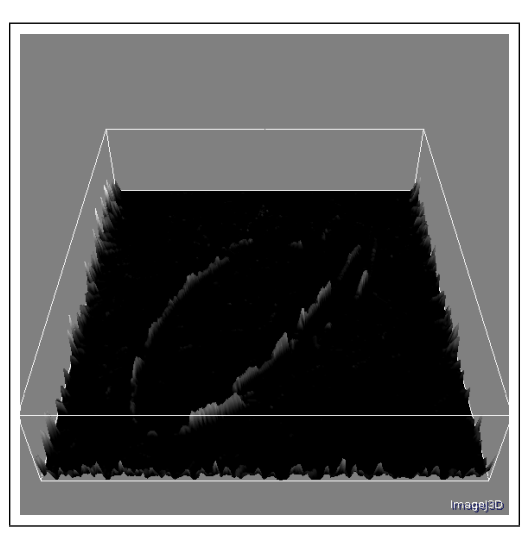

(b)

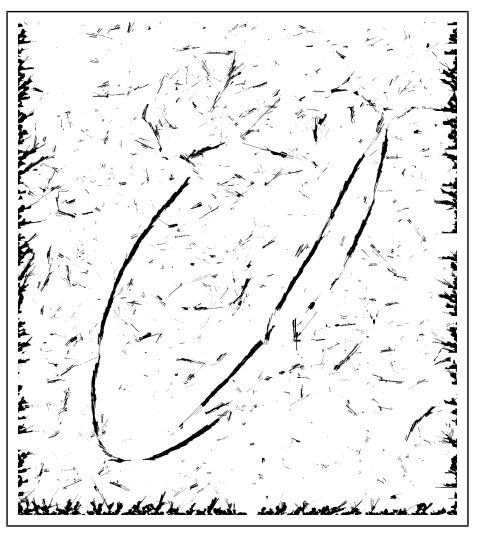

(c)

Figura 3.8: (a) Imagem negada da erosão por linhas de tamanho 72 pixels em diferentes orientações. (b) Imagem da superficie. (c) Resultado da limiarização.

\subsubsection{Refinamento do resultado}

A imagem binária resultante na etapa de detecção de linhas apresenta componentes do tipo segmentos de curva, mas apresenta também componentes que são ruídos.

Para filtrar parte dos ruídos, utilizamos o operador abertura por área, uma vez que os ruídos são componentes menores que os segmentos das curvas. A maior parte do ruído na imagem correspondem a componentes com área aproximada 600 pixels, area $\leftarrow 600$. Portanto, calculamos a abertura de area (veja 2.11), isto é:

$$
T_{6}=T_{5} \circ(\text { area })_{B},
$$


na qual $B$ é um elemento estruturante tipo cruz de raio 1 (que define a conectividade 4).

A imagem resultante é mostrada na figura 3.9(b).

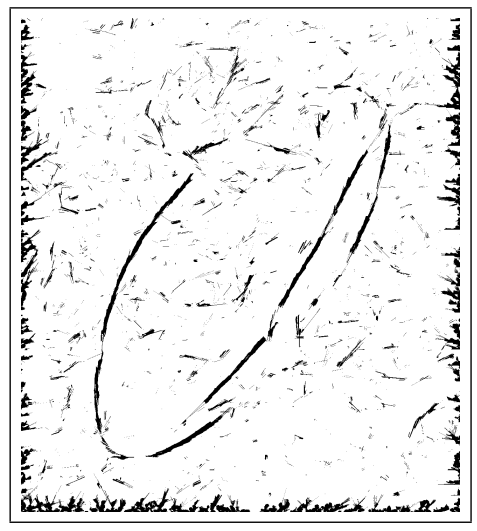

(a)

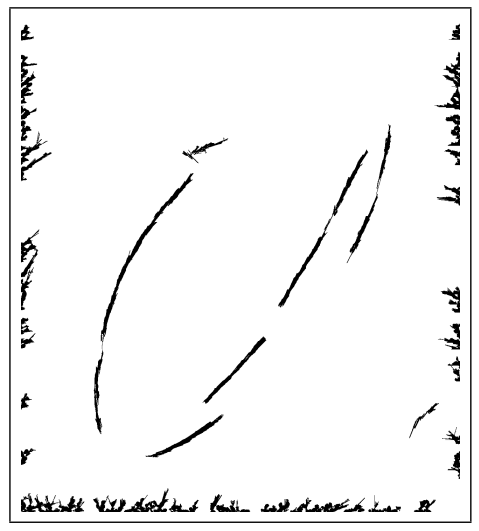

(b)

Figura 3.9: (a) Imagem binária. (b) Resultado da abertura com área de 600 pixels.

Um outro tipo de ruído, devido ao efeito de borda de imagem, concentra-se nas bordas da imagem e em geral possui área grande. Esse tipo de ruído na imagem referência pode ser visto na figura 3.10(a). No processo de erosão da imagem em níveis de cinza, os ruídos que tocam a borda da imagem não são eliminados. Portanto, após a limiarização eles permanecem e como são em grande quantidade tendem a formar componentes grandes que não são eliminados pela abertura por área. Aplicamos o operador para remover componentes que tocam a borda da imagem (veja 2.13), isto é:

$$
T_{7}=\Gamma_{B}\left(T_{6}\right),
$$

na qual $B$ é um elemento estruturante tipo cruz de raio 1.

O resultado após a remoção de tais componentes é mostrado na figura 3.10(c). Pode-se observar que grande parte das linhas do contorno do ovo são extraídas, enquanto os ruídos são eliminados.

\subsection{Detecção de elipses a partir do mapa de linhas}

O algoritmo baseado na transformada Hough é utilizado para detectar elipses sobre os segmentos de linhas detectados na fase anterior. A seguir descrevemos os quatro parâmetros da transformada:

1. janela $B$, que é utilizada para calcular os máximos locais no histograma que acumula os votos para candidatos a centro de elipses. Em nosso método, o tamanho da janela $B$ deve ser proporcional à quão distante um máximo local deve estar em relação a outros máximos locais. 


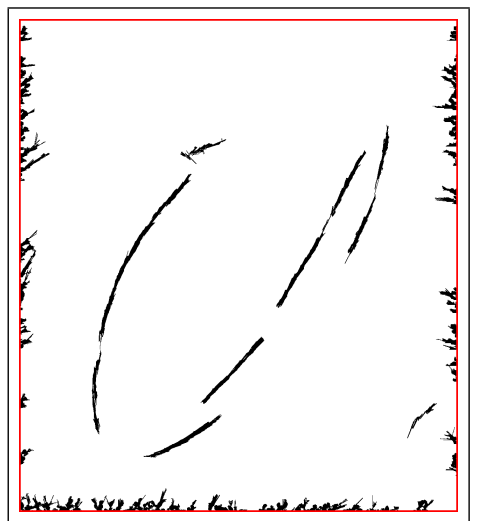

(a)

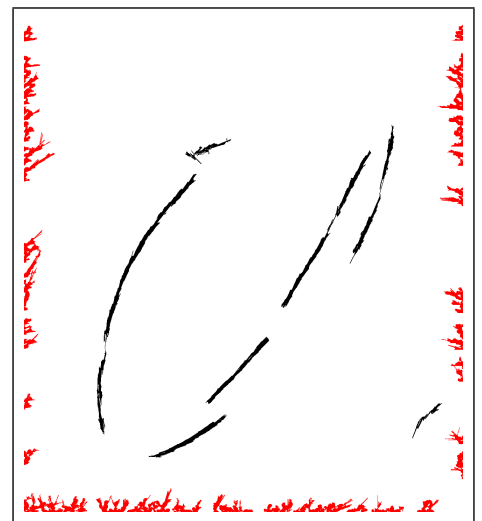

(b)

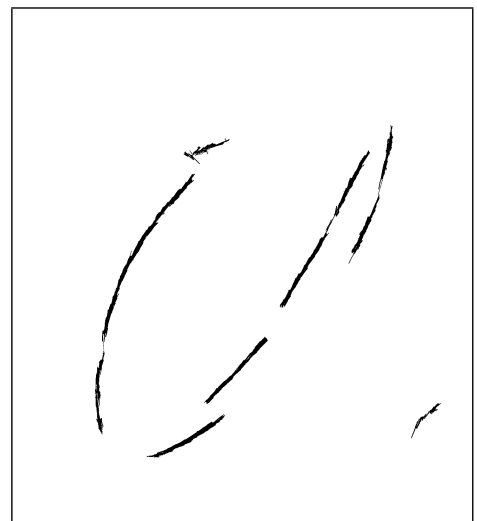

(c)

Figura 3.10: Resultado após remoção de componentes que tocam as bordas.

No caso de janelas pequenas, vários máximos locais, uns próximos aos outros podem ser selecionados. O custo de computação para estimar os demais parâmetros da elipse (a saber, eixo maior, eixo menor e orientação) é diretamente afetado pelo número de candidatos a centro de elipse.

No caso de janelas grandes, maiores que a máxima distância entre dois centros de elipses, um ponto que corresponde a centro de elipse poderá não ser corretamente detectado por não satisfazer o critério de maximidade local.

2. tamanho máximo de uma elipse tamanhoMaximoElipse, que representa a maior distância entre dois pontos do contorno dos ovos. No caso de considerar um tamanho maior, tem-se a desvantagem de detectar falsas elipses de tamanho maior ao tamanho dos ovos. No caso de considerar um tamanho menor, tem-se a desvantagem de não detectar elipses que passam sobre o contorno dos ovos.

3. o tamanho mínimo de uma elipse tamanhoMinimoElipse, que representa a menor distância entre dois pontos do contorno dos ovos. Usa-se para não considerar elipses muito pequenas em relação ao tamanho dos ovos.

4. a proporção mínima de uma elipse proporcaoMinima, que representa a porcentagem do perímetro de uma elipse com presença de pixels. É utilizada para decidir se um grupo de segmentos de linha em disposição elíptica representa ou não uma elipse.

Devido ao grande tamanho das imagens e a complexidade computacional do algoritmo da transformada Hough, decidiu-se re-dimensionar as imagens a um terço do seu tamanho original. Baseado em testes, a janela de tamanho $B \leftarrow 80 \times 80$ pixels, permitiu obter os melhores resultados. O tama- 
nho máximo de uma elipse tamanhoMaximoElipse foi fixado em 500 pixels, pois estudaram-se as imagens do conjunto e a distância máxima entre dois pontos do contorno dos ovos é menor que 500 pixels. O tamanho mínimo de uma elipse tamanhoMinimoElipse foi fixado em 110 pixels, pois estudaram-se as imagens do conjunto e a distância mínima entre dois pontos do contorno dos ovos é maior que 110 pixels. A proporção mínima de uma elipse proporcaoMinima foi fixada em 0.25 ou $25 \%$, pois observa-se que nas imagens obtidas da fase 1 , poucos segmentos foram recuperados do contorno dos ovos, e baseado em testes observou-se que esse valor é adequado para as imagens consideradas.

Assim, tendo em consideração as características específicas de nossas imagens com ampliação 40x, decidiu-se calcular a transformada Hough usando o algoritmo 4 com os seguintes parâmetros: $B \leftarrow 80 \times 80$, tamanhoMaximoElipse $\leftarrow$ 500, tamanhoMinimoElipse $\leftarrow 110 \mathrm{e}$ proporcaoMinima $\leftarrow 0.25$, isto é:

$$
\begin{array}{r}
T_{8} \leftarrow \quad \text { houghElipses }\left(T_{7}, B, \text { tamanhoMaximoElipse },\right. \\
\text { tamanhoMinimoElipse,proporcaoMinima })
\end{array}
$$

O resultado após a transformada Hough e detecção de elipses é mostrado na figura 3.11(a). Pode-se observar que duas elipses foram detectadas, sendo que uma delas encontra-se sobreposta ao contorno do ovo.

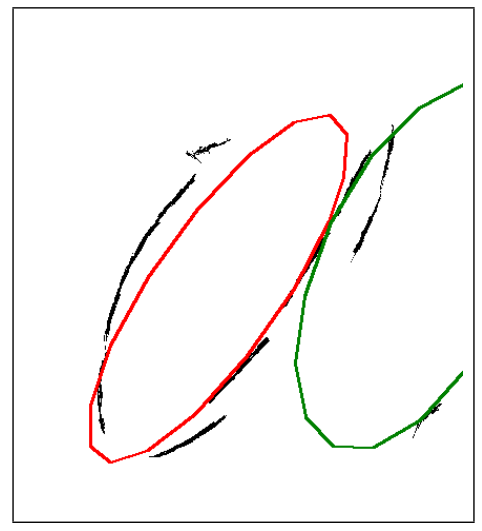

(a)

Figura 3.11: Imagem de saída da detecção de elipses usando a Transformada Hough. 


\section{Capítulo 4}

\section{Resultados}

Neste capítulo apresentamos inicialmente uma descrição das imagens adquiridas em laboratório, utilizadas na parte experimental deste trabalho. Em seguida apresentamos uma avaliação dos resultados considerando duas métricas de análise de desempenho. Apresentamos também exemplos de resultados de cada etapa das fases (1) e (2) da abordagem descrita no capítulo anterior.

Para aplicar a metodologia proposta, foi elaborado um script em linguagem Python com ligação à linguagem C. Nesse script usou-se funções da biblioteca SDC Morphology Toolbox para Python [25] que disponibiliza operadores de Morfologia Matemática. Também utilizou-se parte do programa desenvolvido em C por R.A. McLaughlin, baseado na técnica descrita em [35], para detectar elipses usando a transformada Hough.

Além disso, foi utilizado o software ImageJ [18] para gerar imagens da superfície e melhor analisar as formas presentes nas imagens processadas em cada fase da metodologia proposta.

Para gerar alguns resultados adicionais de detecção de bordas como o Método Sobel, Laplaciano e Gradiente Morfológico, usou-se a plataforma colaborativa Adessowiki [1] voltada para programação científica em processamento de imagens em Python.

Parte desses resultados foi apresentado no V Simpósio de Iniciação Científica e Pós-Graduação do IME-USP, em novembro de 2010 [8]. Os resultados completos foram apresentados no Workshop de Visão Computacional, em maio de 2012 [9]

\subsection{Conjunto de dados}

As imagens foram adquiridas no Laboratório de Parasitologia na Faculdade de Ciências Médicas da Santa Casa de São Paulo, usando um microscópio óptico (Nikon Eclipse 50i) acoplado a uma câmera CCD de 5,0 megapixels. Foram consideradas um total de 16 lâminas com presença de

ovos de S. mansoni. Cada lâmina resulta em aproximadamente 1600 regiões de imagens, quando considerada a ampliação 40x.

Entre as 16 lâminas, foram capturadas 81 imagens que correspondem a regiões na lâmina com e 
sem ovos, e foram capturadas em três ampliações distintas (10x, 20x e 40x), e gravadas em formato TIFF de 24 bits, com uma resolução de $2560 \times 1920$ pixels (total de 4,9 megapixels). Em cada captura das imagens, foi ajustado manualmente o foco do microscópio para melhorar a nitidez dos ovos.

As imagens foram adquiridas em diferentes ampliações, visando-se possibilidade de investigações em diferentes resoluções. Por exemplo, quando os ovos aparecem como objetos ovalados de cor clara em fundo escuro, uma filtragem seguida de limiarização na imagem de resolução baixa pode ser suficiente. Porém, para a detecção de outras características como o contorno dos ovos, pode ser necessária uma resolução maior. As regiões capturadas sem ovos incluem, em geral, estruturas lineares e objetos ovalados que poderiam ser confundidos com ovos. A tabela a seguir descreve a categoria das imagens que foram capturadas com ampliações 10x, 20x e 40x.

\begin{tabular}{|l|c|c|c|}
\hline \multirow{2}{*}{ Descrição } & \multicolumn{3}{|c|}{ Ampliações } \\
\cline { 2 - 4 } & $10 \mathrm{x}$ & $20 \mathrm{x}$ & $40 \mathrm{x}$ \\
\hline Imagens que contém ovos & 54 & 54 & 54 \\
\hline Imagens que não contém ovos & 27 & 27 & 27 \\
\hline Total de imagens & $\mathbf{8 1}$ & $\mathbf{8 1}$ & $\mathbf{8 1}$ \\
\hline
\end{tabular}

Neste trabalho foram usadas imagens com ampliação maior (40x), porque em ampliações menores alguns detalhes, como por exemplo partes do contorno de ovos, são perdidos. Essa perda é pelo fato de que em vários dos ovos o contorno não ser nítido e possuir pouca espessura. A tabela a seguir descreve a característica das imagens de ampliação 40x usadas no trabalho. As imagens que contém ovos, mas nas quais não é possível distinguir visualmente o contorno de ovos (um total de 18 imagens), não foram consideradas.

\begin{tabular}{|c|l|}
\hline Quantidade & Descrição \\
\hline 36 & imagens que contém ovos, com contorno visível \\
\hline 27 & imagens que não contém ovos \\
\hline $\mathbf{6 3}$ & Total de imagens \\
\hline
\end{tabular}

As imagens foram originalmente capturadas em cores de 24 bits, mas, para efeito de processamento digital, optou-se por trabalhar em níveis de cinza. Essa escolha foi feita porque as linhas aparecem na maioria das vezes em cor marrom, e em outros casos em cores escuras. Assim, a conversão de cores para tons de cinza é realizada sem perda de informação útil para nosso objetivo. 


\subsection{Parâmetros}

Os resultados da fase 1 do método proposto são imagens binárias contendo segmentos de linha e são armazenados em formato PBM uma vez que a parte de detecção de elipses (baseado em um programa desenvolvido por R.A. McLaughlin [23]) está preparado apenas para leitura desse formato. Devido à complexidade do algoritmo de detecção de elipses, essas imagens foram redimensionadas a um terço do seu tamanho original, isto é, a uma resolução de $853 \times 640$ pixels. Essa redução foi escolhida pois verificou-se experimentalmente que não há perda de informação para a próxima fase.

O desenvolvimento das etapas da primeira fase, assim como o ajuste de parâmetros de ambas as fases, foram realizadas experimentalmente de forma a otimizar os resultados de detecção de ovos em imagens de ampliação 40x. Os parâmetros utilizados são revistos a seguir, obedecendo cada fase e etapas do método proposto:

1. Detecção de estruturas do tipo linha:

(a) Realce de linhas

i. Suavização da imagem: $B \leftarrow 8 \times 60, s \leftarrow 80$ e $\theta \leftarrow 0,23,45,68,90,113,135,158$.

ii. Filtro de ordem: $B \leftarrow 1 \times 6, k \leftarrow 1$ e $\theta \leftarrow 0,23,45,68,90,113,135,158$.

iii. Fechamento Top-Hat: $B$ disco de raio 7 pixels.

(b) Detecção de linhas

i. Erosão por linhas: $B \leftarrow 1 \times 72$.

ii. Composição dos resultados: $\theta: 0,5,11,16,22,27,33,38,45,50,56,61,66,71$, $77,82,9095,101,106,112,117,123,128,135,140,146,151,157,162,168$ e 173 e $l \leftarrow 1$.

(c) Refinamento do resultado

i. Abertura por área: area $\leftarrow 600$ e $B$ elemento estruturante tipo cruz de raio 1 .

ii. Remoção de componentes da borda da imagem: $B$ elemento estruturante tipo cruz de raio 1.

2. Detecção de elipses: $B \leftarrow 80 \times 80$, tamanhoMaximoElipse $\leftarrow \quad 500$, tamanhoMinimoElipse $\leftarrow 110$ e proporcaoMinima $\leftarrow 0.25$.

\subsection{Avaliação de Resultados}

O resultado esperado ao final do processamento das duas fases é a sobreposição de uma elipse sobre o contorno de cada ovo. Os resultados são classificados como TP (true positive), FP (false 
positive) ou FN (false negative). Um TP é uma elipse detectada que sobrepõe-se sobre um ovo. Um FP é uma elipse detectada em uma região sem ovo. Um FN é uma região com presença de ovo na qual não foi detectada uma elipse. Observa-se que não existe uma definição para TN (true negative) quando a análise é baseada em regiões ou grupo de pixels [20]. As definições são ilustradas na figura 4.1.

Os resultados foram avaliados verificando se as elipses detectadas correspondem ou não a regiões com presença de ovos de S. mansoni. Foram consideradas as métricas Object Detection Rate (ou True Positive Rate) $t_{p}$ e False Alarm Rate $f_{a}$ usadas para analisar o desempenho em detecção de objetos [20], definidas respectivamente por

$$
\begin{aligned}
& t_{p}=\frac{N_{T P}}{N_{T P}+N_{F N}}, \\
& f_{a}=\frac{N_{F P}}{N_{T P}+N_{F P}},
\end{aligned}
$$

nas quais $N_{X X}$ indica a quantidade total de ocorrências do tipo $X X(X X \in\{T P, F P, F N\})$.

Para realizar o ajuste de parâmetros do método proposto e avaliar os resultados, as imagens foram separadas em dois grupos. A tabela a seguir descreve as características dos grupos:

\begin{tabular}{|l|c|c|c|}
\hline Grupo & imagens com ovo & imagens sem ovo & Total \\
\hline A & 28 & 20 & 48 \\
\hline B & 8 & 7 & 15 \\
\hline
\end{tabular}

O Grupo A contém 48 imagens, e foram utilizadas para ajustar o método durante o desenvolvimento do trabalho. No Grupo A existem 28 imagens com presença de ovos de S. mansoni. O Grupo B contém 15 imagens, que foram adquiridas após o ajuste do método ter sido concluído. As imagens do Grupo B, que contém 8 imagens com presença de ovos de S. mansoni, foram utilizadas para avaliar o método.

O resultado obtido para o Grupo A, ao aplicar o método proposto foi:

\begin{tabular}{|l|c|}
\hline Classificação & Ocorrências \\
\hline TP & 23 \\
\hline FN & 5 \\
\hline FP & 2 \\
\hline
\end{tabular}

Na tabela a seguir apresentamos o resultado das métricas. 


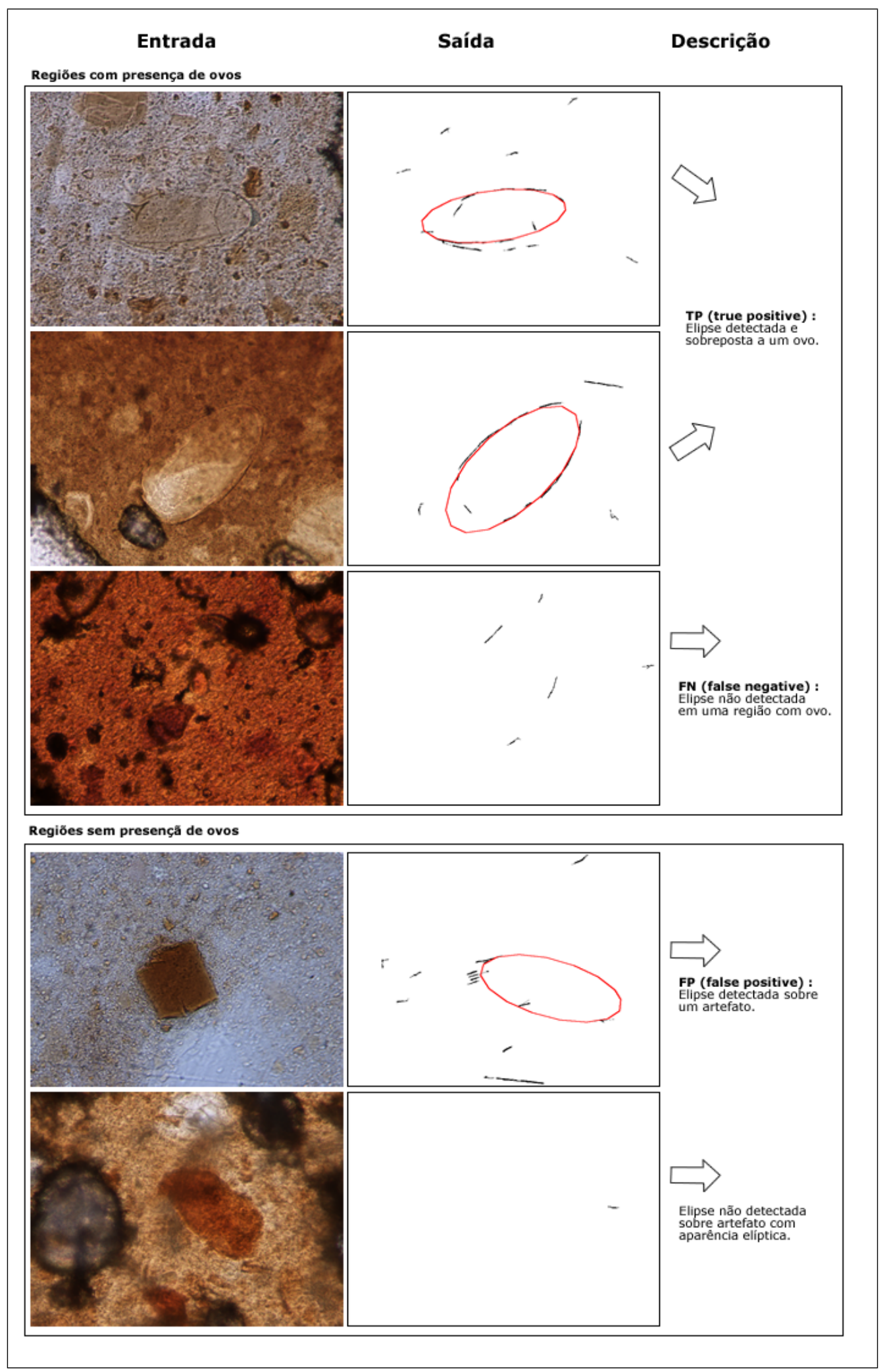

Figura 4.1: Resultados TP, FP ou FN. 


\begin{tabular}{|l|c|}
\hline Métricas & Resultados \\
\hline$t_{p} A$ & 0.8214 \\
\hline$f_{a} A$ & 0.0800 \\
\hline
\end{tabular}

O resultado obtido para o Grupo B, ao aplicar o método proposto foi:

\begin{tabular}{|l|c|}
\hline Classificação & Ocorrências \\
\hline TP & 6 \\
\hline FN & 2 \\
\hline FP & 1 \\
\hline
\end{tabular}

Na tabela a seguir apresentamos o resultado das métricas.

\begin{tabular}{|l|c|}
\hline Métricas & Resultados \\
\hline$t_{p} B$ & 0.7500 \\
\hline$f_{a} B$ & 0.1428 \\
\hline
\end{tabular}

O resultado para o Grupo A são superiores pois este grupo foi utilizado para o desenvolvimento do método e ajuste dos parâmetros. O $t_{p} A$, a proporção de ovos detectados corretamente, é de $82.14 \%$. O False alarm rate, $f_{a} A$, é de $8 \%$.

No Grupo B, observa-se que o alarme falso $f_{a}$ é $14.28 \%$. Este é um resultado aceitável, pois indica que nosso método não tende a confundir artefatos de diversas formas (incluindo as elípticas) com ovos de S. mansoni. Embora a taxa de detecção $t_{p} B$ de $75 \%$ possa ser considerado aceitável face à complexidade das imagens, devido ao propósito do método, de auxiliar o diagnóstico, este resultado precisa ser melhorado, mesmo que implique em aumento na taxa de alarme falso.

Para evidenciar a importância da etapa de pré-processamento, realizou-se também experimentos sem essa etapa (isto é, sem as etapas de suavização e sem a aplicação do filtro de ordem). Usando os mesmos parâmetros para as demais etapas, nenhuma elipse foi detectada. Ajustando-se os parâmetros das outras etapas, apenas $50 \%$ dos ovos são detectados. Dessa forma, observa-se a utilidade da etapa de pré-processamento pois melhora consideravelmente os resultados do método proposto.

\subsection{Exemplos de detecção}

Inicialmente mostramos alguns resultados obtidos sobre regiões da imagem restritas aos ovos. Nas figuras 4.2 a 4.7 apresentamos resultados de cada etapa da fase 1, no processo de detecção de curvas, e também resultados da fase 2 , no processo de detecção de elipses. 
Nas figuras observa-se que várias linhas alvo foram detectadas. O importante é a disposição elíptica que essas linhas apresentam, permitindo que seja detectada uma elipse. Também foram detectadas algumas linhas correspondentes a estruturas sem interesse, com espessura menor e várias fragmentações. Observa-se também que algumas linhas alvo não foram detectadas devido a fragmentações e descontinuidade nas curvas, pois no processo de erosão por linhas 3.2.2, elas são perdidas.

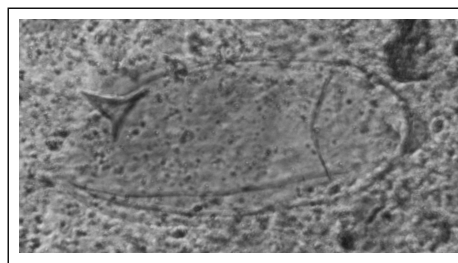

(a)

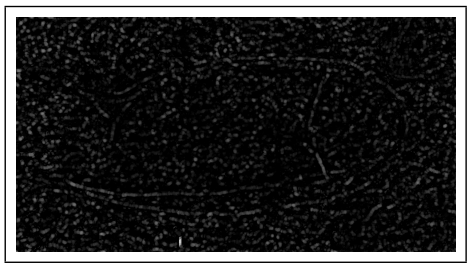

(d)

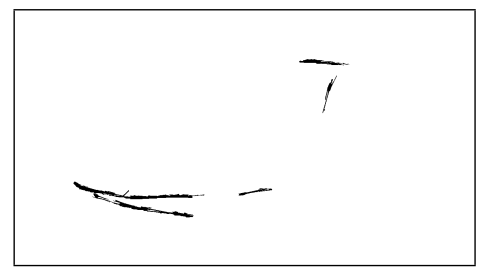

(g)

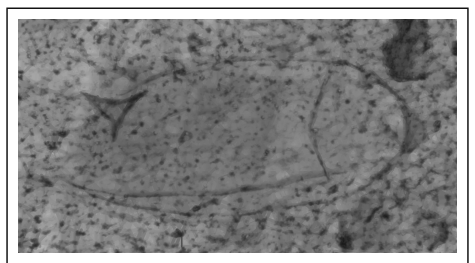

(b)

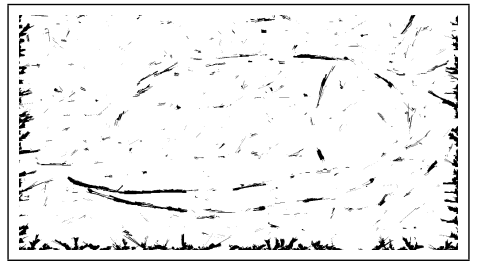

(e)

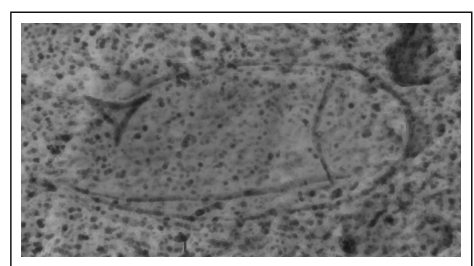

(c)

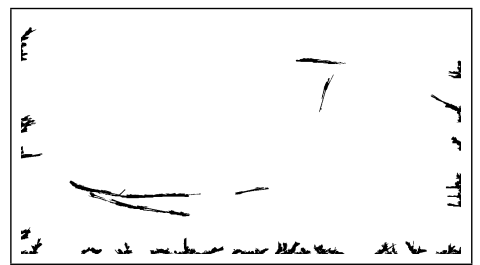

(f)

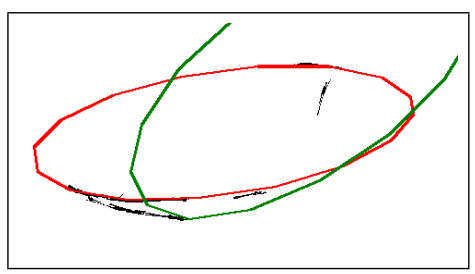

(h)

Figura 4.2: Sequência de operações. (a) Imagem de entrada. (b) Suavizado. (c) Filtro de Ordem. (d) Fechamento Top-Hat. (e) Máximo de erosões por linhas de diferentes orientações, seguida de limiarização. (f) Abertura por área. (g) Remoção de componentes que tocam a borda. (h) Detecção de elipses usando a Transformada Hough. 


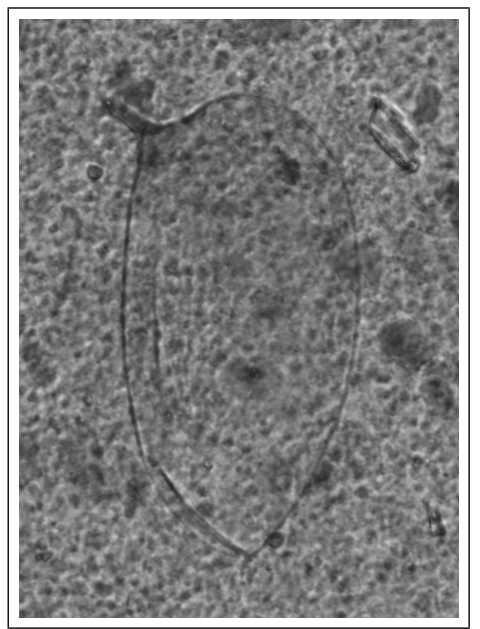

(a)

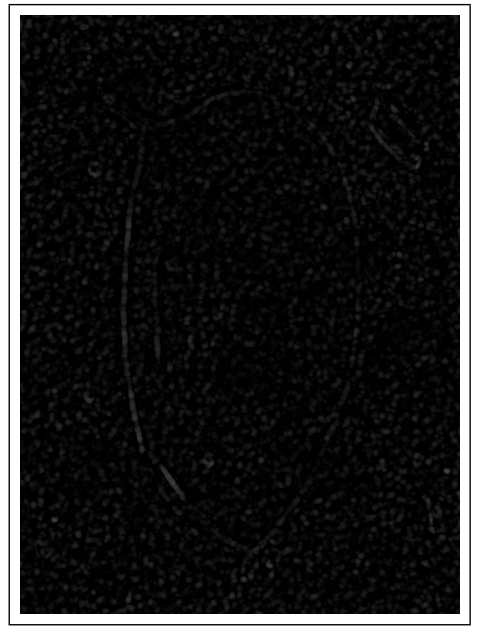

(d)

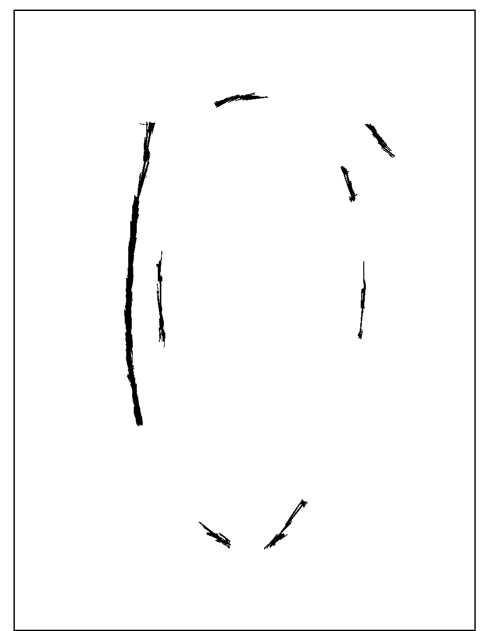

(g)

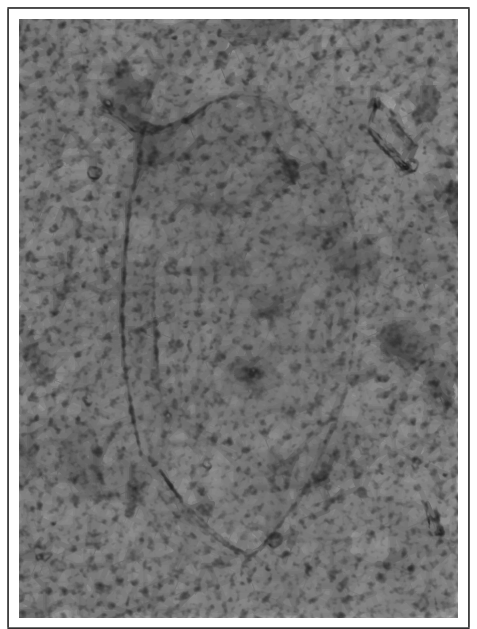

(b)

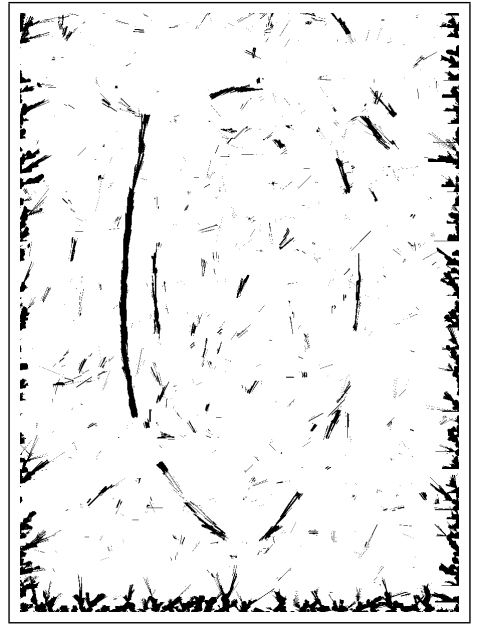

(e)

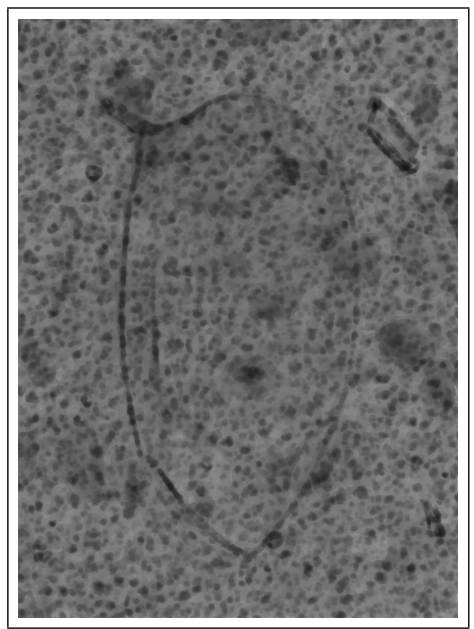

(c)

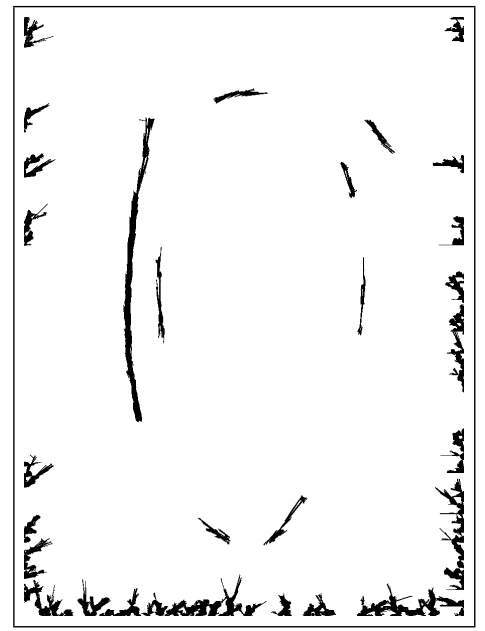

(f)

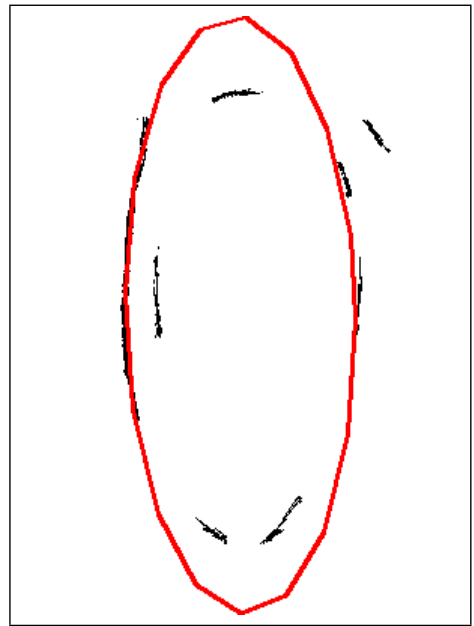

(h)

Figura 4.3: Sequência de operações. (a) Imagem de entrada. (b) Suavizado. (c) Filtro de Ordem. (d) Fechamento Top-Hat. (e) Máximo de erosões por linhas de diferentes orientações, seguida de limiarização. (f) Abertura por área. (g) Remoção de componentes que tocam a borda. (h) Deteç̧ão de elipses usando a Transformada Hough. 


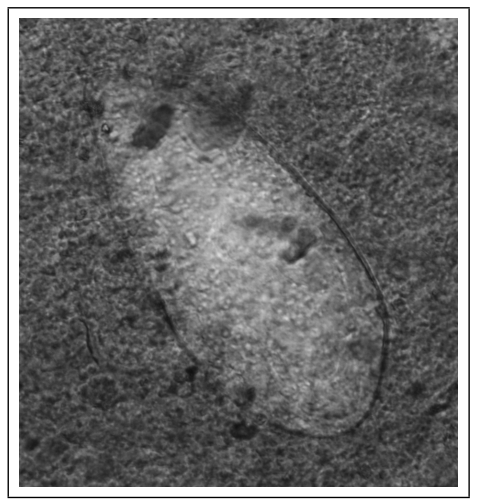

(a)

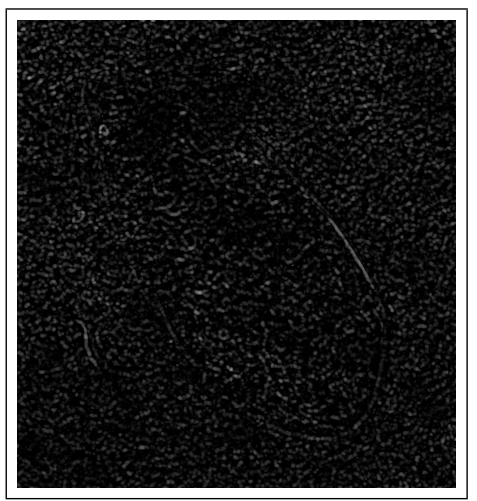

(d)

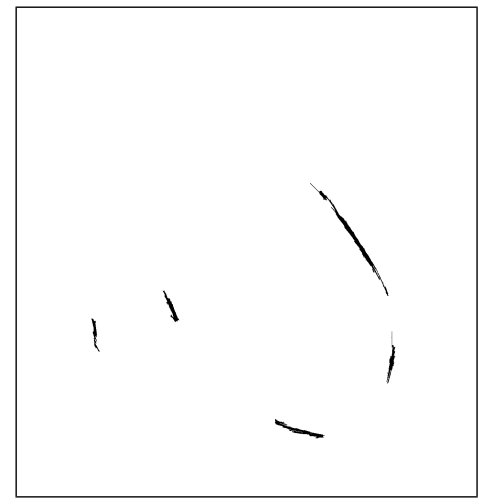

(g)

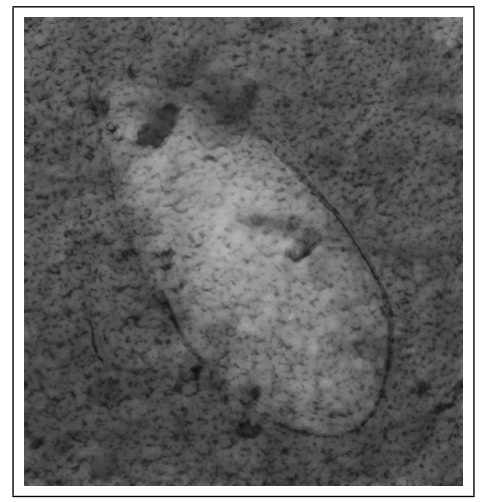

(b)

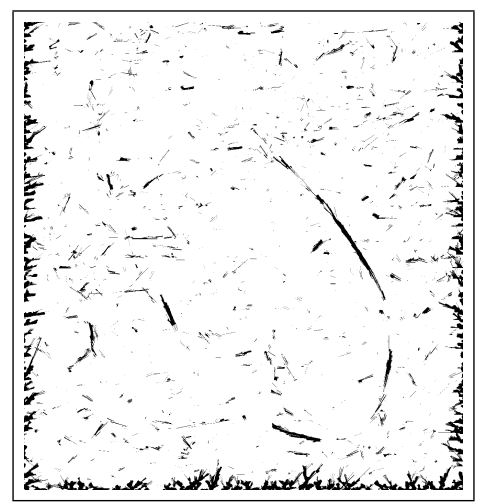

(e)

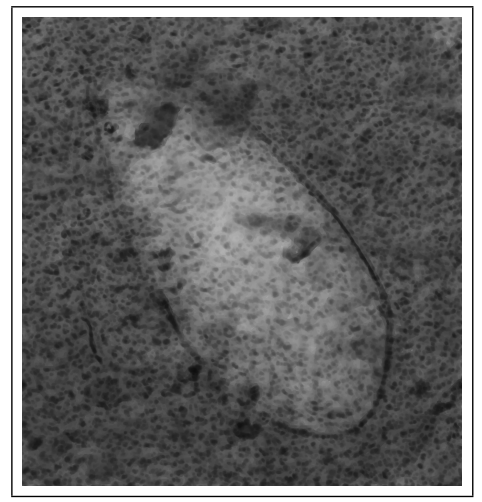

(c)

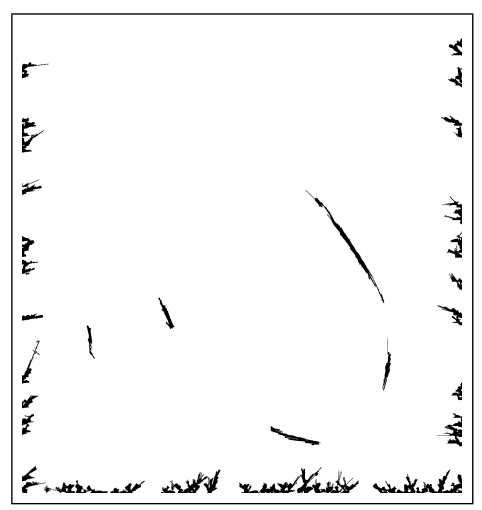

(f)

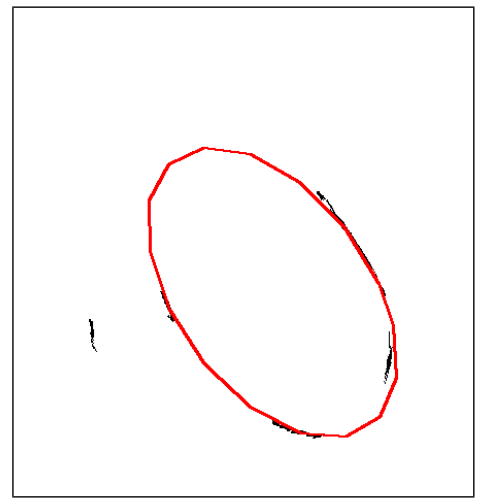

(h)

Figura 4.4: Sequência de operações. (a) Imagem de entrada. (b) Suavizado. (c) Filtro de Ordem. (d) Fechamento Top-Hat. (e) Máximo de erosões por linhas de diferentes orientações, seguida de limiarização. (f) Abertura por área. (g) Remoção de componentes que tocam a borda. (h) Deteç̧ão de elipses usando a Transformada Hough. 


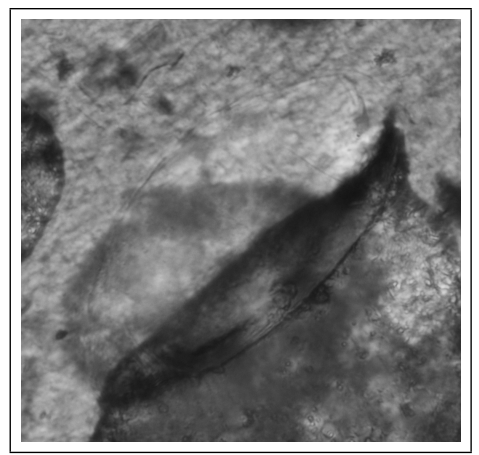

(a)

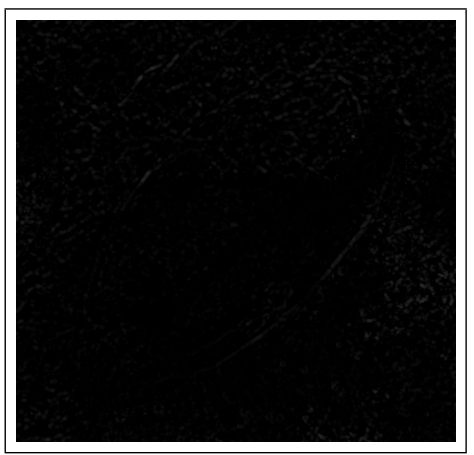

(d)

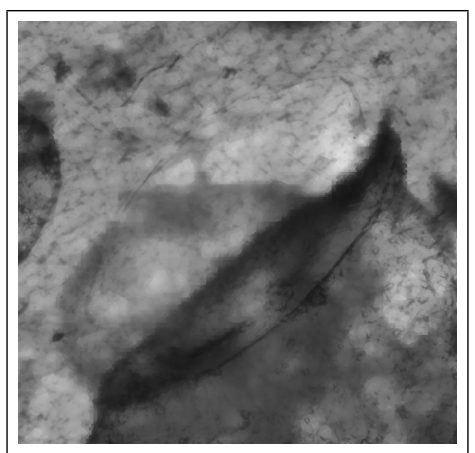

(b)

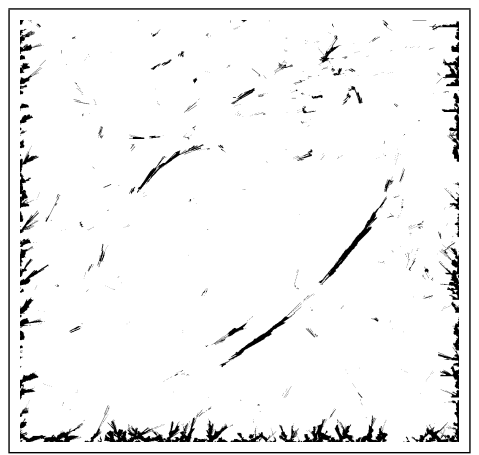

(e)

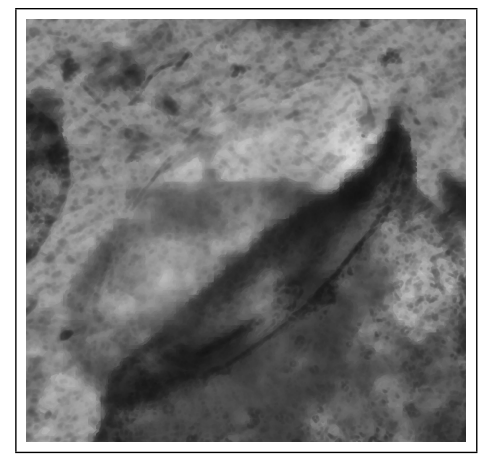

(c)

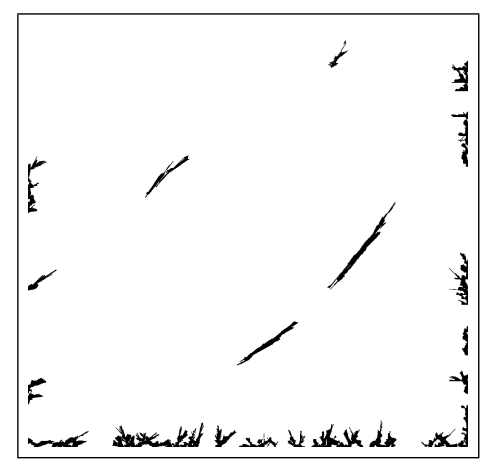

(f)

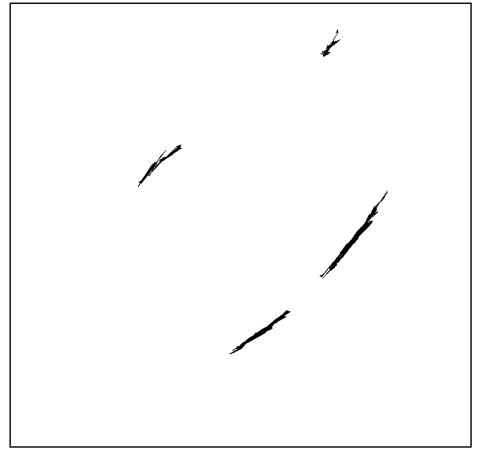

(g)

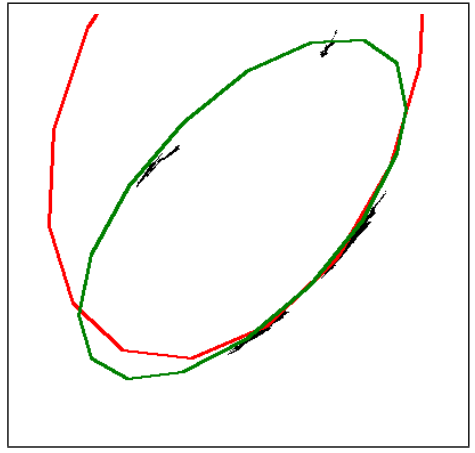

(h)

Figura 4.5: Sequência de operações. (a) Imagem de entrada. (b) Suavizado. (c) Filtro de Ordem. (d) Fechamento Top-Hat. (e) Máximo de erosões por linhas de diferentes orientações, seguida de limiarização. (f) Abertura por área. (g) Remoção de componentes que tocam a borda. (h) Detecção de elipses usando a Transformada Hough. 


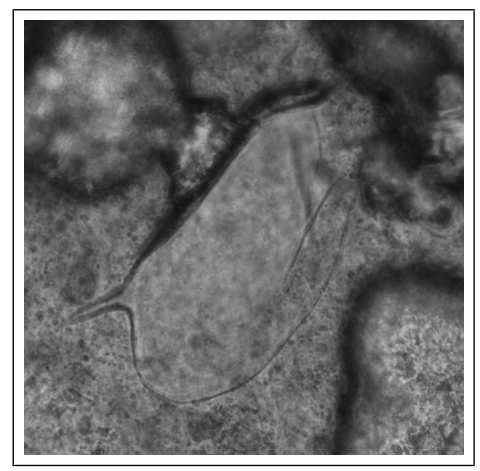

(a)

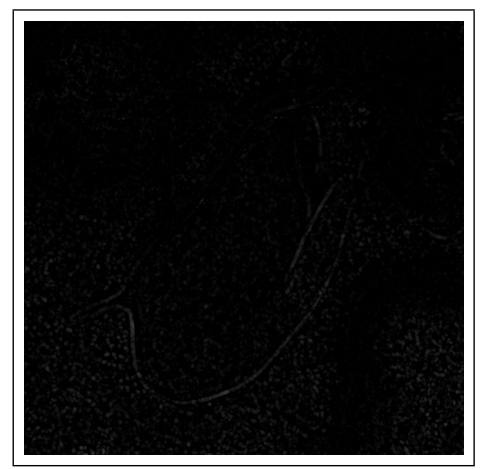

(d)

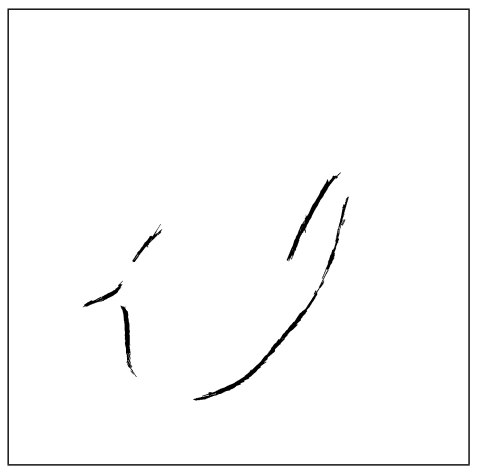

(g)

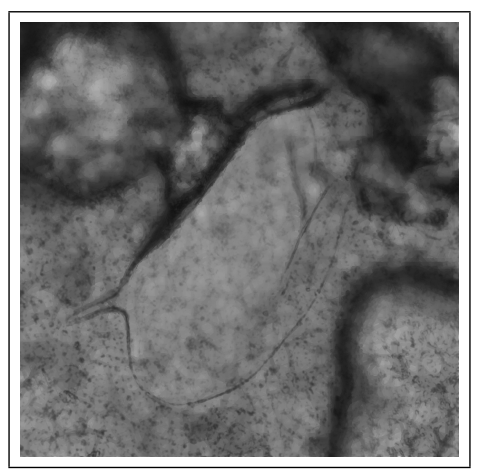

(b)

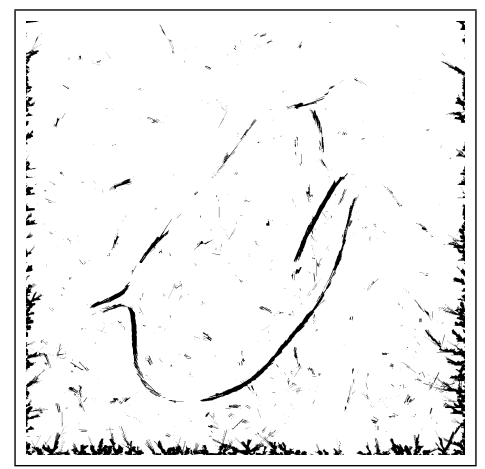

(e)

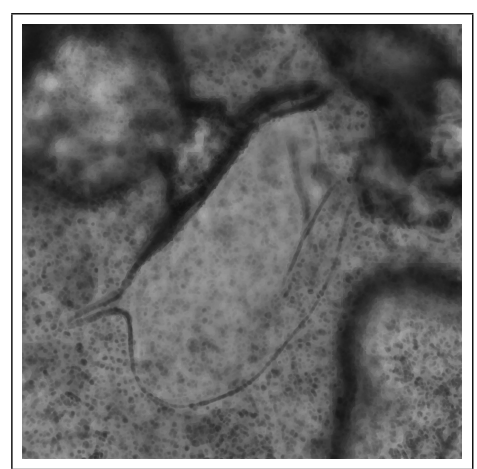

(c)

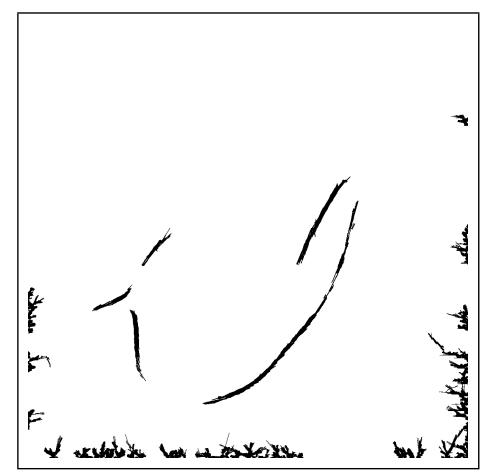

(f)

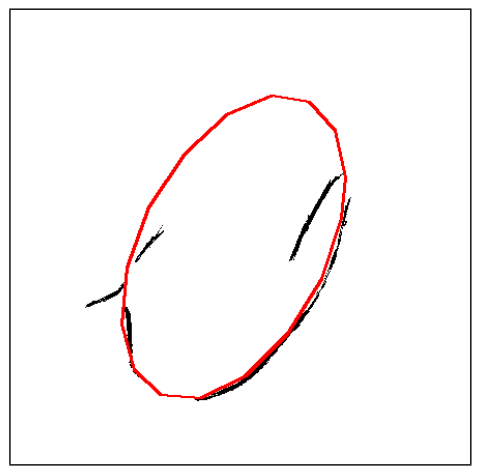

(h)

Figura 4.6: Sequência de operações. (a) Imagem de entrada. (b) Suavizado. (c) Filtro de Ordem. (d) Fechamento Top-Hat. (e) Máximo de erosões por linhas de diferentes orientações, seguida de limiarização. (f) Abertura por área. (g) Remoção de componentes que tocam a borda. (h) Deteç̧ão de elipses usando a Transformada Hough. 


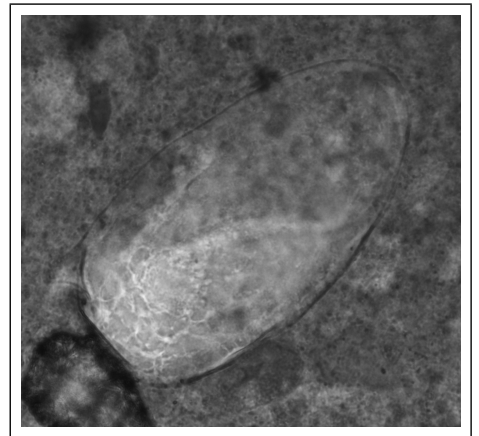

(a)

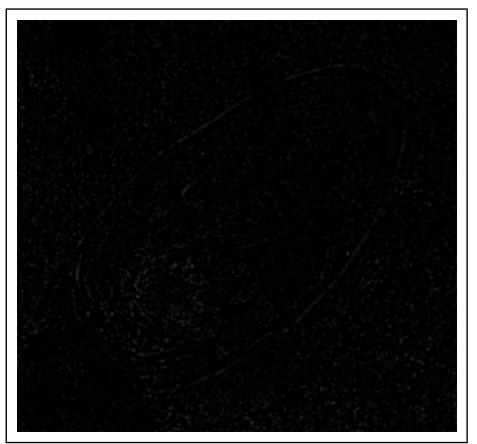

(d)

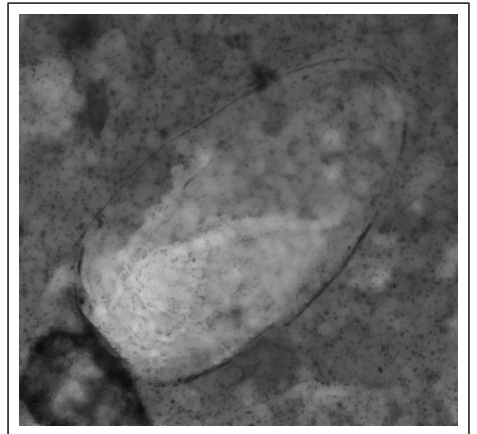

(b)

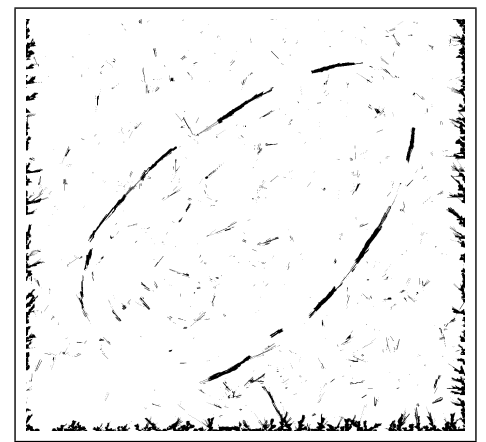

(e)

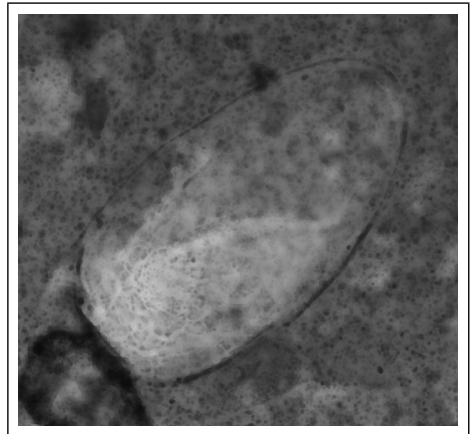

(c)

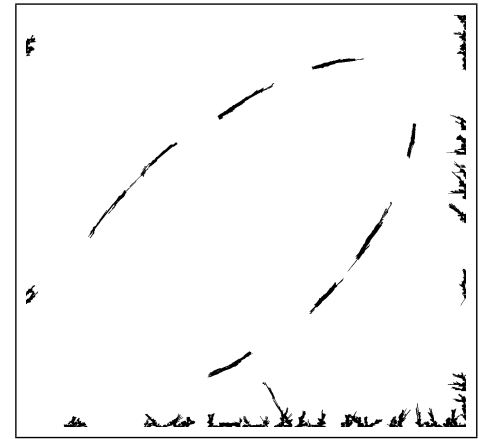

(f)

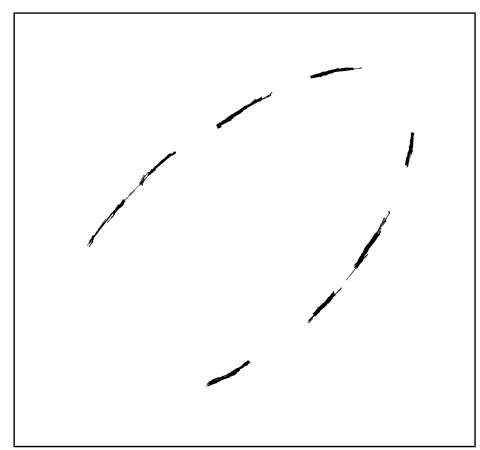

(g)

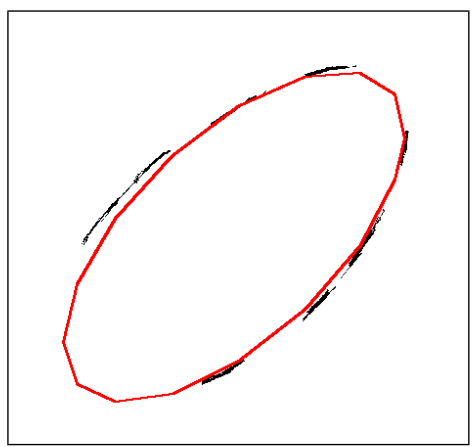

(h)

Figura 4.7: Sequência de operações. (a) Imagem de entrada. (b) Suavizado. (c) Filtro de Ordem. (d) Fechamento Top-Hat. (e) Máximo de erosões por linhas de diferentes orientações, seguida de limiarização. (f) Abertura por área. (g) Remoção de componentes que tocam a borda. (h) Deteç̧ão de elipses usando a Transformada Hough. 
A técnica de detecção de linhas deve, idealmente, ser capaz de detectar apenas estruturas que se assemelham a linhas. Por isso nesta subseção mostramos os resultados da técnica quando aplicada sobre regiões que não contém ovos. Essas regiões contêm diversos artefatos que em muitos dos casos apresentam contornos na forma de linhas, como mostradas nas figuras 4.8 e 4.9. Observa-se que as linhas detectadas nessas imagens possuem uma espessura e tamanho similar às linhas alvo, porém essas linhas em geral não estão dispostas em forma elíptica, não ocorrendo sobreposição de uma elipse.

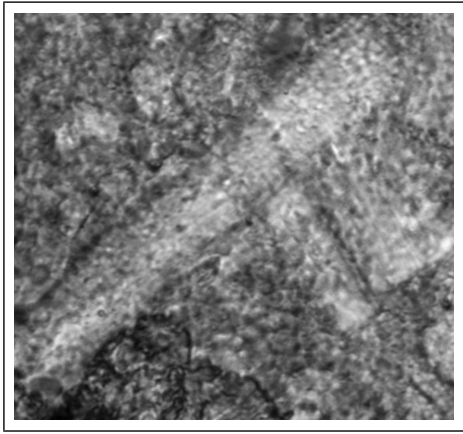

(a)

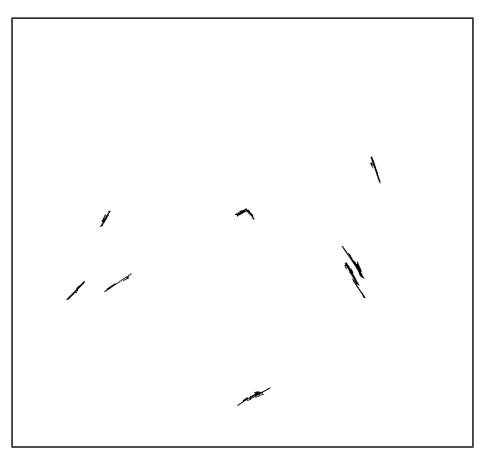

(b)

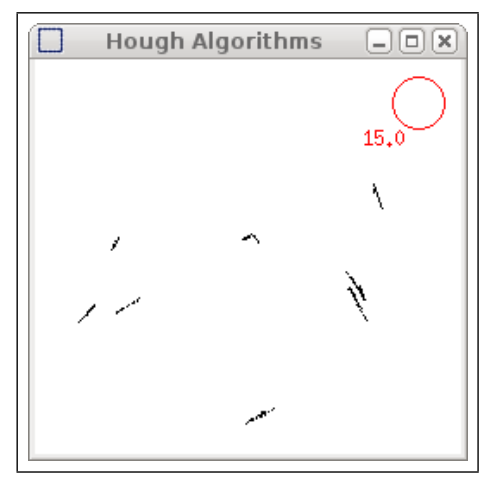

(c)

Figura 4.8: Resultados em imagem sem ovo. (a) Imagem de entrada. (b) Detecção de linhas. (c) Detecção de elipses usando a Transformada Hough.

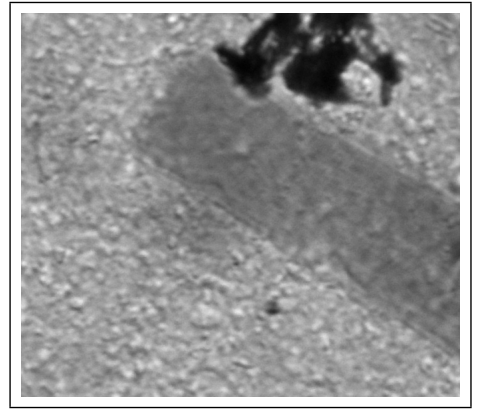

(a)

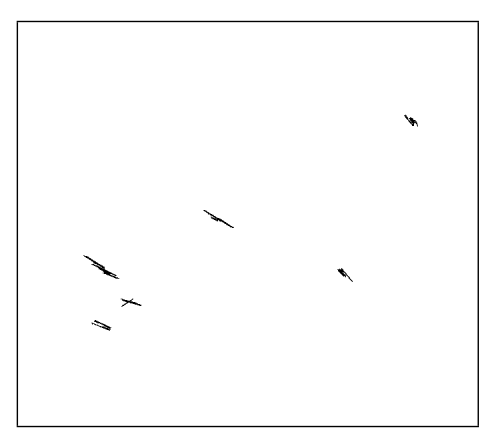

(b)

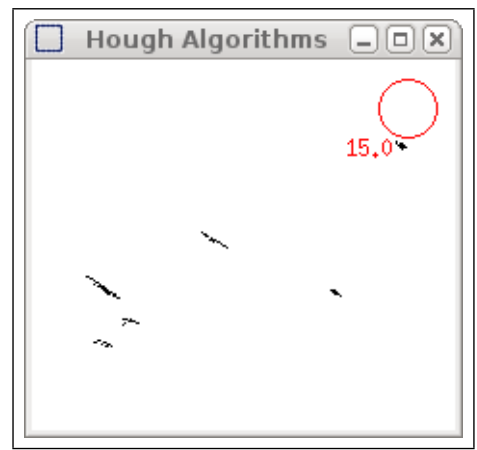

(c)

Figura 4.9: Resultados em imagem sem ovo. (a) Imagem de entrada. (b) Detecção de linhas. (c) Detecção de elipses usando a Transformada Hough.

O efeito do algoritmo sobre uma região maior pode ser visto nas figuras 4.10 a 4.18. Essas imagens correspondem a regiões integrais capturadas com ampliação 40x. As cinco primeiras imagens contém ovos e as quatro últimas não contém. As linhas detectadas nessas cinco imagens e que são parte do contorno de ovos apresentam uma espessura maior que as linhas que não são parte do contorno, e elipses são detectadas sobre os contornos. 
Na figura 4.14 observa-se que foram detectadas três elipses, pois além das linhas alvo detectadas também foram detectadas linhas sem interesse, e em combinação apresentam formas elípticas. Assim, o algoritmo da transformada Hough detecta as elipses. Neste trabalho, desde que o método detecte pelo menos uma elipse sobreposto ao ovo, considera-se um TP (true positive).

As linhas do fundo são de menor largura, menor espessura e bastante fragmentadas como observa-se nas figuras 4.15, 4.16 e 4.18, sendo difícil intuir a presença de uma forma elíptica nelas. Porém, observa-se na figura 4.17 que é detectada uma elipse, pois existem segmentos de linha similares a nossas linhas alvo.

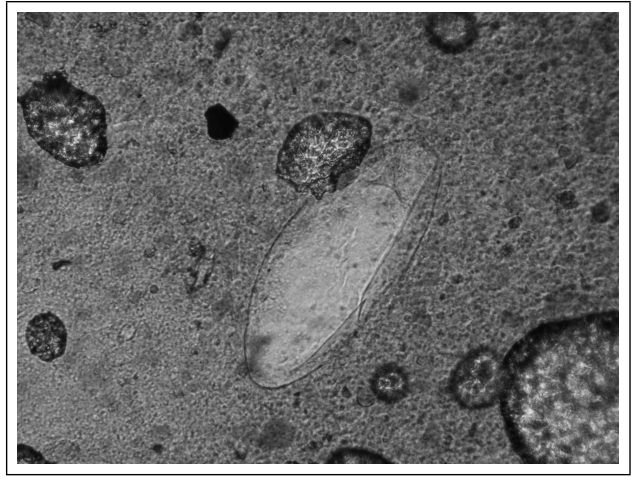

(a)

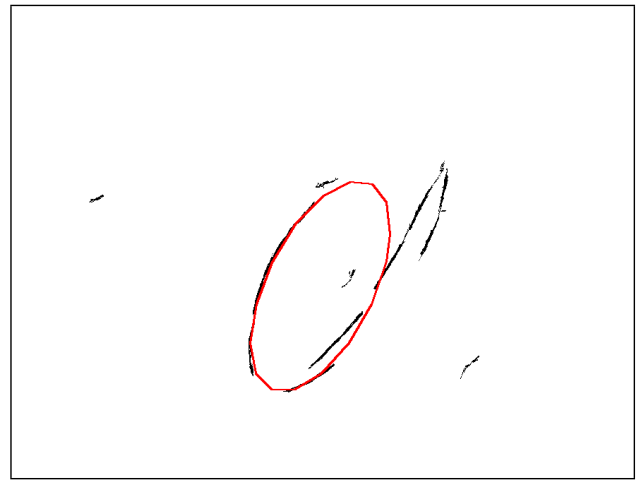

(b)

Figura 4.10: Resultados em uma região maior que tem presença de ovo. (a) Imagem de entrada. (b) Método proposto.

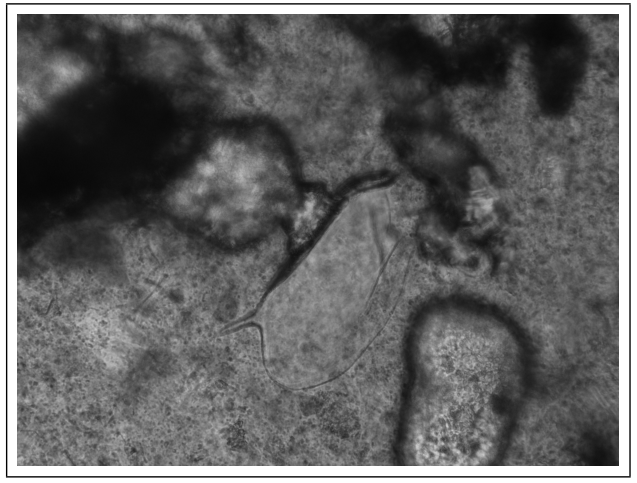

(a)

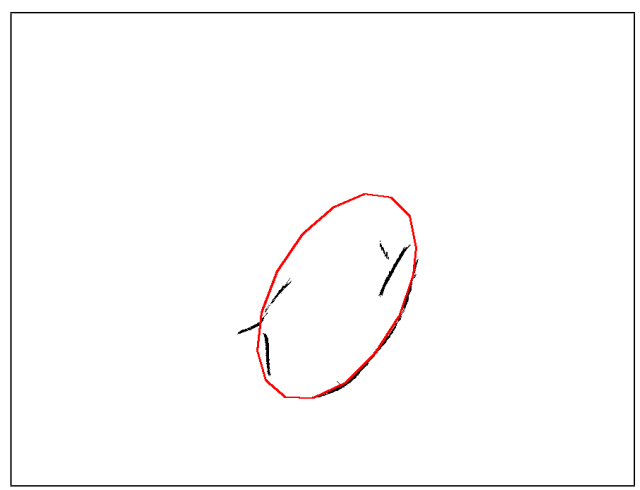

(b)

Figura 4.11: Resultados em uma região maior que tem presença de ovo. (a) Imagem de entrada. (b) Método proposto.

\subsection{Resultados com outros métodos}

Apenas para efeito ilustrativo, mostramos nas figuras 4.19 e 4.20 os resultados obtidos com alguns métodos de detecção de bordas, como os métodos de Sobel, Laplaciano e Gradiente Mor- 


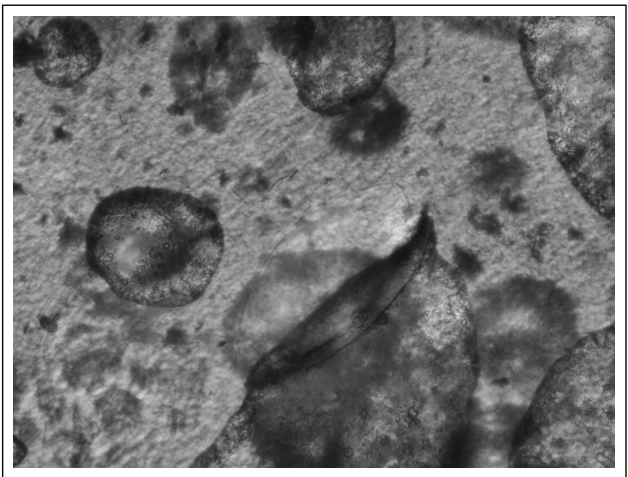

(a)

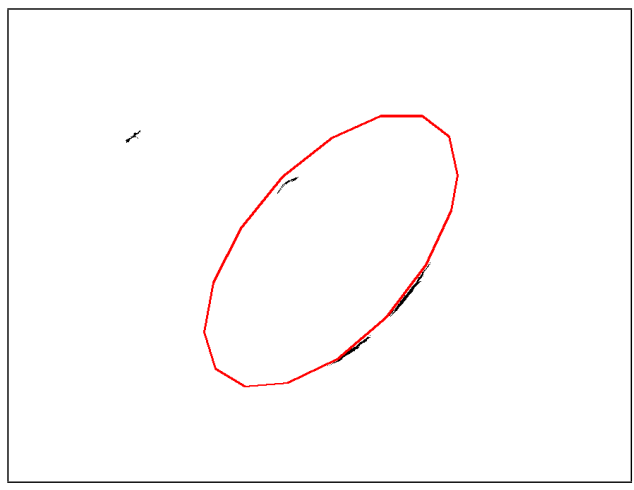

(b)

Figura 4.12: Resultados em uma região maior que tem presença de ovo. (a) Imagem de entrada. (b) Método proposto.

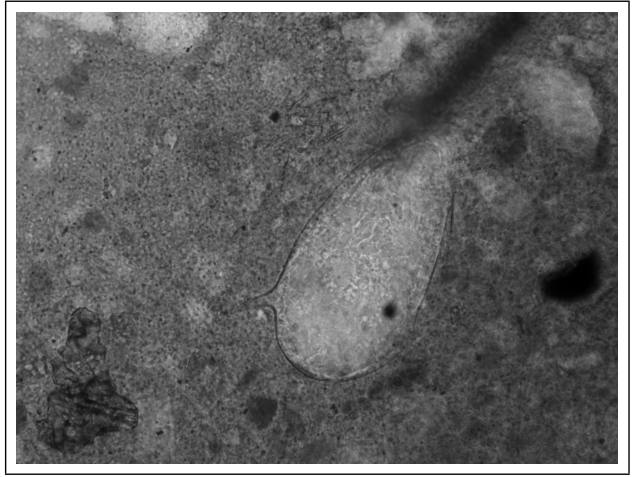

(a)

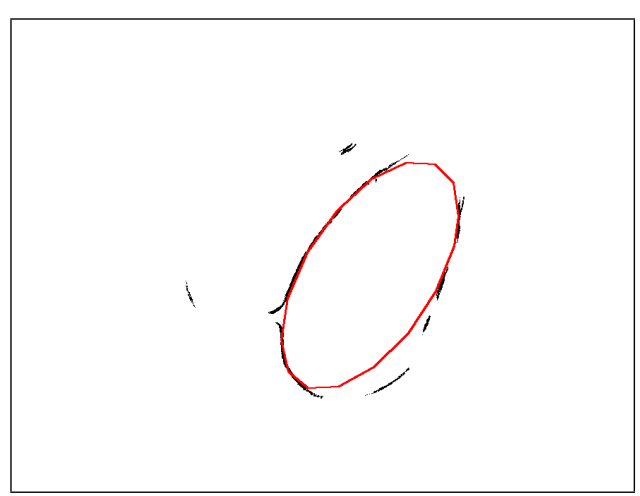

(b)

Figura 4.13: Resultados em uma região maior que tem presença de ovo. (a) Imagem de entrada. (b) Método proposto.

fológico. Essa comparação visual ilustra a importância das etapas de processamento proposto nas quais buscou-se realçar as linhas e eliminar ruídos. 


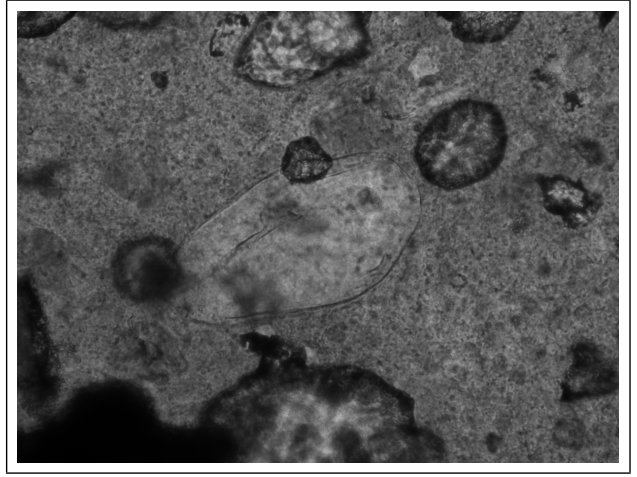

(a)

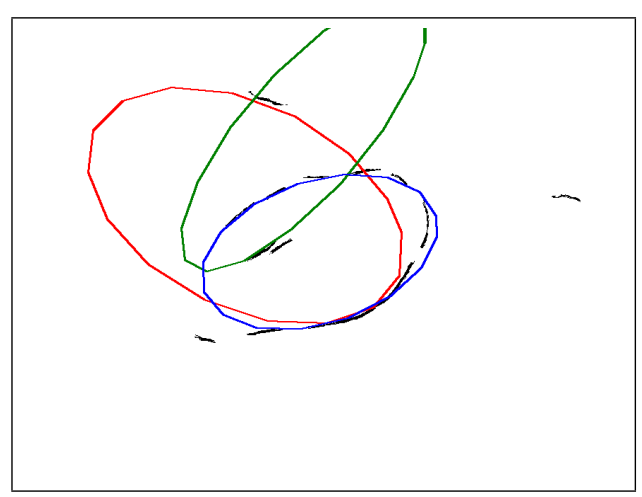

(b)

Figura 4.14: Resultados em uma região maior que tem presença de ovo. (a) Imagem de entrada. (b) Método proposto.

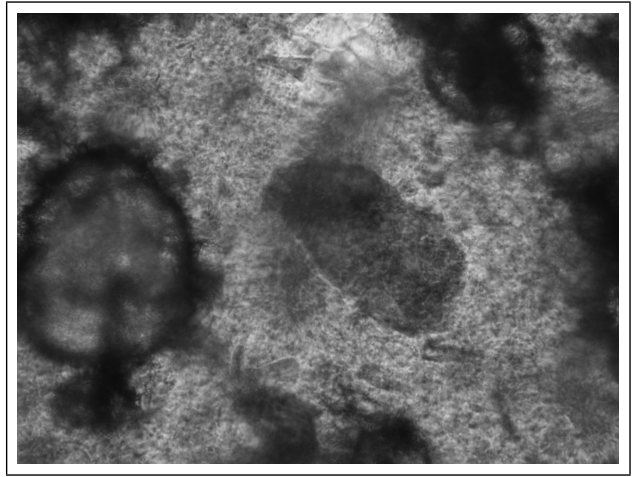

(a)

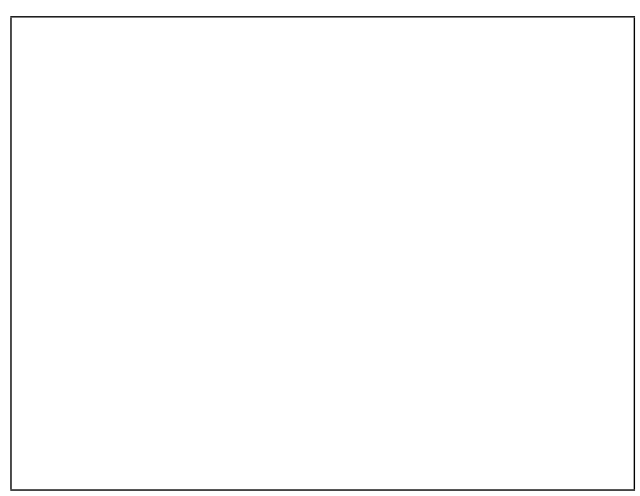

(b)

Figura 4.15: Resultados em uma região maior que não tem presença de ovo. (a) Imagem de entrada. (b) Método proposto.

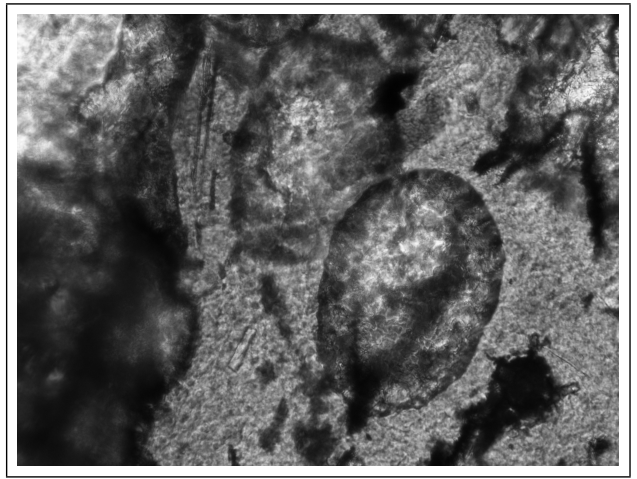

(a)

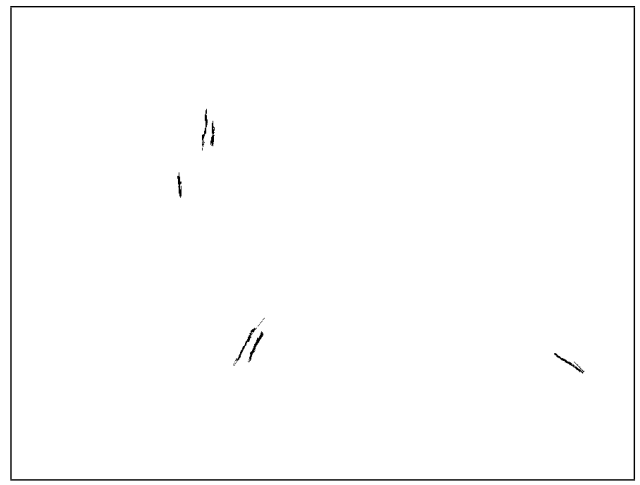

(b)

Figura 4.16: Resultados em uma região maior que não tem presença de ovo. (a) Imagem de entrada. (b) Método proposto. 


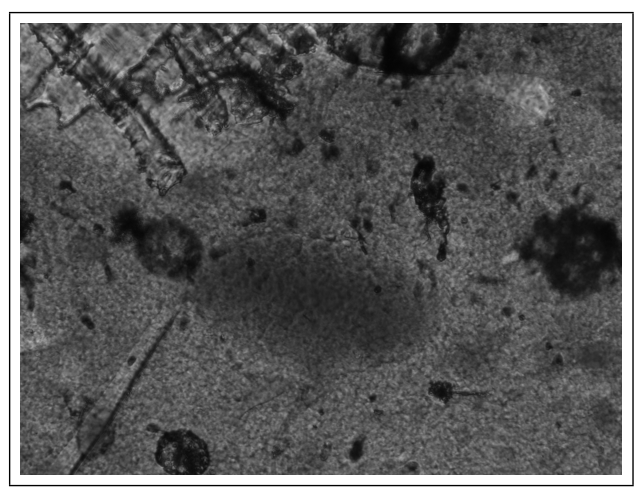

(a)

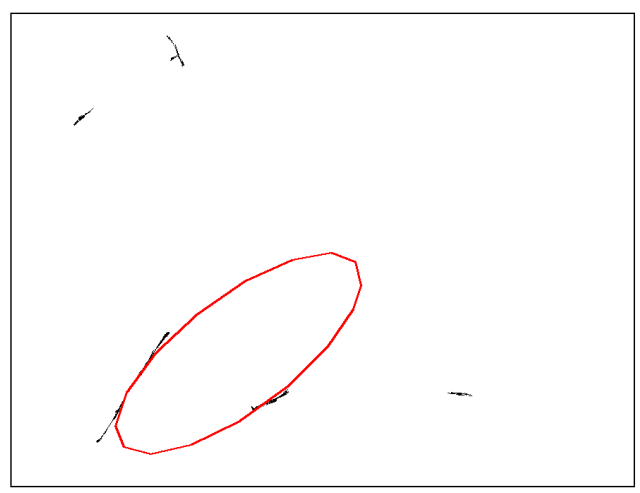

(b)

Figura 4.17: Resultados em uma região maior que não tem presença de ovo. (a) Imagem de entrada. (b) Método proposto.

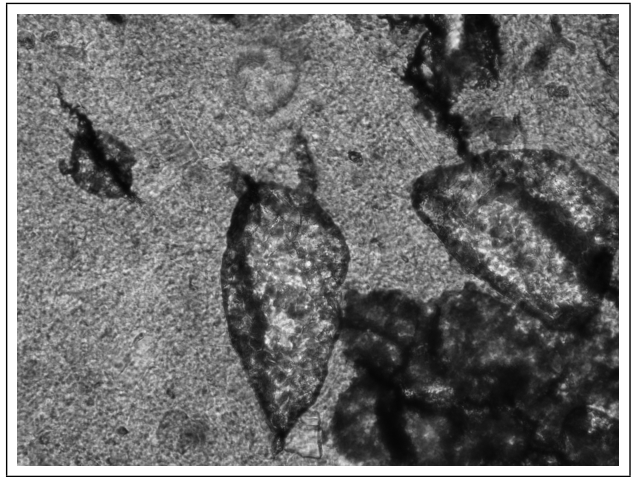

(a)

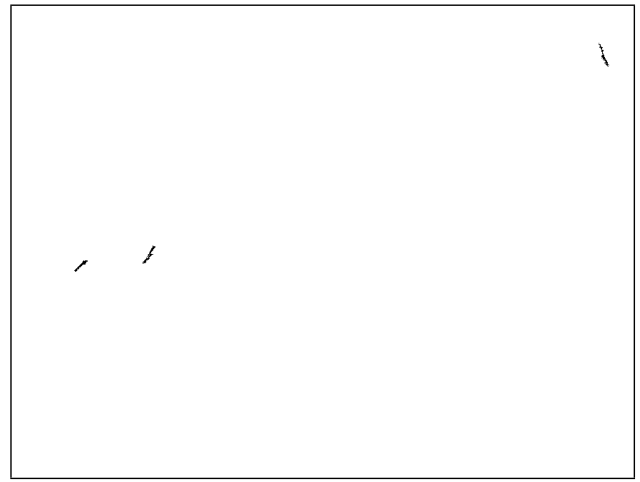

(b)

Figura 4.18: Resultados em uma região maior que não tem presença de ovo. (a) Imagem de entrada. (b) Método proposto. 


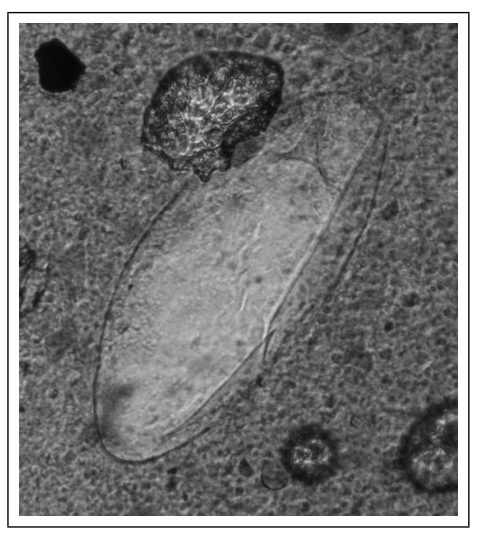

(a)

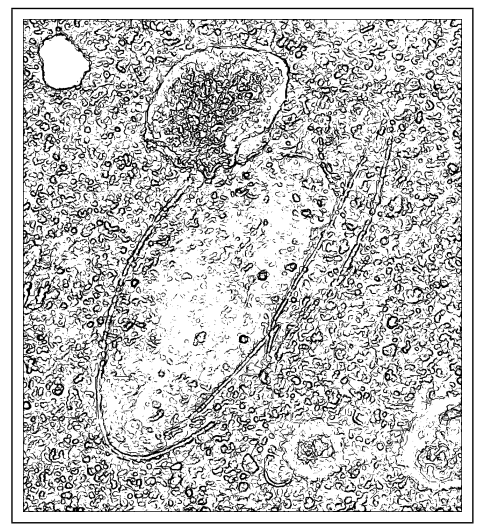

(c)

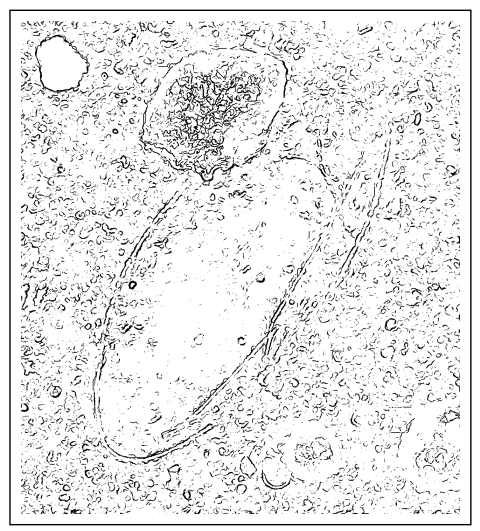

(e)

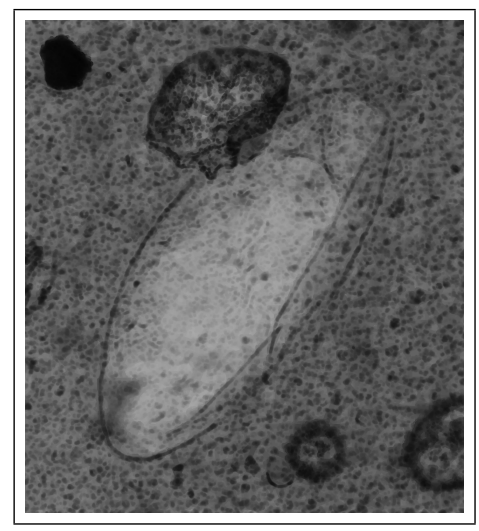

(b)

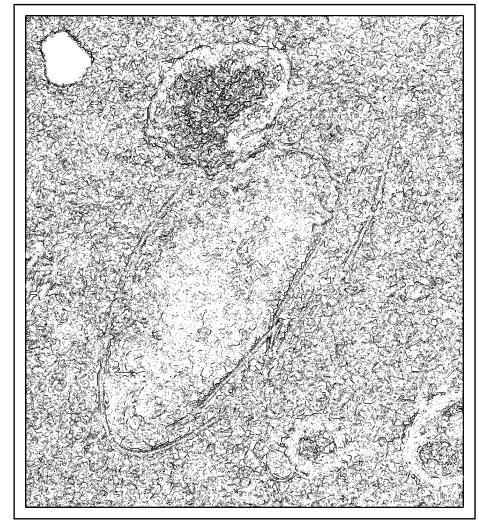

(d)

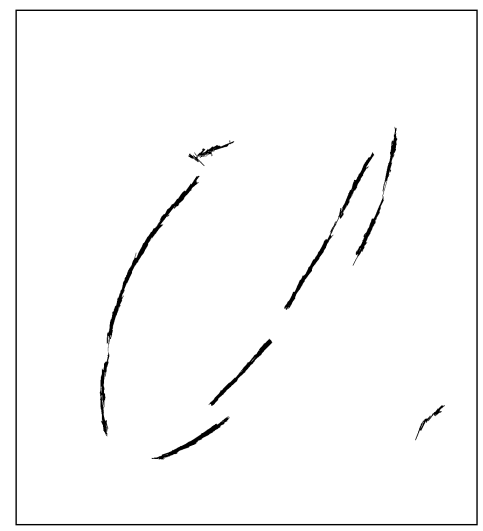

(f)

Figura 4.19: Comparação de métodos de detecção de bordas. (a) Imagem de entrada. (b) Resultado do método de suavizado e filtro de ordem. (c) Imagem negada do Método de Sobel. (d) Imagem negada do Método Laplaciano. (e) Imagem negada do Gradiente Morfológico. (f) Método proposto. 


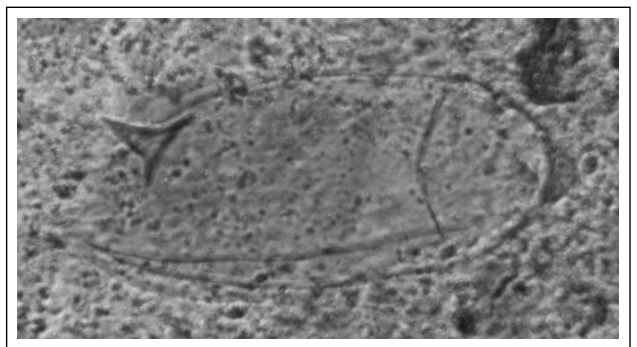

(a)

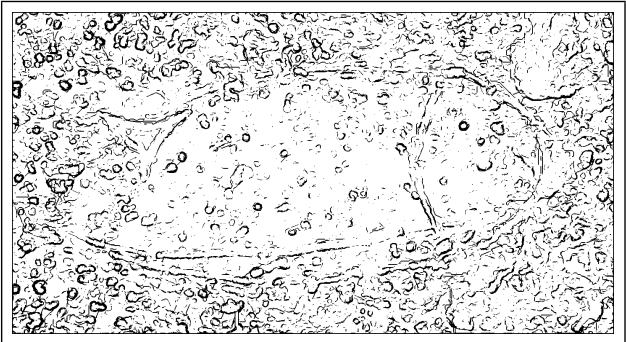

(c)

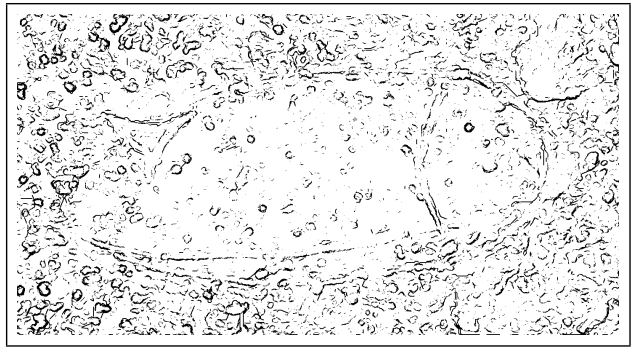

(e)

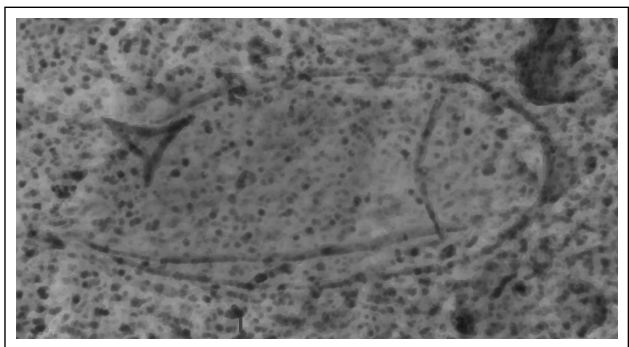

(b)

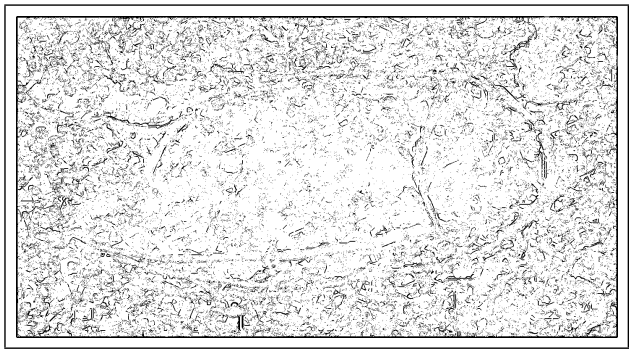

(d)

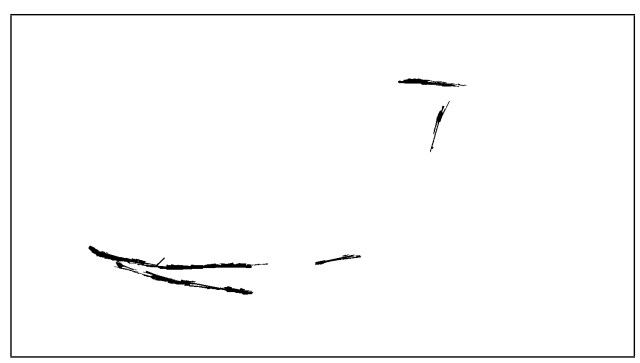

(f)

Figura 4.20: Comparação de métodos de detecção de bordas. (a) Imagem de entrada. (b) Resultado do método de suavizado e filtro de ordem. (c) Imagem negada do Método de Sobel. (d) Imagem negada do Método Laplaciano. (e) Imagem negada do Gradiente Morfológico. (f) Método proposto. 


\section{Capítulo 5}

\section{Conclusões}

Neste trabalho consideramos o problema de detecção de ovos de S. Mansoni em imagens microscópicas. Os ovos alvo apresentam algumas características que podem ser explorados na detecção. No entanto, essas características não são robustas, não sendo visíveis ou uniformes em todas as ocorrências dos ovos. Além disso, as imagens são complexas em termos de cor, textura e artefatos, não sendo possível, por exemplo, fazer uma caracterização do background.

Portanto, neste trabalho decidimos investigar a detecção de ovos a partir da detecção de seu contorno, que em vários dos ovos observados aparecem como linhas escuras, em formato aproximadamente elíptico. Para detectar esses contornos, propomos uma abordagem de duas fases, na qual primeiramente são detectadas linhas escuras e em seguida subconjuntos dessas linhas que estejam dispostas em formato elíptico. As imagens foram capturadas realizando-se um ajuste manual no foco do microscópio, de forma a melhorar a nitidez dos ovos.

A detecção de linhas é realizada utilizando-se uma sequência de operadores morfológicos que têm por finalidade realçar e detectar estruturas do tipo linha, e também filtrar, dentre as linhas detectadas, aquelas que não são de interesse. O fechamento top-hat atua de forma a realçar as linhas alvo na imagem. Os operadores morfológicas subsequentes foram desenhados para remover ruídos, mas de forma a também preservar as linhas alvo. As elipses são detectadas utilizando-se um algoritmo baseado na transformada Hough, aplicado sobre o mapa de linhas detectadas na primeira fase.

No conjunto de dados sobre o qual foi realizado o desenvolvimento do método, a taxa de detecção foi de $85 \%$, enquanto para um segundo conjunto, adquirido após o desenvolvimento do método, essa taxa foi de $75 \%$. Essas taxas podem ser consideradas aceitáveis, dada a complexidade das imagens tratadas. 


\subsection{Contribuições do trabalho}

- Criação de um conjunto de imagens de regiões de lâminas de microscópio com e sem ovos de S. Mansoni, adquiridas em três ampliações distintas (10x, 20x e 40x).

- Desenvolvimento de um método, de duas fases, para a detecção de ovos a partir da detecção de seu contorno. A primeira fase detecta estruturas do tipo linha (escuras) e a segunda fase detecta elipes sobrepostas às linhas detectadas na primeira fase.

- Implementação do método desenvolvido, juntamente com uma interface gráfica em linguagem Python para facilitar a execução das fases do método proposto. A parte referente à primeira fase foi implementada usando-se funções da biblioteca SDC Morphology Toolbox [25] e a parte referente ao algoritmo para detecção de elipses baseado na transformada Hough foi implementado adaptando-se uma implementação feita por R. A. McLaughlin [23].

O algoritmo proposto explora apenas uma das características visuais, as linhas que delimitam o contorno, dos ovos. Como essa característica não aparece em todos os ovos, apenas esse algoritmo não é suficiente para a detecção de todos os ovos. Para o desenvolvimento de um sistema que vise auxiliar o diagnóstico a partir da análise de imagens microscópicas, outros algoritmos, que explorem outras características dos ovos (como cor), precisam ser desenvolvidos.

Desta forma, o método proposto nesta dissertação pode ser visto como um componente que pode ser utilizado para o desenvolvimento de tal sistema. Métodos que exploram diferentes características dos ovos para detectá-los seriam integrados, de forma a maximizar a taxa de detecção. Idealmente, um sistema desses deve ser capaz de detectar todos os ovos, mesmo que para isso apresente alguns falsos positivos. O especialista precisaria, então, analisar apenas as regiões indicadas pelo sistema.

\subsection{Trabalhos futuros}

- Conforme comentado acima, outras características visuais comuns aos ovos devem ser exploradas na detecção, pois nem todas elas são visíveis em todas as ocorrências dos ovos, e também porque a combinação dos resultados de diferentes algoritmos de detecção deverá resultar em uma melhor taxa de detecção.

- As imagens foram adquiridas em três ampliações distintas. Neste trabalho foram usadas imagens com ampliação maior, pois o contorno de ovos por ser uma linha com espessura pequena, tende a aparecer bastante fragmentada em ampliações menores. Outras características como cor (os ovos geralmente aparecem como regiões mais claras) podem ser exploradas em imagens de ampliação menor. Uma vez que as imagens estão disponíveis em três ampliações, uma abordagem multi-resolução de processamento de imagens também é possível. 
- As imagens foram adquiridas com ajuste manual do foco. Esse ajuste foi necessário para que as linhas alvo aparecessem com nitidez suficiente que permitisse sua detecção. No entanto, em um sistema de auxílio ao diagnóstico, a aquisição das imagens de todos os possíveis campos visuais assim como o ajuste de foco deve ser automático, sem intervenção humana. 


\section{Apêndice A}

\section{Implementações associadas}

Como parte do projeto de pesquisa, a abordagem proposta foi implementada e o código desenvolvido encontra-se disponível em:

http://www.vision.ime.usp.br/ edelgado/projeto.php

Todo o processo correspondente ao método proposto pode ser executado a partir de uma GUI, no ambiente Python. A GUI permite ajustar os parâmetros de cada fase e também executar cada fase do processo individualmente. O parâmetro de entrada de uma fase é o diretório no qual encontram-se as imagens a serem processadas naquela fase; o parâmetro de saída é o diretório no qual devem ser armazenadas as imagens resultantes do processamento correspondente àquela fase.

Neste apêndice apresentamos os requisitos e configurações do software desenvolvido.

\section{A.1 Requisitos}

O software foi desenvolvido para o sistema operacional Linux. Para utilizá-lo, alguns pacotes são necessários:

- Python versão 2.5 ou superior, disponível em:

http://www.python.org/download/

- PIL (Python Imaging Library), disponível em:

http://www.pythonware.com/products/pil/

- NumPy e Scipy, disponíveis em:

http://new.scipy.org/download.html

- SDC Morphology Toolbox for Python, disponível em:

http://www.mmorph.com/mmorph/download2/python.php3. A biblioteca contém arquivos binários e arquivos para a instalação da licença. Para maiores detalhes sobre a instalação da licença, deve ser consultado o arquivo INSTALL. 


\section{A.2 Configurações}

Em um terminal Linux, as variáveis de ambiente PATH e LD_LIBRARY_PATH devem ser configuradas:

- incluir o caminho da licença do pacote SDC Morphology Toolbox for Python (MMorph) na variável de ambiente PATH. Por exemplo, se o pacote estiver em

/home/user/software/morph4python16/, deve-se fazer

export PATH=\$PATH:/home/user/software/morph4python16

- incluir à variável de ambiente LD_LIBRARY_PATH, o diretório das bibliotecas compartilhadas do software e do pacote MMorph. Por exemplo, se o pacote MMorph estiver em

/home/user/software/morph4python16/ e o software desenvolvido em

/home/user/software/, deve-se fazer

export LD_LIBRARY_PATH=\$LD_LIBRARY_PATH:/home/user/sof tware/morph4python16

:/home/user/software

\section{A.3 Funções auxiliares}

$\mathrm{Na}$ implementação, a maior parte dos operadores morfológicos são chamadas às funções do pacote MMorph. Foram codificadas funções para:

- ler todos os arquivos de imagens, com uma dada extensão, de um diretório. Por exemplo, na fase de suavização e aplicação do filtro de ordem, as imagens de entrada e de saída são armazenadas em arquivos do tipo TIF; na fase de detecção de linhas as entradas são arquivos do tipo TIF e as saídas são armazenadas em arquivos do tipo PBM; na fase de detecção de elipses, as entradas são arquivos do tipo PBM e as saídas do tipo PNG. Desta forma, podese processar um grupo de imagens, desde que estejam armazenadas em um mesmo diretório. Além disso, uma vez que para cada fase usam-se extensões distintas, torna-se possível também executar apenas uma determinada fase sobre o grupo de imagens (desde que as fases anteriores tenham sido executadas previamente), sem explicitar o nome dos arquivos.

- salvar uma imagem em formato PBM

- construir um elemento estruturante geral com comprimento, largura e orientação específica

- aplicar um filtro de ordem sobre uma imagem; o código referente aos cálculos do filtro de ordem foi escrito em $\mathrm{C}$ e ligado ao Python

- calcular a transformada Hough para detecção de elipses; código C cedido por R. A. McLaughlin, ligeiramente modificado, foi adaptado para funcionar ligado ao Python. 


\section{Referências Bibliográficas}

[1] Adessowiki, Collaborative scientific writing and programming, 2011, http://parati.dca.fee. unicamp.br/adesso/wiki/. 37

[2] J. Barrera, G. J. F. Banon, R. A. Lotufo, and R. Hirata Jr., MMach: a Mathematical Morphology Toolbox for the Khoros System, Electronic Imaging 7 (1998), no. 1, 174-210. 7

[3] L. Chitsulo, P. Loverde, and D. Engels, Focus: Schistosomiasis, Nature Reviews Microbiology 2 (2004), no. 1, 12-13. 1

[4] L. Costa and R. Cesar Jr., Shape analysis and classification, first ed., CRC Press, 2001. 8

[5] Ministério da Saúde do Brasil, Esquistossomose, 2010, http://portal.saude.gov.br/ portal/saude/profissional/area.cfm?id_area=1551, [Online; acesso 29 de novembro de 2010]. 1

[6] _ Esquistossomose, informações gerais sobre a doença, 2010, http://portal.saude. gov.br/portal/saude/profissional/visualizar_texto.cfm?idtxt=31768, [Online; acesso 02 de dezembro de 2010]. 1

[7] M. M. G. de Macedo, Uso da Transformada de Hough na Vetorização de Moldes e outras Aplicações, Universidade (2005), 1. xiii, 19

[8] Edwin Delgado H. and N. S. T. HIRATA, Uma abordagem morfológica para detecção de linhas em imagens com fundo complexo, V Simpósio de Iniciação Científica e Pós-Graduação do IME-USP, 2010. 37

[9] Edwin Delgado H., N. S. T. HIRATA, and Eduardo Finger, Detecção de ovos de S. mansoni em imagens microscópicas, VIII Workshop de Visão Computacional, 2012. 37

[10] E.R. Dougherty and R.A. Lotufo, Hands-on morphological image processing, Society of Photo Optical, 2003. 8, 10, 11, 12, 13, 14, 15, 16

[11] Richard O. Duda and Peter E. Hart, Use of the hough transformation to detect lines and curves in pictures, Commun. ACM 15 (1972), 11-15. ix, 18

[12] Eduardo Finger, Immunodominance and severe schistosomiasis mansoni, Ph.D. thesis, Tufts University School of Medicine, 2004. 1, 2

[13] X. Ge and Y. Cui, Edge detection and target recognition from complex background, Advanced Computer Control (ICACC), 2010 2nd International Conference on, vol. 2, IEEE, 2010, pp. 441-444. 26

[14] R. Gonzalez and R. Woods, Digital image processing, second ed., Addison-Wesley Publishing Company, 2002. 7, 8, 10, 12, 13, 16 
[15] H. J. A. M. Heijmans, Morphological image operators, Academic Press, Boston, 1994. 8

[16] G. Heygster, Rank filters in digital image processing, Computer Graphics and Image Processing 19 (1982), no. 2, 148-164. 17

[17] Cheng-Hsiung Hsieh and Po-Chin Huang, Adaptive rank order filter for image noise removal, Computer Science and Information Engineering, 2009 WRI World Congress on, vol. 7, 31 2009-april 2 2009, pp. $90-94.26$

[18] ImageJ, Image processing and analysis in java, 2011, http://rsbweb.nih.gov/ij/index. html. 37

[19] R. Hirata Jr., Segmentação de imagens por morfología matemática, Master's thesis, Instituto de Matemática e Estatística - USP, 1997. 12

[20] N. Lazarevic-McManus, J. Renno, D. Makris, and G. A. Jones, Designing evaluation methodologies: the case of motion detection, Proceedings of 9th IEEE International Workshop on PETS, Citeseer, 2006, pp. 23-30. 40

[21] J. Lee, R. Haralick, and L. Shapiro, Morphologic edge detection, Robotics and Automation, IEEE Journal of 3 (2002), no. 2, 142-156. 26

[22] H. Li, M.A. Lavin, and R.J. Le Master, Fast Hough transform: A hierarchical approach, Computer Vision, Graphics, and Image Processing 36 (1986), no. 2-3, 139-161. 18

[23] R. A. McLaughlin and M. D. Alder, The Hough transform versus the UpWrite, Pattern Analysis and Machine Intelligence, IEEE Transactions on 20 (2002), no. 4, 396-400. 19, 39, 58

[24] Robert A. McLaughlin, Randomized Hough Transform: Improved ellipse detection with comparison, Pattern Recognition Letters 19 (1998), no. 3-4, 299-305. 19

[25] MMorph, SDC Morphology Toolbox para Python, 2011, http://www.mmorph.com. 37, 58

[26] D. Qi, F. Guo, and L. Yu, Medical Image Edge Detection Based on Omni-directional MultiScale Structure Element of Mathematical Morphology, 2007 IEEE International Conference on Automation and Logistics, 2007, pp. 2281-2286. 8

[27] J. Serra, Image analysis and mathematical morphology, Academic Press, 1982. 6

[28] L. G. Shapiro and G. C. Stockman, Computer visión, Prentice Hall, 2001. 18

[29] P. Soille, Morphological image analysis, 2nd ed., Springer-Verlag, Berlin, 2003. 6

[30] X. Song and Y. Neuvo, Robust edge detector based on morphological filters, Pattern Recognition Letters 14 (1993), no. 11, 889-894. 25, 26

[31] Noriji Suzuki, Color atlas of human helminth eggs, third ed., Japan Association of Parasite Control (JAPC), Japan, 1981. 3

[32] M. Uecker, C. E. Copetti, L. Poleze, and V. Flores, Infecções parasitárias: diagnóstico imunológico de enteroparasitoses, RBAC 39 (2007), no. 1, 15-19. 1, 2

[33] Wikipedia, Esquistossomose - Wikipédia, a enciclopédia livre, 2010, http://pt.wikipedia. org/wiki/Esquistossomose, [Online; acesso 19 de novembro de 2010]. ix, 2 
[34] Z. Yu-Qian, G. Wei-Hua, C. Zhen-Cheng, T. Jing-Tian, and L. Ling-Yun, Medical images edge detection based on mathematical morphology, 27th Annual International Conference of the Engineering in Medicine and Biology Society, 2005, pp. 6492 - 6495. 25

[35] H. K. Yuen, J. Illingworth, and J. Kittler, Detecting partially occluded ellipses using the Hough transform, Image and Vision Computing 7 (1989), no. 1, 31-37. ix, xiii, 19, 20, 21, 23, 37

[36] F. Zana and J.C. Klein, Segmentation of vessel-like patterns using mathematical morphology and curvature evaluation, IEEE Transactions on Image Processing 10 (2001), no. 7, 1010 1019. 26

[37] C. Zhang, S. Murai, and E. Baltsavias, Road network detection by mathematical morphology, Proceeding of ISPRS Workshop: 3D Geospatial Data Production: Meeting Application Requirement, Citeseer, 1996, pp. 7-9. 26

[38] L. Zhong and Y. Zhang, Robust rank vector median filter, Intelligent Information Technology Application, 2009. IITA 2009. Third International Symposium on, vol. 1, IEEE, 2009, pp. 696699. 26 


\title{
Índice Remissivo
}

\author{
definições \\ definições básicas, 10 \\ definições preliminares, 7 \\ limiarização, 10 \\ Transformada Hough, 18 \\ Transformada Hough para elipses, 19 \\ Transformada Hough para retas, 18
}

resultados de cada fase, 42

resultados de outros metodos, 50 